\title{
Leonore Scheffler
}

\section{Indirektes Erzählen durch Leerstellen}

\section{in Jurij Trifonovs Roman} "Zeit und Ort"

Verlag Otto Sagner München · Berlin · Washington D.C.

Digitalisiert im Rahmen der Kooperation mit dem DFG-Projekt „Digi20“

der Bayerischen Staatsbibliothek, München. OCR-Bearbeitung und Erstellung des eBooks durch den Verlag Otto Sagner:

http://verlag.kubon-sagner.de

() bei Verlag Otto Sagner. Eine Verwertung oder Weitergabe der Texte und Abbildungen, insbesondere durch Vervielfältigung, ist ohne vorherige schriftliche Genehmigung des Verlages unzulässig. 


\section{Bayoriach \\ Binatiblbllothets \\ Monchen}

ISBN 3-87690-682-2

(c)

by Verlag Otto Sagner, München 1998.

Abteilung der Firma Kubon \& Sagner,

Buchexport/import GmbH, München

Offsetdruck: Kurt Urlaub, Bamberg

$98>87690$ 


\section{Vorträge und Abhandlungen}

zur

\section{Slavistik}

herausgegeben von Peter Thiergen (Bamberg)

\section{Band 34}




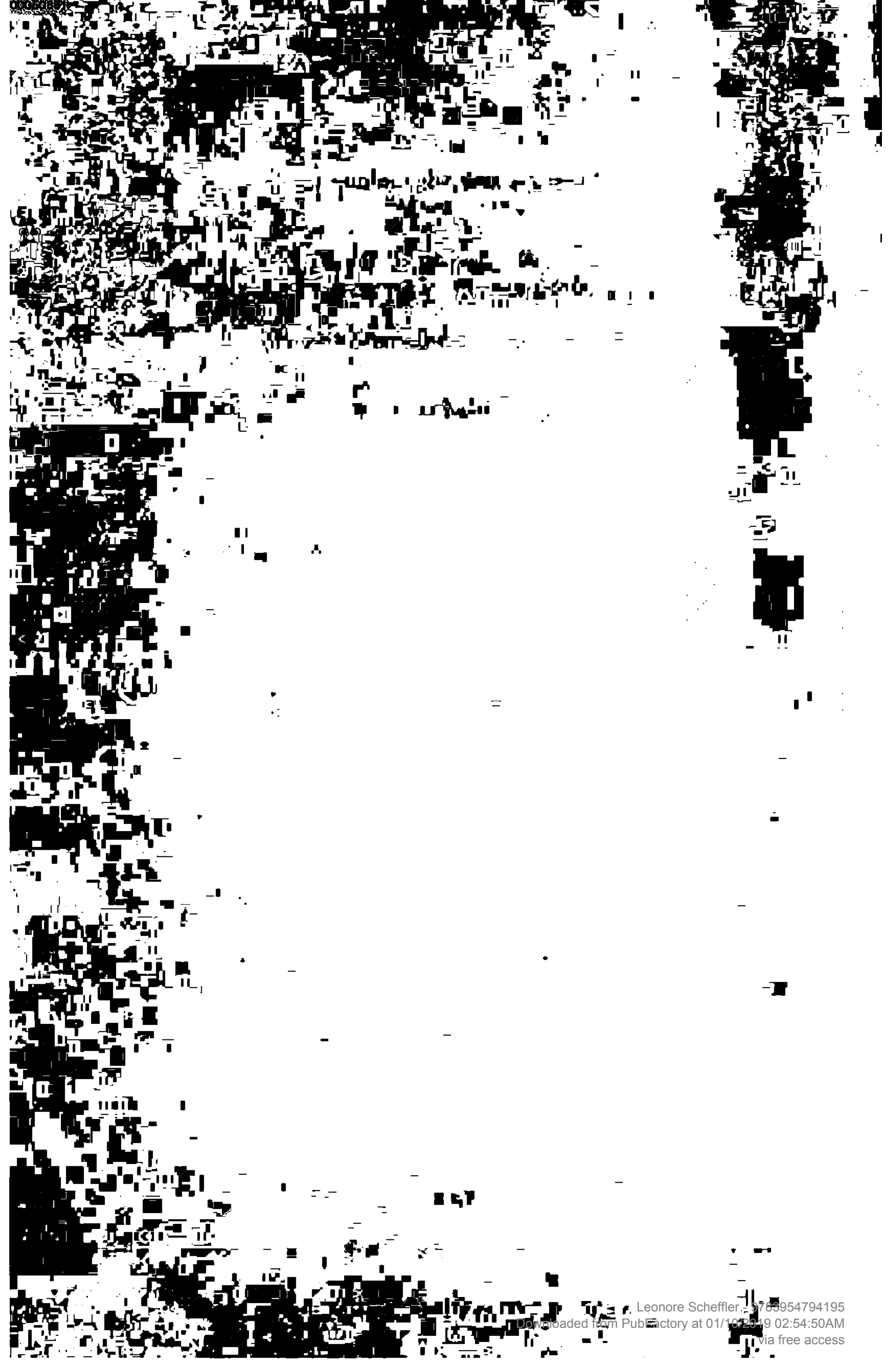




\title{
Leonore Scheffler
}

\author{
Roman-punktir. - Indirektes Erzählen durch
}

Leerstellen in Jurij Trifonovs Roman Zeit und Ort 
PVA

98.

962

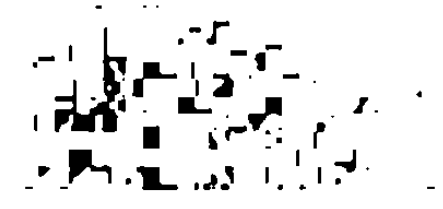




\section{INHALTSVERZEICHNIS}

1.) Vorbild Čechov

2.) Zamjatin - Verwalter und Vermittler der Erzähltradition

3.) Die Struktur des Romans Zeit und Ort

3.1.) Kapitelfolge und äußeres Zeitgefüge

3.2.) Das Verhältnis von Ich- und Er-Erzählung in der Kapitelfügung 18

3.3.0.) Das Motto des Romans

3.3.1.) Kapitel 1: Die Strände der dreißiger Jahre

3.3.2.) Kapitel 2: Zentral-Park

3.3.3.) Kapitel 3: Tverskoj Boulevard I

3.3.4.) Kapitel 4: Tverskoj Boulevard II 35

3.3.5.) Kapitel 5: Jakimanka 40

3.3.6.) Kapitel 6: Die Gasse hinter dem Belorussischen Bahnhof

3.3.7.) Kapitel 7: Tverskoj Boulevard III

3.3.8.) Kapitel 8: Tverskoj Boulevard IV

3.3.9.) Kapitel 9: Das Ende des Winters am Trubnaja Platz

3.3.10.)Kapitel 10: Bol'šaja Bronnaja

3.3.11.)Kapitel 11: Das neue Leben am Stadtrand 71

3.3.12.)Kapitel 12: Zeit und Ort $\quad 80$

3.3.13.)Kapitel 13: Diesen Winter überleben $\quad 84$

4.) Schlußbetrachtung

Literaturverzeichnis 


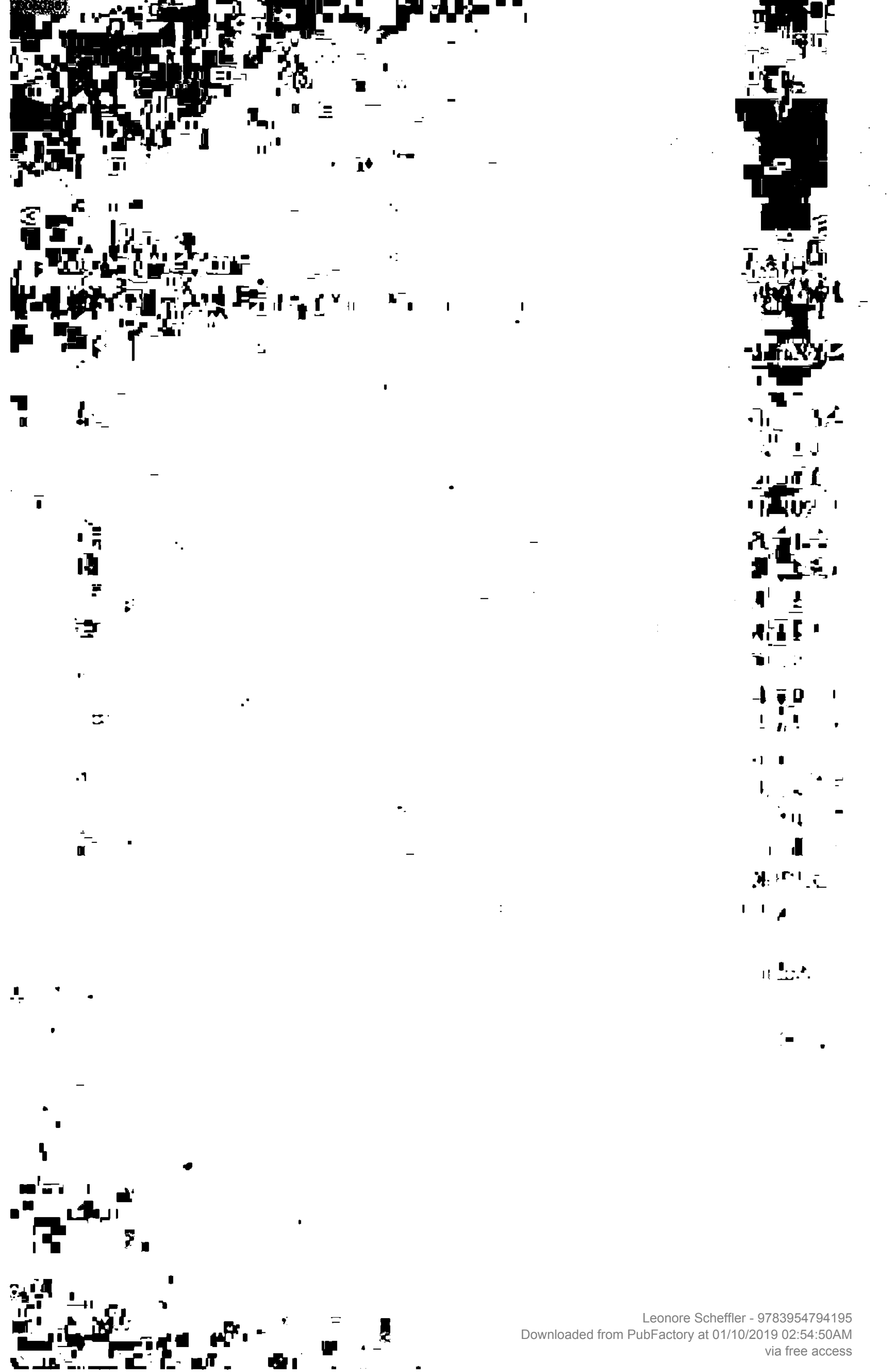




\section{Vorbemerkung}

Jurij Trifonovs letzter großer Roman Vremja i mesto, I vom Autor selbst als sein bedeutendstes Werk verstanden, skizziert im Erleben epischer Figuren eine zeitgeschichtliche Epoche: Moskau, in der Zeit vom August 1937 bis Anfang 1980. Trifonov sah es als die wichtigste Aufgabe der Literatur wie auch als seine persönlich wichtigste Aufgabe als Schriftsteller an, "das Phänomen Leben und das Phänomen Zeit darzustellen. Diese beiden Kategorien zusammengenommen..."2 Deshalb mußte er auch an der selbst erlebten Zeit ein besonderes Interesse haben. Obgleich nicht mit der Absicht, eine Autobiographie im eigentlichen Sinn zu schreiben, benutzt Trifonov doch das eigene Leben deutlich erkennbar als unmittelbare Stoffquelle. Es ist wesentlich sein Leben und sein Erleben, seine Zeit und sein Ort, die in den Roman eingehen: die Lebensdaten, der Geburtsort Moskau, das Geburtsjahr (das des Autors = 1925 - analog dem des Ich-Erzählers und der Zentralfigur im Roman = 1926); das anfängliche Leben in einer Prominentensiedlung bei Moskau; das Verschwinden des Vaters im Jahre 1937, nachfolgend die Zwangsausweisung der Mutter und deren Trennung von den Kindern, die beengten Wohnverhälınisse in einer Moskauer Gemeinschaftswohnung, die Arbeit in einer Moskauer Flugzeugfabrik während des Krieges, anschließend das Literaturstudium am Moskauer Gor'kij-Institut, der schwierige Weg eines jungen Schriftstellers in der Ždanov-Zeit, Glück und Scheitern einer Ehe u. a. m. Die Überschriften der meisten Kapitel des Romans bezeichnen eine Moskauer Lokalität, zu der der Autor eine enge persönliche Beziehung hatte.

"Das Phänomen des Lebens und das Phänomen der Zeit darzustellen" das heißt, sich erinnern und vergegenwärtigen, aus welcher zeitlichen Distanz auch immer. Der Schriftsteller, der sich diese Aufgabe stellt, leistet bei seiner Arbeit Vergegenwärtigung. Dieser Sachverhalt wird in Zeit und Ort explizit zum Thema erhoben: Der Autor Trifonov schreibt einen Roman über einen

1 Der Roman ist im Verlauf zweier Jahre, vom Sommer 1978 bis Sommer 1980 entstanden. N. N. Shneidman präzisiert aufgrund persönlicher Korrespondenz mit dem Autor die Eckdaten: Beginn nach dem 11. August 1978. Abschluß vor dem 3. Juli 1980. - In: N. N. Shneidman: The New Dimensions of Time and Place in lurii Trifonov's Prose of the 1980s. In: Canadian Slavonic Papers (27). 2/1985. S. 189. - Erstmals wurde der Roman postum publiziert, in Dru‡ba narodov, Sept./Okt. 1981.

2 Ralf Schröder: Gespräch mit Juri Trifonow. Ein "Roman mit der Geschichte". In: Weimarer Beiträge, 8/1981. S. 147. 
Ich-Erzähler, der seine Erinnerungen an seinen Jugendfreund, den Schriftsteller Saša Antipov, zu Papier bringt. Letzterer aber ist selbst mit einem Roman beschäftigt, in dem ein anderer Schreiber wiederum einen Roman über einen zeitlich vorausgehenden Schriftsteller verfaßt. Und dieser tut seinerseits das gleiche. Eine Konzeption nach dem Verfahren der "Puppe in der Puppe", zurückprojiziert bis zu einer Person des 18. Jahrhunderts. Die zuletzt aufgeführte ist "die kleinste", von ihr weiß man am wenigsten; die dem Autor zeitlich am nächsten stehende - "die größte", von ihrer Lebenssituation liegen die umfassendsten Kenntnisse vor.

Der Roman Zeit und Ort, ein Buch der Erinnerung, ist eine Antwort auf die eingangs gestellte rhetorische Frage: "Muß man sich erinnern?" (Nado li vspominat'?), gestellt vom Ich-Erzähler, der Antipovs Lebensgeschichte erzählen wird. Der Zwischenbescheid, den der Erzähler selbst gibt, lautet nach dem ersten Abschnitt abweisend: "Aus Saša, dem Jungen, ist längst ein alter Mann geworden. Deshalb braucht das [Erinnem] überhaupt niemand mehr."3 Der eigenen apodiktischen Erklärung widersprechend aber setzt der Erzähler sogleich seine Erinnerung fort. "Niemand braucht das mehr" (nikomu ničego ne nado) ist aus der Sicht des Zeitgenossen gesagt, der ohne geschichtliches Bewußtsein allein aus der Gegenwart leben will. Der Erzähler hingegen, der Vergangenes vergegenwärtigt, weiß, daß sich die Bedeutung des Lebens in der Gegenwart - die des Lebens einer Person wie auch die des Lebens der Gesellschaft insgesamt - erst in der Besinnung auf die Vergangenheit erschließt. "Muß man sich erinnern? Du mein Gott, das ist genauso dumm wie: Muß man leben? Denn erinnern und leben - das ist verschmolzen, ein Ganzes. Das eine kann man nicht ohne das andere zerstören, und es bildet zusammen einen Begriff (nekij glagol), für den es keine Bezeichnung gibt." 4 Als Sinnträger ist gegenwärtiges Leben immer schon von seiner Vergangenheit her definiert. 5

3 Jurij Trifonov: Sobranie sočinenij v četyrech tomach. Tom cetvertyj. Moskva 1987. S. 254. - Alle Zitate aus dem Roman beziehen sich auf diese Ausgabe, die den Text der Erstpublikation (s. Anm. 1) nachdruckt. Sie sind wegen der besseren Lesbarkeit der Ausführungen von mir meistens übersetzt worden.

4 S. 260.

5 Ähnlich warnt die alte Darja in Valentin Rasputins Povest' Proščanie s Materoj beim Besuch der Gräber ihrer Vorfahren vor dem Vergessen von Geschichte: "Pravda v pamjati. U kogo net pamjati, u togo net žizni." - In: Valentin Rasputin: Povesti. 3. Aufl. Moskau 1980. S. 158. 


\section{1.) Vorbild Čechov}

Trifonov praktiziert in diesem letzten großen Werk eine Erzählweise, die er im Laufe seiner schriftstellerischen Tätigkeit zunehmend vervollkommnet hat und die in ihrem Ursprung an Čechovs prägnant objektivierende Schreibart anknüpft. Mit Čechov verband ihn frühzeitig eine enge Wahlverwandtschaft. Schon in einem seiner ersten publizistischen Aufsätze mit dem programmatischen Titel Pravda i krasota (1959) - einem Zitat aus Čechovs Erzählung Student - verweist Trifonov auf die Funktion des Vorbildes: Čechovs Entdeckung der Wirksamkeit der einfachen Worte, der Kürze, des Unausgesprochenen; seine Fähigkeit, im charakteristischen Detail - wie ein impressionistischer Maler - ein Ganzes festzuhalten. Diese Stilfindung, die auf die kleine Alltagsszene und die Erforschung der Motive menschlichen Verhaltens ausgerichtet ist, begründet sich bei Čechov wesentlich im Verzicht darauf, allgemeine Ideen oder weltanschauliche Empfehlungen vermitteln zu wollen. Čechov selbst besaß keine konsistente Weltanschauung, und er empfand diesen Mangel, den Verlust des christlichen Glaubens seiner Kindheit ebenso wie das spätere Mißtrauen in jedes politische Programm, durchaus als eine Anfrage an seine künstlerische Legitimation. ${ }^{6}$ Trifonov, dem das in der Kindheit anerzogene Weltverständnis gleichfalls fragwürdig geworden war, plagten Skrupel ähnlicher Art offenbar nicht. Er, der Sohn eines alten, seit 1905 aktiven kommunistischen Funktionärs, der im Jahre 1937 Stalins "Säuberungen" zum Opfer fiel, wächst in die Welt einer kommunistisch-atheistischen Gesellschaft hinein. Und er beginnt während seines Studiums am Moskauer Gor'kij-Institut (1944-1949) mit ersten Erzählungen in der Konzeption des sozialistischen Realismus, von dem er sich in der Zeit nach Stalin aber zunehmend distanziert, so daß er später selbst an sein erzählerisch vielleicht bestes Frühwerk, die Povest' Studenty (1950), nur noch ungern erinnert werden möchte. ${ }^{7}$ Die Entthronung der Stalinisten, der Verfall ihrer

6 Cechov an A. S. Suvorin, am 25. 11. 1892: 'My pišem žizn' takoju. kakaja ona est', a dal'̌e ni trppppu..(...) $U$ nas net ni bližajšich ni otdalennych celej. (...) Politiki u nas net. $v$ revoljuciju my ne verim, boga net, prividenij ne boimsja, a ja lix̌no dažc smerti $i$ slepoty ne bojus'. Kto ničego ne chočet, ni na čto ne nadeetsja i ničego ne boitsja, tot ne možet byt' chudožnikom. Bolezn' èto ili net - delo ne v nazvanij, no soznat'sja nado. tto položenie naše chuže gubematorskogo."

7 Jurij Trifonov: V kratkom - beskonečnoe. (Besedu vel A. Bočarov). In: Voprosy literatury. 8/1974: "Ja prosto ne mogu segodnja ni odnoj stranicy étogo romana perecitat"." S. 171. - (Die Povest' wurde für 1950 mit einem Stalinpreis dritter Klasse ausgezcichnet.) 
Ideologie, die Nachricht vom Schicksal seines Vaters, führen Trifonov zur Desillusionierung, wenngleich nicht wie manchen anderen in die Rolle des Opponenten gegenüber dem sowjetischen Staat. Nur erzählt er seit Ende der 60er Jahre nicht mehr mit der Absicht, für ein kommunistisches Weltbild zu werben, sondern er wendet sich statt dessen der Darstellung des Moskauer Alltags, des einfachen Menschen in alltäglichen Situationen, insbesondere des durchschnittlichen Intellektuellen zu. Wie Čechov beschreibt er "das Leben, wie es ist", präzis, ohne Tendenz, ungeschönt, allein der Wahrheit der empirischen Realität verpflichtet. ${ }^{8}$ Und wie sein Vorbild sieht auch er, daß der Vergegenwärtigung der "unschönen" Wahrheit des Vorfindlichen ein Impuls innewohnt, der an das Gewissen des Menschen appelliert, der dem Leser bedeutet: So ist es zwar, doch so sollte es nicht sein, und so braucht es nicht zu sein. Der Glauben an den Menschen aber, an dessen Bildungsfähigkeit, insbesondere an die Fähigkeit zur sittlichen Entwicklung, das ist für beide, ganz am irdisch Erfahrbaren orientierte Autoren die Grundlage der Rechtfertigung ihrer schriftstellerischen Tätigkeit. ${ }^{9}$

8 "Ja stremljus' lis' k tomu, - i èto proischodit bessoznatel'no, - ctoby nachodit" absoljutno dostovernye, $v$ Żizni uvidennye charaktery stremljus' $k$ kakoj-to vnutrennej ich pravdivosti. Ėto kak by ideal'naja mišen', kotoruju ja stremljus' porazit'." Ebd., S. 178.

9 Siehe z. B. Cechovs Brief an A. N. Plešeev vom 4. 10. 1888: "Ja ne liberal, ne konservator, ne postepenec, ne monach, ne indifferentist. Ja chotel by byt' svobodnym chudožnikom i - tol'ko, i žaleju, čto bog ne dal mne sily, čtoby byt' im. Ja nenavižu nasilie vo vsech ich vidach (...) Moe svjatoe svjatych - èto celovečeskoe telo, zdorov'e, um. talant, vdochnovenie, ljubov' i absoljutnejšja svoboda, svoboda ot sily i lži, v cem by poslednie dve i vyražalis'." Und an I. I. Gorbunov-Posadov vom 31. 12. 1894, wo es heißt: "Verovat' $v$ boga ne trudno. $V$ nego verovali $i$ inkvizitory, i Biron i Arakceev. Net, Vy $\vee$ celoveka uverujte!" - Trifonov thematisiert in verschiedenen Aufsätzen die erzieherische Funktion der Kunst zur Sittlichkeit. Z. B. in Na vse vremena: "V našej literature sejžas možno govorit' o 'nravstvennych poiskach'. Ėto možno pokazat 'sja strannym: literatura vsegda nravstvennyj poisk!" - In: Jurij Trifonov l= Anm. 3]. Bd. 4. S. 552. - In: Vybirat', rešat' sja, Łertvovat': "Zadaca, možet byt', v tom i sostoit, (...) celoveku menjat'sja k lucemu." Ebd., S. 528. - Oder in: Ralf Schröder: Gespräch mit Juri Trifonow (= Anm. 2), S. 151: "Aber mir scheint, wir leinbezogen die Schriftsteller Abramov, Možaev, Belov, Sukł̌n. Rasputin] haben ein gemeinsames sittliches Anliegen, ein sittliches Gefühl für den Wert des Menschen, die Achtung vor dem Menschen als solchem, was manchmal vielleicht in unserer Literatur vergessen wurde." 


\section{2.) Zamiatin - Verwalter und Vcrmittler der Erıähltradition}

Čechovs literarischer Erbe und Sachwalter Evgenij Zamjatin hat in den Jahren 1919-1921 im Petrograder "Haus der Künste" in einer Reihe von Vorträgen, die er zur Unterrichtung angehender Schriftsteller über das Thema "Lekcii po technike chudožestvennoj prozy" gehalten hat, Čechovs, von ihm selbst mittlerweile rezipiertes und praktiziertes Erzählverfahren zu begründen und zu vermitteln versucht. Er hat dabei zwei korrelative Prinzipien hervorgehoben: das Prinzip der künstlerischen Ökonomie und das Prinzip der gemeinsamen schöpferischen Arbeit des Autors und des Lesers. 10 Das Prinzip der künstlerischen Ökonomie geht von der Frage nach der höchstmöglichen künstlerischen Effektivität aus. Diese werde dann erreicht, wenn nicht - wie in der gewöhnlichen Erzählsprache (povestvovatel'nyj jazyk) - (fast) alles ausgesprochen wird, sondern - wie in der Gedankensprache (myslennyj jazyk) - die Sätze unvollständig bleiben, bruchstückhaft, manchmal reduziert auf ein wichtiges Wort, so daß sich die Aufmerksamkeit des Lesers konzentrieren muß, um das Nichtgesagte zu ergänzen. Auf diese Weise kann in einem kleineren Abschnitt der Erzählzeit eine größere Menge an Informationen, Eindrücken und Vorstellungen vermittelt werden. "Der zentrale Gedanke wird nicht auf den Seiten, nicht in den Zeilen gegeben, sondern irgendwo zwischen den Zeilen. Bei diesem Verfahren schafft der Autor einen gleichsam in Worten nicht materialisierten Gedanken, nur den Geist des Gedankens. [...] Indem Sie diese embryonale Sprache des Gedankens hervorbringen, geben Sie dem Gedanken des Lesers nur einen Anfangsimpuls und zwingen den Leser selbst, eben diese einzelnen Leitpfähle der Gedanken mit Zwischengliedern von Assoziationen oder fehlender Elemente des Syllogismus zu verbinden. Die auf das Papier eingetragenen Leitpfähle lassen den Leser in der Gewalt des Autors, sie gestatten dem Leser nicht, sich zur Seite zu wenden; aber zugleich lassen die leeren, unausgefüllten Zwischenräume zwischen den Leitpfählen die Freiheit für ein partielles Schöpfertum des Lesers selbst. Mit einem Wort, Sie machen den Leser selbst zu einem Teilhaber an der schöpferischen Arbeit."11

Das "nedogovorit" aber muß in der schriftstellerischen Praxis geübt werden, insbesondere dadurch, daß der Autor sein Manuskript nach der

10 Evgenij Zamjatin: O jazyke. In: Socinenija v tetyrech tomach. München 1970-1988. Bd. 4. S. $386 \mathrm{ff}$.

$11 \quad$ Ebd., S. 388 und 387. 
ersten Fertigstellung kürzt, konzentriert, alles Überflüssige wegstreicht. "Eine Povest', eine Erzählung können Sie dann als völlig ausgereift und vollendet ansehen, wenn man dort nichts mehr herauswerfen kann, kein einziges Kapitel, keinen einzigen Satz, kein einziges Wort. Alles, was man herauswerfen kann, muß man erbarmungslos herauswerfen. Nur das eine Markante, das eine Unumgängliche soll bleiben. Nichts Überflüssiges: Nur dann können Sie sagen, daß Ihr Werk geschaffen ist und lebt."12 Eine solche, an Čechov geschulte, komprimierte Schreibart aber führt vom traditionellen Erzählen weg, hin zu einer neuen Art des Zeigens. "Die Neorealisten erzählen nicht, sie zeigen (ne rasskazyvajut, a pokazyvajut), so daß zu ihren Werken besser die Bezeichnung 'Schaustellungen' (pokazy) als die Bezeichnung 'Erzählungen' (rasskazy) passen würde."13

Jurij Trifonov, der Zamjatins "Lekcii" kaum gekannt haben kann, denn diese wurden erst nach seinem Tod publiziert (München 1988), und der sich in seiner Herkunft als Schriftsteller auch nicht als "Neurealist" in Zamjatins Sinn versteht, d. h., nicht als ein Erzähler, der die realistische Erzählweise mit der symbolistischen zu verbinden sucht, obgleich auch seine Texte symbolhaltig sind, findet in der eigenen Auseinandersetzung mit Čechov zu ähnlichen Einsichten, wenn er 1973 in seinem Aufsatz Anfang ohne Ende (Neskončaemoe načalo) bilanziert: "Früher habe ich zusammenhängender geschrieben. Eines haftete am anderen, eines ging fließend aus dem anderen hervor. In dieser Verbundenheit (svjaznost') war aber auch Gebundenheit (svjazannost'). [...] Jetzt strebe ich entferntere, tiefere Verbindungen (svjazi) an, die der Leser selbst erfühlen und erraten muß. [...] Freie Stellen Abbrüche - Leerräume (probely - razryvy - pustoty) - das ist es, was für die Prosa ebenso notwendig ist wie für das Leben."14 In seinem letzten großen Werk, für das er die Bezeichnung "punktir" bzw. "roman punktirom" gebraucht, 15 folgt Trifonov dem Prinzip der künstlerischen Ökonomie und dem Prinzip der gemeinsamen schöpferischen Arbeit des Autors und des Lesers mit höchster Konsequenz.

12 Ders.: $O$ sjužete i fabule. Ebd., S. 394.

13 Ders.: Sovremennaja russkaja literatura. Ebd., S. 361. - Zuerst als Vortrag an der Lebedjaner Volkshochschule, am 8. September 1918 gehalten. Erstpublikation in Grani 32/ Okt.-Dez. 1956. S. 90-101.

14 Trifonov (= Anm. 3). Bd. 4. S. 531.

15 Ralf Schröder erwähnt das aus seinem letzten Gespräch mit Trifonov im Frühjahr 1980. In Trifonov (= Anm. 2), S. 152 und in: Moj god esce ne nastupil... - Ral' $f$ Šreder. Iz besed s Juriem Trifonovym. In: Literaturnoe obozrenie. 8/1987. S.97. 


\section{3.) Dic Struktur des Romans Zeit und Ort}

Die Struktur von Zeit und Ort zeichnet sich nach der eigenen Auskunft des Autors durch zwei Besonderheiten aus. Zum einen durch die relative Eigenständigkeit der einzelnen Kapitel. "Jedes Kapitel des Romans Zeit und Ort ist eine Novelle, die auch einzeln, autonom existieren kann, zugleich aber gehören auch alle Kapitel zusammen. Sie werden nicht nur durch die Romangestalten, sondern auch durch die Kette der Zeit vereint." 16 Zum anderen folgt das Erzïhlen dem "Prinzip der punktierten Linie" (punktir), und dies nicht nur hinsichtlich der zeitlichen Abstände zwischen den Kapiteln, deren nicht mitgeteilte Geschehnisse, sofern sie für das Verstehen des Sinnzusammenhanges wichtig sind, vom Leser rekonstruiert werden müssen, sondern auch hinsichtlich der Leerräume (probely) zwischen den berichteten, den oft nur indirekt angedeuteten und den im Bericht ausgelassenen Ereignissen sowie der Verständnisfähigkeit der agierenden Figuren einerseits und dem Leser andererseits. Das Erzählverfahren der "nedogovorennost"”, der sinnträchtigen Andeutung statt deren vollständiger Ausführung, die der Leser aufnehmen, die er mit anderen assoziieren, ins richtige Verhältnis setzen, interpretieren, an die er sich bisweilen über lange Erzählpassagen hinweg erinnern muß, wird von Trifonov in einzigartig kompakter Weise gehandhabt. Die für das Spätwerk des Autors charakteristische epische Dichte 17 erhält hier ihre wesentliche Begründung. Das hohe Maß an Leerstellen erfordert vom Leser, der sich nicht nur mit einem Oberflächeneindruck begnügen will, deshalb aber auch ein mehrfaches, intensives Sich-Einlesen in den Text. ${ }^{18}$ Erst dadurch er-

16 Trifonov (= Anm. 2). S. 152.

17 "Menja presleduct želanie pressovat' izobražaemoe, čtoby kak možno bol'se skazat'." Trifonov (= Anm. 7), S. 190. - A. C. Hughes: "The essence of Trifonov's mature style can, perhaps, be best summed up by the word "density'." - In: "Bol'shoi mir" or "zamknutyi mirok": Departure from Literary Convention in Iurii Trifonov's Recent Fiction. In: Canadian Slavonic Papers. (22). 1980. S. 474.

18 Auf die Notwendigkeit des intensiven Sich-Einlesens in Trifonovs Texte wurde von der Forschung schon wiederholt verwiesen. Vgl. Brigitte Schultze: Jurij Trifonovs "Der Tausch" und Valentin Rasputins "Geld für Maria". Ein Beitrag zum Gattungsverständnis von Povest' und Rasskaz in der russischen Gegenwartsprosa. Göttingen 1985. S. 22: "Dieses Sich-Einlesen (Tat'jana Patera spricht von včityvanie) ist eine grundsätzliche Anforderung an den Leser des Obmen, von Trifonovs literarischem Werk (einschließlich literaturkritischer Äußerungen und vieler feuilletonistischer Beiträge) überhaupt." Der Verweis auf Tat'jana Patera bezieht sich auf: Jurij Trifonov. His Work with Emphasis on the Moscow Novels. Phil. Diss. McGill University 1981. S. $5 \mathrm{ff}$. 
schließen sich Zusammenhänge und Sinnstrukturen. Erst dabei wird einsehbar, daß die vielen Einzelpunkte des Erzählvorgangs nicht disparat nebeneinander stehen, sondern daß sie Punkte potentieller Sinnlinien sind und da $\beta$ sich die Unbestimmtheiten, die der Text dem Leser aus wirkungsästhetischen Gründen zumutet, mit Bedeutung, wenn auch oftmals nicht nur mit einer ausschließlichen, füllen lassen. ${ }^{19}$

Ralf Schröder konstatierte in seiner rückblickenden Abhandlung über Trifonovs Werk in bezug auf Zeit und Ort: "Die große Epochenkomposition entwickelt sich nicht aus einer durchgehenden Fabel, sondern ist in den verwirrend vielen, scheinbar zufällig angeordneten - ja, chaotisch anmutenden wie aus dem vollen Leben gegriffenen Alltagsdetails so kunstvoll verborgen, $\mathrm{da}$ sie das künstlerische Gewebe nicht durchbricht, nur zwischen den Zeilen, im sogenannten Podtext, in den 'Lücken und freien Stellen' vom Leser erschlossen werden kann."20 Das heißt aber: Adressat des Romans ist ein Leser, der die Epoche letztlich schon kennt, ein Leser, der imstande ist, Andeutungen als solche zu verstehen und Sinnzusammenhänge zwischen ihnen wie auch zum episch nicht ausgeführten Zeitgeschehen selbst herzustellen. Die Feststellung, daß der Roman nicht von einer durchgängigen Handlung getragen wird, deren Grundkonzept sich auf traditionelle Art in einer Fabel zusammmenfassen ließe, ist zwar zutreffend, für das einzelne Kapitel jedoch, die "einzelne Novelle", vom Autor als in sich geschlossene Erzähleinheit konzipiert, kann das durchaus gelten. Und die in den Kapiteln dargestellten Handlungen, Ereignisse, Erlebnisse und Erinnerungen, die sich lückenhaft durchaus zu Sinnlinien ordnen, sind, wenngleich in einem kontinuierlich personalen Erzählmilieu und auf eine jeweils eigene Weise geeignet, ein Stück

19 Der Anglist Wolfgang Iser hat in seiner Konstanzer Antrittsvorlesung vom 9. 6. 1969 unter Verweis auf die gemeinsame schöpferische Arbeit von Autor und Leser eben die Tatsache hervorgehoben, daß die Bedeutungen eines literarischen Textes erst im Leseakt selbst hervorgebracht werden, wobei der künstlerisch anspruchsvollere Text durch seinen größeren Betrag an Unbestimmtheiten dem Leser auch die anspruchsvollere Eigenleistung abverlangt. - (Wolfgang Iser: Die Appellstruktur der Texte. Unbestimmtheit als Wirkungsbedingung literarischer Prosa. 3. Aufl. Konstanz 1972.) - Dennoch unterscheidet sich Zeit und Ort wesentlich von einem modernen Bewußtseinsroman wie etwa von James Joyce' Ulysses, zu dem Iser vermerkt, daß hier der U'nbestimmtheit durch ihre Vielzahl an Deutungsmöglichkeiten keine Grenzen mehr gesetzt sind, sondern der Autor statt dessen "den Leser auf die Suche nach dem Sinn schickt", ohne daß er ihm noch mit hilfreichen Hinweisen bei der Bedeutungsfindung entgegenkäme. - Iser, $S$. $28 \mathrm{ff}$.

20 Ralf Schröder: Zum Schaffen Juri Trifonows. In: Weimarer Beiträge. 8/1981. S. 156. 
"Epoche im Ausschnitt" wiederzugeben. Das einzelne Kapitel soll deshalb auch Ausgangspunkt der Untersuchung sein. Jedes soll als Sinneinheit für sich betrachtet, die Struktur seiner szenischen Vielfalt, die Struktur der "punktierten Linie", soll untersucht und der Frage nachgegangen werden, wodurch im Text Unbestimmtheit entsteht, auf welcher Ebene die Leerstellen positioniert sind und welche Konvergenzpunkte der Text als Bedeutungsträger anbietet.

\section{1.) Kapitelfolge und äußeres Zeitgefüge}

Mit Ausnahme der Kapitel fünf und sechs, die zeitlich hinter das dritte Kapitel zurückgreifen, erscheinen alle übrigen elf Kapitel des Romans in chronologischer Anordnung:

1.) Die Strände der dreißiger Jahre

2.) Zentral-Park

3.) Tverskoj Boulevard - I

4.) Tverskoj Boulevard - II

5.) Jakimanka

6.) Die Gasse hinter dem Belorussischen Bahnhof

7.) Tverskoj Boulevard - III

8.) Tverskoj Boulevard - IV

9.) Das Ende des Winters am Trubnaja Platz

10.) Bol'šaja Bronnaja

11.) Das neue Leben am Stadtrand

12.) Zeit und Ort

13.) Diesen Winter überleben
August 1937,

Sommer 1938 -

Winter 1939/1940,

Anfang 1946,

Februar 1947,

Ende Oktober 1941, 1943 - 1944,

Frühjahr - Sommer 1947,

Februar 1950 - April 1951 ,

6. März 1953, August 1957, Herbst 1970 November 1971, Mai - Juli 1978, Herbst 1979 Anfang 1980.21

21 Im Romantext sind die Kapitel nicht numeriert, sie tragen nur Überschriften. In den nachfolgenden Ausführungen wird wegen der Einfachheit des Verweises auch die hier angegebene Numerierung verwendet. 


\section{2.) Das Verhältnis von Ich- und Er-Erzählung in der Kapitelfügung}

Es ist im wesentlichen Saša Antipovs Geschichte, die in dritter Person erzählt wird, und zwar von einem Erzähler, der in den Kapiteln 2, 5, 6 und 13 als Antipovs Altersgenosse und Freund in erster Person Teile seiner eigenen Lebensgeschichte einbezieht. In Kapitel 3 beginnt er zwar in der ersten Person mit einem Rückgriff in die eigene Biographie, wechselt aber nach dem ersten Abschnitt in die dritte über, um anschließend von Antipov zu berichten. Kapitel 6 rekapituliert in der ersten Person die Situation des Kennenlernens und der beginnenden Freundschaft mit Antipov im Jahre 1943/1944, den der Erzähler nach dem Krieg für lange Zeit wieder aus den Augen verliert und erst am Ende der Romanhandlung, Anfang 1980, durch Zufall wiedertrifft. Diese erneute Begegnung gibt Saša Antipov Gelegenheit, dem Freund seine Lebensgeschichte in Einzelheiten mitzuteilen. Das wird zwar nicht expressis verbis gesagt, aber die Rezeption von Antipovs Geschichte durch den Ich-Erzähler und deren Wiedergabe im Roman bestätigen das resultativ. (Zur Zeit ihrer ersten Gemeinsamkeiten, Kapitel 6, konnten dem Erzähler nur die Ereignisse aus Antipovs Leben bekannt sein, die in die Zeit vor 1943, = Kapitel 1, gehören.)

Am Anfang der Romanhandlung, in Kapitel 2, erscheint der Ich-Erzähler als ein Junge gleichen Alters, mit einem ähnlichen familiären Schicksal. In Kapitel 5 erscheint er als Zeuge eines Erlebens der gleichen Zeit am gleichen Ort. Kapitel 6 schildert die erste Begegnung der beiden 17/18jährigen Jungen, die in der Zeit gemeinsamer Fabrikarbeit Freunde werden, wobei der Erzähler zu seinem Mißvergnügen entdeckt, daß er Antipov ähnlich ist, und zwar nicht nur in seinem äußeren Lebenslauf, sondern auch in seinem Temperament, seinen Neigungen und Interessen: “Aber mir gefiel Antipov nicht. In ihm war etwas, was mich beunruhigte. Ich konnte das lange nicht begreifen, dann habe ich es erraten - er war mir zu ähnlich. Sogar äußerlich: Auch er trug eine Brille, war schweigsam und bedächtig. Teufel noch mal, ich wollte doch der einzige Schweigsame und Bedächtige sein. Wir waren fast vollkommen gleichaltrig, ich - ein halbes Jahr jünger. Beide lebten wir ohne Eltern, ich bei der Großmutter, und er bei der älteren Schwester und einer angeheirateten Tante. Und ebenso wie ich befaßte er sich damit, Papier vollzuschmieren und träumte davon, nach dem Kriege am Literaturinstitut zu studieren. [...] Wir hatten vor dem Krieg beide den Literaturzirkel im Haus der Pioniere in der Stopani-Gasse besucht. [...] Er miß- 
fiel mir, weil ich in ihm mein Übel spürte. Und dagegen konnte ich nichts machen. [...] Unsere Schicksale waren sich bitter ähnlich, und wir wußten das, aber niemals unterhielten wir uns über das Schmerzliche und Bittere."22 Diese Schicksals- und Wesensgleichheit befähigen den Erzähler dann auch in besonderer Weise, am Ende Antipovs Geschichte in ihren Tiefen und Zusammenhängen nachzuvollziehen, zu verstehen und authentisch darstellen zu können. Im Schlußkapitel, das thematisch nochmals mit einem kleinen Ausschnitt aus dem gegenwärtigen Alltag des Erzählers eine Analogie des gemeinsamen Erlebens herstellt, wird der Erzähler, der, anders als Antipov, nicht die Berufslaufbahn des Schriftstellers, sondern die des Mathematikers eingeschlagen hatte, erzähltechnisch in den Stand des möglichen Berichterstatters versetzt.

\subsection{0.) Das Motto des Romans}

Das Motto des Romans weist nicht nur in sich selbst Bruchstellen auf, es setzt auch einen ersten großen Leerraum gegenüber dem Text, wobei die Unbestimmtheit zwischen dem Motto und den epischen Figuren eine qualitativ andere ist, als die, die zwischen Motto und Leser besteht.

Zeit und Ort Ihrer Geburt

Nationalität

Waren Sie

Gehörten Sie zu

Ihre Teilnahme an

Das Datum Ihres Todes

Während die ersten beiden Fragen noch die Vermutung nahelegen, es handle sich um einen neutralen Personalfragebogen, deuten Frage drei bis fünf, die auf persönliche Aktivitäten eines Befragten abzielen, darauf hin, daß hier ein mündliches Verhör skizziert wird, denn der letzte Satz, Das Datum Ihres Todes, ist keine Frage mehr, sondern die Konklusion, die ein Staatsanwalt in der Form eines Urteils aus den Antworten des eben Verhörten zieht. Bezeichnet wird mit dem Motto eine reale Situation, ${ }^{23}$ die der Stalinzeit, vornehmlich die des Jahres 1937 (die Präzisierung läßt sich aus dem dritten Kapitel ableiten), mit der Trifonov in knappester Form den zeitgeschichtli-

23 Nicht eine "traumhaft verzerte", wie Ralf Schröder (= Anm. 20), S. 156 meint. 
chen Kontext umreißt, in dem sich das Leben des heranwachsenden Saša Antipov und seines Freundes vollzieht: Eine anonyme (staatliche) Macht greift schicksalhaft und kommentarlos in das Leben der Menschen ein. Eine Realität, die von den Betroffenen nicht zu verstehen ist und die auch nicht erklärt wird, die aber über allen als Verhängnis schwebt.

Dem Leser erschließt sich die Bedeutung des Mottos erst allmählich, obgleich sie auf das nachfolgende Kapitel am konkretesten, nämlich auf Saša Antipovs Vater, zu beziehen ist. Das Geschehen des ersten Kapitels - auch wenn es die Konstatierung des Erzählers enthält: "Sašas Vater kam niemals mehr aus Kiev zurück" - wird fast durchgängig aus der Sicht eines arglosen elfjährigen Jungen erzählt, der von den zeitgeschichtlichen Konflikten, denen der Vater in der Situation des Abschieds zum Opfer fällt, nichts wissen kann.

\subsection{1.) Kapitel 1: Die Strände der dreißiger Jahre (August 1937)}

Zentrales Ereignis des ersten Kapitels ist das Verschwinden von Saša Antipovs Vater. Dieses Ereignis wird jedoch im Erzählvorgang nicht ausgeführt, sondern nur indirekt, im Erleben zurückbleibender Personen, wiedergegeben.

Die epischen Figuren aus der Welt der Erwachsenen sind - im Gegensatz zu den Kindern wie auch zum Leser am Beginn der Romanhandlung mit dem Fatum, das das Motto bezeichnet, vertraut, wenngleich auch bei ihnen offen bleibt, wieweit die Einsicht in die tieferen Zusammenhänge und die tatsächliche Kenntnis der im Romantext nicht ausgeführten schicksalhaften Vorgänge reicht. Weil über das Verhängnis nicht gesprochen werden darf, entstehen Leerräume sowohl zwischen dem Zeitgeschehen und den einzelnen Personen als auch auf der Ebene des Zusammenspiels der Personen selbst. Anschaulich wird das in Kapitel 1 am Verhalten von Saša Antipovs Mutter zu ihren Kindern. Die Mutter ahnt, was es mit dem Abschied des Vaters auf sich hat, aber sie kann die quälende Ahnung niemandem mitteilen. Und die quälende Ahnung steigert sich zu lähmender Angst. Als der elfjährige Sohn an öffentlichem Ort lautstark und trotzig auf der Klärung der Frage nach der pünktlichen Rückkehr des Vaters besteht, gibt sie dem Kind statt einer beschwichtigenden Antwort eine Ohrfeige und beginnt zu weinen. Die fragende Neugier der Kinder muß abgelenkt werden, weg vom TabuThema, in eine andere Richtung. Doch die Kinder merken, da $\beta$ die Mutter ihnen nicht die Wahrheit sagt. - Als Saša einige Tage später vom Verwalter 
der Sommerhaussiedlung (das ist die Person, die möglicherweise den Vater denunziert hat) übel mißhandelt wird, muß er feststellen, daß Mutter und Schwester, statt ihm zu Hilfe zu kommen, der Szene seiner Mißhandlung aus der Ferne "sonderbar, kalt, ohne sich über Polikarpyč zu empören, ohne Mitgefühl, unbeeindruckt von seiner Tapferkeit"24 zugesehen haben.

Das gesamte erste Kapitel ist auf dem Kontrastprinzip aufgebaut. Der Kontrast besteht zwischen dem "Bescheidwissen" der Erwachsenen und der naiven Unbefangenheit eines Kindes, das anläßlich des Verschwindens seines Vaters ungewollt in das Wissen der Erwachsenen und deren bewußt erlebte, unheilvolle Welt hineinwächst. Erzählt wird aus der Sicht eines Elfjährigen, der die bisher für ihn noch heile Welt auf kindliche Weise, vorwiegend in sinnlichen Eindrücken wahrnimmt. Der Abschied vom Vater auf dem Bahnsteig in Moskau verbindet sich für ihn in der Erinnerung mit der Vorstellung "sonnig, geräuschvoll und fröhlicher Lokomotivqualm", aber auch mit einem "unerklärlichen Zittern", mit dem er den Vater am Finger festzuhalten suchte. Die Atmosphäre der Beängstigung, in der die Eltern ihr (letztes) Gespräch führen, hatte sich dem Kind instinktiv mitgeteilt.

Der Erzählvorgang des zweiten Teils des Kapitels, in dem der Erzähler das Tempus wechselt - aus der Distanz des rückblickenden Präteritum geht er ins unmittelbar vergegenwärtigende Präsens über - vollzieht eine stufenweise Destruktion der heiteren Unbefangenheit. Das Geschehen spielt in ciner Sommerhaussiedlung in der Nähe von Moskau, 25 die der Junge im Gegensatz zur Großstadt als beglückend und befreiend erlebt, weil er hier barfuß gehen kann. Auch hier ist das Kind noch ganz auf sensuelle Wahrnehmung seiner Umgebung ausgerichtet: die kühlen Dielenbretter der Treppe, die schon erwärmte Terrasse, die Düfte des Gartens in der wohltuenden Wärme eines frühen Augustmorgens, - Frühtau, Kiefern, Erde. Der Abschied vom Vater ist anscheinend vergessen. Verärgert reagiert der Junge auf die Vergeßlichkeit der Mutter, die "erschöpft, wie sie sagt" aus der Stadt zurückkehrt, ohne ihm "das wichtige Buch" mitgebracht zu haben. "Kak ona govorit, izmocalennaja" - der im Text kursiv gesetzte Begriff der erlebten Rede,

24 S. 260.

25 Gemeint ist die Prominentensiedlung Serebrjanyj bor. Das geht aus verschiedenen Lokalangaben (die Gärten von Strogino, das Flugfeld von Tušino) hervor und wird später, im 5. Kapitel bestätigt, wo es heißt: "Er [Antipov] erzählte. [...], was für ein Landhaus sie in Serebrjanyj bor gehabt haben." - S. 333. 
dreimal wiederholt, ironisch gemeint, verdeutlicht, wie weit das Kind vom Verständnis der Sorgen seiner Mutter entfernt ist.

Saša lebt mit drei gleichaltrigen Jungen in der Welt des Spiels, solange, bis sich in einer harmlosen Szene herausstellt, daß einer von ihnen ein Spitzel ist, und dies offensichtlich nicht aus eigenem Antrieb, sondern mit Auftrag seiner Eltern (...eine von vier Personen, im Auftrag einer "höheren Instanz", - ein Bild für die gesellschaftliche Gesamtsituation im Rußland der damaligen Zeit?...). Während die drei anderen raten, wer wohl am anderen Ufer des Flusses badet, "weiß" Čunja, daß es nicht Gal'ka sein kann, denn diese sei weggefahren. Der apodiktischen Auskunft widerspricht niemand, denn Čunja "muß es wissen", weil sein Vater "Verwalter" ist. Ungefragt gibt Čunja dann aber noch weiteres Wissen preis: Er habe, von seiner Mutter geschickt, Gal'ka in der Wohnung beobachtet und gesehen, wie sie Papiere verbrannt hat. Zwei anscheinend völlig zusammenhanglose Vorgänge: Sie ist weggefahren. Sie hatte Papiere verbrannt. Für den "wissenden" Čunja, der beides in unmittelbarer Folge berichtet, besteht aber zwischen beidem offensichtlich ein Zusammenhang, den auch die anderen Jungen spüren. (...Heißt: Sie ist weggefahren $=$ Sie ist abgeholt und/oder zu einer Behörde bestellt worden?...) - "Schweigen trat ein. Sie wußten nichts zu sagen. Geheime Sehnsucht (toska) quälte Saša. Nichts Schlimmes hatte sich in seinem Leben ereignet, aber er wollte nach Hause. Vielleicht ist plötzlich ein Telegramm gekommen."26 Unbewußt assoziiert Saša Antipov das Gehörte mit dem "Wegfahren" seines Vaters, von dem man bisher vergeblich auf ein Telegramm gewartet hat.

Als im anschließenden Wortgeplänkel der Kinder an Čunjas Adresse gerichtet der Ausdruck "Spion" fällt, ist der Bruch vollzogen, und die Szene eskaliert. Der so Bezichtigte revanchiert sich und schwimmt eiligst davon, voller Angst, daß man das, was sie bisher als Spiel betrieben haben, den anderen "absaufen lassen" (delat' aup), bis er sich ergibt, mit ihm jetzt ernstlich praktizieren könnte. Und auf der anderen Seite des Flusses schlägt die Situation des Spiels dann tatsächlich in Ernst um, durch die Person von Cunjas Vater Polikarpyč, in dessen rettende Sphäre sich der verfolgte Sohn geflüchtet hatte. Jener aber ist nicht nur Autoritätsperson als Erwachsener gegenüber den Kindern und nicht nur als Familienangehöriger gegenüber Fremden, sondern auch als Vertreter einer offiziellen Ordnung. Der hinter- 
hältig lächelnde Polikarpyč, der mit seinem Schnurrbart an einen Kater erinnert, ${ }^{27}$ bereitet der Spielszene der Kinder dadurch ein Ende, daß er deren metaphorische Sprache in die Realität zurückübersetzt. Nicht, daß das "Ersäufen" (topit') grundsätzlich verboten wäre, aber gestattet ist es nur dem, der eine Erlaubnis dafür hat (...ein Personenkreis, zu dem zwar nicht die spielenden Kinder, möglicherweise aber er selbst gehört?...). “Ohne Erlaubnis ist überhaupt niemandem etwas gestattet. Das lasse ich nicht zu."28 Daraufhin gebraucht der Ordnungshüter, der Saša inzwischen am Ohr gepackt und ihm schmerzhaft den Kopf verdreht hat, seinerseits eine doppeldeutige Metapher: "Es ist gesagt worden, junge Hunde soll man ersäufen, solange sie noch blind sind." 29 Damit belegt er den Jungen nicht nur mit einem allgemein abwertenden Bild, er bezeichnet ihn damit vielmehr ganz persönlich: Saša ist (...wie sein Vater...) ein vernichtungswürdiges Wesen, das man aus der Welt schaffen sollte, bevor es von den Zusammenhängen etwas versteht. Und Saša hat bisher tatsächlich nichts verstanden. Er läuft nicht einmal weg wie die anderen, sondern läßt sich, den Schmerz unterdrückend, nur schweigend malträtieren. Wissend aber ist ihm gegenüber sein Mißhandler und dessen Frau, die ihren Mann mit dem verräterischen Satz unterbricht: "Laß den Jungen! Er hat auch ohne dich was auszulöfeln." 30 Und wissend ist Sašas eigene Mutter, die der Szene schweigend zugesehen hatte.

Die Leerräume des Erzählens bestehen auf der Ebene des Erzählverfahrens zwischen einem anonymen Zeitgeschehen, das aus einem verdeckten Hintergrund unheilvoll auf das Leben der Menschen einwirkt und einem noch nicht verstehenden, aber schon erleidenden Kind. Sein Vater verschwindet; es selbst - zur gleichen "Spezies" gehörend - wird symbolhaft gedemütigt. Die punktierten Linien des Kapitels laufen in der Person des Verwalters Polikarpyč als dem unmittelbaren Verursacher zusammen. Auf

27 Der schwarze Schnurrbart - ein Attribut Stalins - wird von Trifonov im Roman auch an anderer Stelle als Anspielung auf den Diktator zur Charakteristik regimetreuer Figuren gebraucht: im Traum für den Schlafplatzvermieter Valerij Izmajlovið̌, der Saડ̌ Antipov denunziert (Kapitel 4); für Smerin, den Staatssicherheitsbeauftragten, der Antipov im Betrieb arretiert und seinen Freund verhört (Kapitel 6). - Der Vergleich Polikarpyと̌s mit einem Kater enthält ferner eine literarische Allusion auf Bulgakovs Master i Margarita, wo ein Kater (bzw. ein katerähnlicher Dickwanst) - "riesig wie ein Eber, schwarz wie Ruß oder eine Saatkrähe und mit verwegenem Kavalleristenschnurrbart" als Gehilfe des Teufels fungiert. (Michail Bulgakov. Master i Margarita. Frankfurt/Main 1969. S. 65.)

S. 259. - Kursiv von mir, L. S.

S. 260.

Ebd. 
der Ebene der Handlung bestehen Räume der Unbestimmtheit nicht nur zwischen dem Kind und den Erwachsenen, sondern auch zwischen den Erwachsenen, die wie Sašas Eltern unter den gesellschaftlichen Ereignissen zu leiden haben und denen, die als Vertreter der gesellschaftlichen Ordnung Leiden verursachen.

Der Rolle des Lesers bleibt es schließlich überantwortet, den euphemistischen Charakter der Kapitelüberschrift zu dechiffrieren. "Die Strände der dreißiger Jahre" - will besagen: So ging es in den dreißiger Jahren im Lande überall zu, wo Leute bisher Ruhe und Erholung fanden. Selbst an diesen Stätten war man nicht vor Spitzeln und Denunzianten sicher. Die positive Konnotation des Wortes "Strand" wird vom Autor ins Ironische gewendet.

\subsection{2.) Kapitel 2: Zentral-Park (Sommer 1938 - Winter 1939/1940)}

Im zweiten Kapitel wird ein neuer Personenkreis eingeführt, der dem Erlebnisfeld des Ich-Erzählers angehört. Das Segment des dargestellten Lebens erhält einen breiteren Grund. Der Ort des Geschehens - wieder Moskau, ein Jahr später. Der große Raum der Unbestimmtheit, den das Motto gegenüber dem Text des ersten Kapitels gesetzt hatte, erstreckt sich auch über das zweite. Und auch hier stellt der Autor die verhängnisvollen Zeitereignisse nicht direkt, sondern nur mittelbar, in ihren Auswirkungen auf einzelne, indirekt betroffene Personen dar. Vom Verschwinden von Menschen, namentlich von Eltern, ist auch hier die Rede, und zwar der Eltern des Erzählers, als er selbst 12 Jahre alt war und der etwa 18jährigen Mignon (Minka, Marina Osipovna). Beide sind jetzt Vollwaisen, ebenso wie Saša Antipov zur gleichen Zeit. Der 12jährige Junge spricht von seinem menschenleeren und entvölkerten Haus (moj dom bezljuden [...] opustelyj dom ${ }^{31}$ ). Auch bei ihm war - wie bei Antipov - zunächst $(=1937)$ der Vater "verschwunden", das geht aus einer späteren Erwähnung im fünften Kapitel, durch die hier noch nicht auftretende Großmutter hervor: "kogda otca ne stalo." 32 In Kapitel 3 (= 1946) hingegen heißt es, daß Antipov seine heimgekehrte Mutter acht Jahre nicht gesehen hatte. Daraus ist rückblickend auf eine analoge Situation für beide Jungen zu schließen: Ein Jahr nach den Vätern,

31 S. 261 und 264. Der zweite Ausdruck ist zugleich eine literarische Anspielung auf Lidija Čukovskajas Opustelyj dom; verfaßt 1939/1940, publiziert 1965 in Paris.

32 S. 327 . Kursiv von mir, L. S. 
eben im Jahre 1938, mit dem das zweite Kapitel einsetzt, hatte man auch die Mütter der beiden abgeholt.

Der Erzähler widmet das zweite Kapitel des Romans der Mutter seines damaligen Schulfreundes Levka Gordeev, einer überaus gütigen Frau. Die Geschichte von Agnija ist das zentrale Ereignis, um das sich die übrigen Erinnerungen entfalten. Agnija (griech: Reinheit, Reinigung[sopfer]) - ein sich aufopfernder Mensch, nicht nur in ihrem Beruf als Krankenschwester Tag und Nacht ansprechbar, ist in ungewöhnlicher Weise zu praktizierendem Mitleid fähig. Sie hilft, heilt, pflegt, beherbergt die, die ihr bedürftig erscheinen. Auch die verwaiste Nichte aus Melitopol und den verwaisten Freund ihres Sohnes (den späteren Erzähler) nimmt sie auf, um ihnen die Einweisung in ein Kinderheim zu ersparen. Dabei wirkt sie resistent gegen die äußere Atmosphäre der Angst, die sie anscheinend gar nicht erreicht. Trotz aller Besorgtheit aber gelingt es ihr nicht, die halbwüchsige Nichte vor moralischen Abwegen zu bewahren. Die punktierte Linie des Erzählens deutet an, daß ihr Selbstmord daraus als Verzweiflungstat resultiert.

Wie im ersten Kapitel kann auch hier das aktuellste Thema, die verschwundenen Eltern, nicht erörtert werden, deshalb entstehen Leerstellen wiederum sowohl zwischen Personen und Zeitgeschehen als auch - auf der Handlungsebene - zwischen den Personen selbst. Jede der agierenden Figuren sieht die aktuellen Ereignisse aus einem eigenen Blickwinkel, der den anderen nur bedingt zu vermitteln ist. Der 12jährige Junge und spätere Erzähler, dem "irgendwo" die Großmutter geblieben war, hat sich mit der neuen, elternlosen Situation bereits abgefunden. Er fragt nicht mehr nach. Und weil er wie Saša Antipov gewohnt ist, das Leben nur von der hellen, freundlichen Seite $z u$ sehen, lebt er unreflektiert mit der ihm eingeredeten Lüge, seine Eltern seien "auf Dienstreise"33. Agnija zerstört ihm zwar die Illusion der schönen Lüge nicht, aber die Tatsache, daß sie zum Mißfallen des Jungen wiederholt nach dem Verbleib seiner Eltern fragt und seine wiederholt gleichlautende Antwort mit dem gleichlautenden Ausdruck des Erstaunens kommentiert (vona, kak - na, so was), gibt ihm indirekt zu verstehen, daß Zweifel möglich sind.

Anders Mignon (Minka, Marina Osipovna), das eben erwachsen gewordene, hübsche, stolze Mädchen aus prominentem Haus. Die Verhaftung der Eltern trifft sie in einer Phase des inneren Umbruchs ihrer ganzen Person.

Der russische Ausdruck "na komandirovke" bleibt näher an der Sache! 
Agnijas sorgende Mühe erreicht sie deshalb nur partiell und sehr bald gar nicht mehr. Zur Überwindung ihres Leides helfen ihr vermutlich mehr und mehr fragwürdige Männerbekanntschaften, die sie bei ihrer Tätigkeit im angrenzenden Freizeitpark macht. Der Erzähler erinnert sich: Er und sein Freund wurden von Agnija geschickt, Minka zu beschützen. "Weil man sie belästigte. Nein, nicht nur von Rowdys, von allen möglichen Männern, Schach- und Billardspielern. Denn sie war ein schönes Mädchen. Und wir verstanden das und verstanden, warum man sie belästigt, und sie tat uns sehr leid." 34 Die Feststellung, daß Mignon anfangs von allen bemitleidet wurde, weil sie viel weinte und sich in ihrer Kammer einschloß, ist in der Begründung mehrdeutig. Im Erzählvorgang wird zunehmend erkennbar, daß sich ihre Trauer, von der man annehmen kann, daß sie zunächst dem Verlust der Eltern gilt, bald mit Liebeskummer mischt. Mignon ist sich der erotischen Faszination, die von ihr ausgeht, bewußt, und diese verhilft ihr zum befreienden, wenngleich nicht unproblematischen Ausbruch aus der Depression in eine "andere Welt". Das ist aber zugleich der Ausbruch aus dem Schutzraum, den Agnija, die Mignons Wegstreben nur als verderblich ansehen kann, für sie geschaffen hatte. "Grüner Mantel, grünes Käppchen, schwarzes Täschchen", eilt Mignon abends aus dem Haus, ohne auf die Frage zu antworten, wann sie wiederkäme (...der Weg in die Prostitution?...). Und Agnija, die "nie auf jemanden böse wurde, nicht zu schimpfen verstand, nicht einmal laut sprechen konnte, immer nur flüsterte"35, läuft ihr mit schluchzendem Schrei, im weißen Kittel hinterher: "Stanislav hat dich was gefragt! Wieso antwortest du nicht, Scheusal?"36 Das war im Herbst. An einem Wintertag hat sich Levkas Mutter erhängt. Die Ereignisse werden, wie sie im Erleben des 12jährigen Jungen aufgetaucht sind, in loser Folge und von anderen Impressionen unterbrochen, ohne kausale Verknüpfung mitgeteilt. Aus späterer Zeit rückblickend greift der Erzähler die punktierte Linie von Mignons Lebensweg noch einmal auf. Mignon endete nicht da, wo Agnija befürchtet hatte. Sie muß bei ihren Männerbekanntschaften (...ziemlich bald oder erst später?...) auch auf einen einflußreichen Förderer (...einen alten Bekannten ihrer prominenten Eltern?...) gestoßen sein, der ihre musikalische Begabung erkannt und ihr den Weg zur Ausbildung als Pianistin an der Moskauer Phil-

\footnotetext{
34 S. 266.

35 Ebd.

36 S. 271.
} 
harmonie gebahnt hat, wo sie jetzt aber nicht mehr ist. Das Leben ist abermals weitergegangen.

Wie der 12jährige Junge keinen Begriff vom Verschwinden seiner Eltern hat, so hatte er auch keine Erklärung für Agnijas tragisches Ende. Und selbst Agnijas Fürsorge für andere, so sehr ihm diese persönlich zugute kam, war ihm nur zum Teil verständlich. Die Gründe für Mignons Aufbruch aus Agnijas Schutz und Schirm lassen seine vorpubertären Phantasien, Ängste, Sehnsüchte und Neidgefühle, die er auch gegenüber älteren Jungen empfindet, zwar ahnen, aber in den tieferen Zusammenhängen noch nicht verstehen. In der Art seines Erlebens von Mignons Person spiegelt sich die Phase seiner eigenen Entwicklung, die eines Heranwachsenden wider. Die "nur" punktierte Linie des Erfassens seiner Welt resultiert für den 12jährigen Jungen also sowohl aus noch fehlender persönlicher Reife wie aus fehlender Kenntnis konkreter Tatsachen als auch aus mangelnder Einsicht in die Wirkmechanismen der Gesellschaft, in der er lebt. Durch das Prisma dieses kindlich Erlebenden muß aber das Verstehen auch der Interaktionslinie der anderen epischen Figuren zwangsläufig punktiert bleiben. Das zeigt insbesondere die dem Jungen nur in ihren äußeren Erscheinungen faßbare Beziehung von Agnija, Stanislav und Mignon.

Stanislav, Levkas Stiefvater, vor sechs Jahren als nicht ganz ausgeheilter, psychisch kranker Patient zwar aus dem Krankenhaus, aber in die Obdachlosigkeit entlassen, von Agnija nicht nur in ihre Wohnung auf-, sondern als neuer Ehemann angenommen, seither mit Sorgfalt umhegt, bleibt krank. Seine Krankheit bestand in vollständiger Lethargie, mit Ausnahme eines zeitweilig geheimnisvollen Interesses an Nachforschungen über den Neskučnyj-Garten, ${ }^{37}$ mit denen er, ohne Erfolg zu haben und für andere unverständlich, etwas erreichen wollte, was ihm aber gleichfalls als Symptom seiner Krankheit ausgelegt wurde. "Niemand wollte in seine Schreibereien

37 Das ist der älteste und ursprünglichste Teil des Parks, von dem im Kapitel die Rede ist. Vor der Oktober-Revolution von 1917 war er einem Adelssitz zugehörig und erhielt in sowjetischer Zeit nach seiner flächenmäßigen Erweiterung. Neuanlage und Neubestimmung 1931 die offizielle Bezeichnung "Central'nyj park kul'tury i otdycha imeni Gor'kogo". - Zur Geschichte des Parks siehe den kürzlich in der Wochenzeitung DIE ZEIT (Nr. 19, 2. Mai 1997, S. 44) erschienenen interessanten Bericht von Karl Schlögel: Ein Garten für den Neuen Menschen. [Heraus zum I. Mai! Doch nicht nur auf der Straße, auch im sozialistischen Park sollte sich die kollektive Kraft manifestieren - das Modell war Moskaus Gorki-Park.] Die Chronik einer monströsen Idylle. 
eindringen, weil man sie für den Unsinn eines Wahnsinnigen hielt"38, auch Agnija. Erst als Mignon begann, im Hause Mandoline zu spielen, ging es ihm besser. Wie er ihrem Mandolinenspiel zuhörte, so hörte sie seinen Erklärungen über den Neskučnyj-Garten aufmerksam zu und läßt sich aus irgendeinem Grund von ihm an Ort und Stelle alles genau erklären. "Und dann war er plötzlich mit einem Mal genesen. Das geschah im Laufe eines Sommers. Anfang Juni, als ich aus Moskau wegfuhr, war er noch krank, und im September, als ich zurückkam, war er schon gesund und ging zum Dienst."39 Die Stellen der Unbestimmtheit, die sich im Erzählvorgang auf der Ebene der Textsemantik um das Verstehen der Person Stanislavs ergeben, kommen beim 12jährigen Erlebenden wie bei seinem Freund Levka durch die ihnen weitestgehend nur mögliche Außensicht zustande, bei Agnija aber dadurch, da $B$ sie trotz ihrer sich aufopfernden Hingabe blind bleibt für die Ursache von Stanislavs Krankheit. Mignon hingegen gelingt es offenbar dank ihrer musikalisch-erotischen Sensibilität und wohl auch aufgrund ihrer höheren Bildung, den Kranken in seinem innersten Wesen ernstzunehmen und sich vorurteilsfrei auf ihn einzulassen. Das ermöglicht seine (zeitweilige) Genesung. - Wie Mignons Lebenslinie führt auch die von Stanislav über die erzählte Gegenwart hinaus und endet beim rückblickenden Erzähler in späterer Zeit. Stanislav hatte Mignon (Marina Osipovna), von der er sich anscheinend am besten verstanden fühlte, seine Studien über den Neskučnyj-Garten überlassen, und diese waren schließlich in die Hände des Erzählers gelangt. Dadurch erhält der Ort des Geschehens, der die Figuren der Gegenwartshandlung in einem Lebensabschnitt miteinander verbunden hatte, seine geschichtliche Vertiefung. Der Verfasser hatte aufzuzeigen versucht, daß die ersten Anfänge des Parks auf einen entfernten, weitläufigen Verwandten zurückzuführen sind, der durch unglückliche Umstände seinerzeit sein redlich erarbeitetes Vermögen verloren hat. Weil man aber die Anerkennung des Resultats seiner Nachforschungen verweigerte und die nachträgliche Würdigung der Gründer des Gartens durch eine Gedenktafel ablehnte, wurde Stanislav krank. Die punktierte Linie des Erzählens deutet an, daß sein Anliegen berechtigt war und daß die Ursachen seiner Krankheit in der erfolglosen Auseinandersetzung mit behördlichen Instanzen zu suchen sind. Damit gehört

Ebd. 
auch Stanislav, auf seine Weise, zu den Opfern der zerstörenden Wirkkräfte der Gegenwartsgesellschaft. 40

Der Leerraum, der im zweiten Kapitel zwischen dem (nicht ausgeführten) Zeitgeschehen und den handelnden epischen Figuren besteht, wird nicht zuletzt dadurch anschaulich charakterisiert, daß der offizielle Namen des Parks (s. Anm. 37) nicht erwähnt wird und daß insbesondere jeder Hinweis auf die wichtige politische Funktion fehlt, die der Park damals für seine sowjetischen Betreiber hatte, nämlich durch propagandistische Veranstaltungen zur Erziehung des neuen "Kollektivmenschen" beizutragen. Die im Erzähltext auftretenden Personen sind allesamt unpolitisch. Das tagtäglich unmittelbar neben ihnen ablaufende "Agitprop"-Spektakel erreicht sie nicht, zumindest nicht in seiner gesellschaftsprägenden Intention. Aus Agnijas Sicht spielt der Park, wenn überhaupt eine, dann eine ungute Rolle. Das ist eine Welt, die man tunlichst meiden sollte. Mignon geht hier vornehmlich ihren privaten Vergnügungen nach, die 12jährigen Jungen ihren kindlichen Abenteuern. Stanislav aber beklagt sich vehement über den Lärm der Musik, die ihm physischen und psychischen Schmerz verursacht: "Hundehochzeit! [...] Einpacken! [...] Alles zusammen einpacken!"41

Vom psychisch krankgewordenen Stanislav spannt sich ein weitgezogener Bogen zum Schlußkapitel des Romans, wo der Erzähler an eben den Ort seiner Kindheit, den das zweite Kapitel im Ausschnitt wiedergibt, zurückkchrt, zum gleichen Zentral-Park mit dem nebengelegenen Krankenhaus, in das er nun seine Tochter bringen muß, die an der gleichen "unbegreiflichen Krankheit, dem Unwillen, zu leben" leidet wie einst Levkas Stiefvater, und zwar aus dem vergleichbaren Grund einer verweigerten Anerkennung.

Der rückblickende Erzähler verweist auf die Verflochtenheit der Geschehnisse, schon damals. Die zunehmende zeitliche Distanz, die zwar ermöglicht hat, manches neu zu sehen, hat andererseits vieles in Vergessenheit geraten lassen, so da $B$ die Stellen der Unbestimmtheit im Text nicht nur als erzählstrategisches Kalkül des Autors Trifonov, sondern auch thematisch als Ausdruck des Vergessens von Begründungszusammenhängen durch den IchErzähler zu werten sind: "Warum weint sie [Agnija]? Ich habe es vergessen, ich erinnere mich nicht, ich habe es nicht erraten, ich habe es nie gewußt.

40 Der halbwahnsinnige Stanislav steht als literarische Figur in der Tradition Gogol's und des frühen Dostoevskij, mit erkennbarem Verweis auf die Kausalität zwischen psychischer Erkrankung und gesellschaftlichem Umfeld.

41 S. 265. 
Jetzt kann man die Wahrheit nicht mehr ausgraben. So viele Jahre sind vergangen." 42 Trotzdem bleibt bei der Ich-Erzählung des zweiten Kapitels problematisch, daß der inzwischen erwachsen gewordene Erzähler, für den sich die Dinge der erinnerten Vergangenheit sehr wohl in bestimmte Zusammenhänge des Verstehens geordnet haben - sonst könnte er dem Leser bei seiner rückblickenden Synopse der damaligen Ereignisse auch keine Sinnlinien anbieten, die zu Konvergenzpunkten führen -, noch einmal versucht, die Dinge so "verständnislos" zu sehen, wie er sie seinerzeit erlebt hat, und selbst noch einmal als Zwölfjähriger sprechen will.

\subsection{3.) Kapitel 3: Tverskoj Boulevard I (Anfang 1946)}

Der Leerraum, der im Textaufbau zwischen Kapitel 1 und 2 in der nur zeiträumlich geführten Parallelität der dargestellten Ereignisse entstanden war, wird im dritten Kapitel dadurch überbrückt, daß sich der Ich-Erzähler von Kapitel 2 jetzt als Erzähler von Antipovs Geschichte vorstellt. Der Tverskoj Boulevard und sein näheres Umfeld ist der Lebensraum, in dem sie beide, er wie auch Antipov, zu Hause waren. Eine knappe, rückblickende Szene in die allerfrüheste Kindheit des Erzählers erinnert an sein damaliges Wohnhaus Ecke Tverskoj Boulevard - Bol'šaja Bronnaja, das Saša Antipov im Erzählverlauf des dritten Kapitels und zu späterer Zeit betreten wird, um hier seinen Literaturlehrer zu besuchen.

Mit einem Zeitsprung von neun Jahren nimmt der Erzähler Antipovs Biographie vom ersten Kapitel wieder auf. Die punktierte Linie spart dabei aus, daß nach Antipovs Vater im folgenden Jahr 1938 auch die Mutter verhaftet und verschickt worden war, und zwar nach Kasachstan. ${ }^{43}$ In Kapitel 1, im August 1937, war die Mutter noch da, in Kapitel 3, Anfang 1946, ist sie wieder da, nach sechstägiger Eisenbahnfahrt eben nach Moskau zurückgekehrt. Ihre Kinder, die Moskau gleichfalls zeitweilig verlassen mußten, wurden später in eine Gemeinschaftswohnung an der Peripherie der Stadt eingewiesen, in der man jetzt mit anderen zusammenlebt. Auf der Personalebene besteht im Zusammenleben der Mutter mit den inzwischen erwachsen gewor-

42 Ebd.

43 Die Präzisierung gibt Kapitel 9 ("Das Ende des Winters am Trubnaja Platz”), wo durch eine im Text neu hinzukommende Person mitgeteilt wird, daß die Mutter in Kasachstan in einem Sovchoz gearbeitet hat. S. 422. 
denen Kindern ein Leerraum von acht Jahren, dessen zwischenzeitliche Ereignisse und Erlebnisse, insbesondere die der Mutter, für den Leser nicht nachgetragen werden. Was inzwischen geschehen ist, spiegelt sich wie in den beiden ersten Kapiteln nur indirekt, in der Veränderung und im Verhalten der Personen wider: Mutter und Schwester, beide vorzeitig gealtert und sich gegenseitig entfremdet, reagieren auf das plötzliche Wiedersehen nach der langen Zeit der Trennung mit einer inneren Erschütterung, die sie sprachlos macht.

Das aktuelle Zeitgeschehen bleibt weiterhin als Hintergrund verdeckt und wird nur in einzelnen typischen Auswirkungen präsentiert: Ein halbes Jahr nach Kriegsende kommen die überlebenden Angehörigen der in den politischen Prozessen der 30er Jahre Verurteilten nach und nach aus der Zwangsverschickung zurück, oft halblegal, weil das Aufenthaltsrecht für die Hauptstadt zusätzlicher, erschwerter Genehmigung bedurfte. Restauriert aus der Zeit der 30er Jahre ist im gesellschaftlichen Leben die Atmosphäre der Repression, der Denunziation und der Angst, die punktuell von der Zivilcourage einzelner durchbrochen wird. Auf der Heimreise konnte die Mutter eine Situation zweifacher Angst durch die Solidarität eines Mitreisenden überstehen: Die von ihr aus Versehen gezogene Notbremse in Verbindung mit einer für Moskau nicht gültigen Einreiseerlaubnis. Sohn Saša, mittlerweile 20jähriger Student am Literaturinstitut, stets mit Notizbuch, um alltägliche Sujets für Erzählungen zu sammeln, notiert sich den Bericht der Mutter in Stichworten, die für andere unverfänglich bleiben. Er hat gelernt, brisante Eintragungen zu verschlüsseln, weil er bereits erfahren hat, daß er für seine Notizen observiert worden ist.

Das Notizbuch - wichtigstes Attribut des angehenden Schriftstellers Antipov - ist zugleich Bindeglied zwischen dem ersten und dem zweiten Teil des Kapitels, denn es geht auf eine Empfehlung seines Literaturdozenten Boris Kijanov zurück, den Antipov im zweiten Teil besuchen wird. (Beide Teile des dritten Kapitels können wie im übrigen die Kapitel selbst - nach der Definition des Autors - als in sich abgeschlossene Erzähleinheiten angesehen werden.)

Kijanov, auch als Schriftsteller bekannt, und die Sekretärin des Lehrstuhls, Susanna Vladimirovna, eine kokette Frau von 40 Jahren, treten im zweiten Teil des Kapitels als neue, für Antipovs Leben wichtige Personen, ins Blickfeld des Lesers. Beide werden für Antipov zu Leitfiguren, die ihn, jede auf ihre Weise, mit Wohlwollen begleiten, fördern und vor Unannehm- 
lichkeiten bewahren. Beide haben ihre persönliche, Kijanov eine sehr komplizierte Geschichte, die zwar beide voneinander kennen, die aber der 20jährige Antipov nicht kennen kann und die sich im durchgängig personalen Erzählmilieu dem Leser gemeinsam mit Antipov erst Schritt für Schritt erschließt.

Susanna, durch zwei Eigenheiten gekennzeichnet, durch ihre unersättliche Liebeslust, mit der sie ältere Herren ebenso zu vereinnahmen versteht wie die jungen Studenten des Instituts, und ihre Fähigkeit zu Mitleid und Hilfsbereitschaft - ähnlich wie bei Agnija (Kapitel 2) eine Elementarform des Anstands gegen die vom Zeitgeist honorierte Gemeinheit - bittet Antipov, den erkrankten Kijanov zu besuchen, "eine Bitte des Lehrstuhls (...) und auch meine persönliche Bitte"44. Eine anscheinend ganz normale Situation, an der Antipov allerdings auffällt, daß Susanna eine etwas hochtrabende Sprache gebraucht (edelmütig/blagorodno/ wäre das von ihm) und daß sie ihm mit geheimnisvoller Geste Lebensmittelmarken und Geld gibt, damit er für Kijanov Lebensmittel und Tabak einkauft. Kijanov sei völlig allein, ohne jede Hilfe, (wovon Susanna weiß, daß das nicht zutrifft), seine Frau sei im Krankenhaus. Antipov läßt sich schicken, ohne über die Zusammenhänge informiert zu sein, die Susanna kennt. Und er trifft seinen Lehrer, den er als eine stets gepflegte Persönlichkeit kannte, in einem Zustand äußerer und innerer Verfallenheit an, der ihn entsetzt. "Aber hier im Zimmer war die Luft muffig. Und es roch nach Unglück." 45 Begreifen kann Antipov, daß Kijanovs Krankheit nicht nur physiologische Ursachen hat und auch nicht nur von den seit dem Tode des im Krieg gefallenen Sohnes behandlungsbedürftigen Depressionen seiner Frau herrührt, von denen Kijanovs helfender Freund Grigorij im Nebenzimmer flüsternd berichtet, sondern wesentlich auch von den angedeuteten, aber nicht näher ausgeführten anderen "Schicksalsschlägen", dem anderen "Unheil", den "allerlei kleinen Unannehmlichkeiten" 46 , die es außerdem noch gab. Offenbar sind letztere die größeren. Grigorij gibt Antipov zu verstehen, daß man ihnen nicht umsonst Brot und Zucker schicke. Das heißt, Kijanov muß sich in einer Situation befinden, in der man ihm sowohl die Lebensmittelkarte als auch die Einkünfte aus seiner berufli-

44 S. 278. - Mitleid und Hilfsbereitschaft verbinden sich bei ihr allerdings oft auch mit dem Interesse an erotischer Annäherung. Das bestätigt Kijanov später schon für die derzeitige Situation (s. u.. Kapitel 10); das erfährt demnächst (Kapitel 4) auch Antipov.

S. 284.

46 S. 286. 
chen Tätigkeit vorenthält, eine Situation, über deren Hintergründe man nicht spricht, wie es Grigorij offenbar gegenüber Susanna Vladimirovna getan hatte, und der dafür von Kijanov entsprechend gerügt wird. Antipov spürt Kijanovs Hilfsbedürftigkeit, aber seine Frage: "Soll ich irgend etwas tun? Ich könnte aufräumen oder Kartoffeln schälen?"47 - geht an der Sache vorbei.

Kijanov braucht Geld. Das zeigt die Tatsache, daß er in eben der Situation von Antipovs Besuch zwei Stapel Bücher verkaufen will. Und Markuša, der Bücheraufkäufer, für den man Antipov zunächst gehalten hatte und der etwa 30 Jahre später (gegen Ende der Romanhandlung, siehe Kapitel 12) auch Antipovs Bibliothek auflösen wird, macht im Kontrast zum Krankenzimmer nebenan fröhlichen Lärm, so daß Antipov sentenzhaft folgert: "Wer Bücher aufkauft, ist lustig, wer verkauft - leidet."48

Das Thema des Leidens aber war Antipov nicht nur im Anblick der Person des kranken Kijanov begegnet, sondern es wird von diesem selbst, nachdem ihm Antipov einen Abschnitt aus seiner letzten Erzählung vorlesen durfte, ganz unmittelbar als Wesen aller guten Literatur bezeichnet. "Literatur ist Leiden. Sie mußten noch nicht leiden, Antipov? Nein? Na, Gott sei Dank. Aber das heißt, dann haben Sie den Menschen noch nichts zu sagen." 49 Diese Sätze und das deprimierende Bild des Kranken treffen Antipov so, daß er nach Überdenken des eigenen Lebens zu Hause seine bisherigen Werke verbrennt. Er muß sich eingestehen, daß er "bedauerlicherweise" noch nicht hatte leiden müssen, und er ist im Alter von 20 Jahren offensichtlich auch nur bedingt fähig, das Leiden anderer zu begreifen, auch da, wo es von den eigenen Lebensumständen her möglich und zu erwarten wäre. Er, der ständig mit Notizbuch ausgerüstet war, um im Alltag Material für seine Erzählungen zu sammeln, kann das Leiden der Mutter und der Schwester an ihrem beiderseitigen Fremdgewordensein nicht so nachvollziehen, daß er darin einen Stoff zum Erzählen sähe. Am Ende des ersten Teils vom Kapitel hatte die Mutter lautlos weinend an seinem Bett gestanden. Am Ende des zweiten Teils - die Schwester: "“Ich kann nicht mit ihr (...) Ich bin einfach außerstande... Sie ist für mich wie eine Fremde... Dabei habe ich all die Jahre so auf Mama gewartet! Und nun ist sie zurückgekehrt...' Die Schwester brach in ein kaum hörbares, dumpfes Schluchzen aus, das Gesicht auf den Armen. Antipov

47 Ebd.

48 S. 287.

49 Ebd. 
stand daneben und wußte nichts zu sagen." 50 - Wie in den beiden vorausgehenden Kapiteln die begrenzte Fähigkeit des Verstehens ein Spiegelbild für die Phase der persönlichen Entwicklung der erlebenden Kinder war, so ist sie es auch hier für die des zwanzigjährigen, noch nicht durch schmerzliche Erfahrung geprägten Studenten. ${ }^{51}$

Antipovs Lebenslinie wird im zweiten Teil des dritten Kapitels mit der von Kijanov verbunden. Die Kijanov-Linie kommt aber nur soweit zur Geltung, wie sie für Antipov einsehbar ist. Dabei liegen einzelne Orientierungspunkte zunächst noch weit voneinander entfernt, so daß eine sinnstiftende Verbindung zwischen ihnen nicht hergestellt werden kann. Was es mit dem "Geheimnis" um Kijanov, das Grigorij und Susanna kennen, auf sich hat, "das alles wurde ihm erst später klar"52, nämlich nach weiteren Begegnungen im Geschehnisverlauf der anderen "Tverskoj Boulevard"-Kapitel, vollständig aber erst durch Kijanovs eigene Offenbarung in Kapitel 10 ("Bol'šaja Bronnaja", = 1957). Im dritten Kapitel erfährt Antipov zunächst nur von seinem Studienkameraden Kotov, daß Kijanov in den 20er Jahren mit seinem Freund Michail Teterin eine Zeitschrift herausgegeben habe und daß letzterer, durch seinen Roman "Das Aquarium" berühmt geworden, ein angesehenerer Schriftsteller gewesen sei als Kijanov. Kijanov erwähnt seinerseits im Gespräch mit Antipov zwar wohlwollend den Namen seines alten Freundes Teterin vom Jaroslavler Gymnasium und erkundigt sich, ob Antipov von ihm gehört habe, aber weder Antipov noch der Leser kann an dieser Stelle dem Kontext entnehmen, daß zwischen seinem beklagenswerten Zustand und Teterins Biographie irgendein Zusammenhang besteht. Zwischen Antipov und dem neu eingeführten Kijanov beläßt das Erzählverfahren auf der Ebene der Textsemantik von Anfang an einen großen Leerraum, der sich erst allmählich mit Bedeutung füllt.

50 S. 288.

51 Die Forschung hat den Mangel an Emotionalität, Gefühlskälte, die Unfähigkeit zum Mitleiden gelegentlich als grundsätzlich negative Charaktereigenschaft Antipovs bezeichnet, im wesentlichen dann aber auf diese Stelle Bezug genommen. - So lgor' Dedkov: Vertikali Jurija Trifonova. In: Novyj mir. 8/1985. S. 232. Und Natal'ja Ivanova: Proza Jurija Trifonova. Moskva 1984. S. 272.

S. 279. 


\subsection{4.) Kapitel 4: Tverskoj Boulevard II (Februar 1947)}

Ein Jahr später wird Antipovs Lebenslinie am gleichen Ort in enger Anknüpfung an das Handlungsgeschehen des vorigen Kapitels weitergeführt und jetzt unter verschiedenen Aspekten auf eine Phase seines persönlichen Umbruchs konzentriert. Der Erzähler stellt fest: "All das verband sich mit jenem Verborgenen, das man Befreiung von der Angst nennen könnte." $\$ 3$ Die thematischen Ansatzpunkte hierzu finden sich - noch unausgeführt - bereits in Kapitel 3:

1.) Antipov hat Angst, in der gewählten Laufbahn als Schriftsteller zu versagen. Er hat im Unterschied zu anderen noch nichts publizieren können. Und Kijanov hatte sich bedeckt gehalten und ihn beim Vortrag seiner ersten Erzählung weder gelobt noch getadelt. 2.) Er hat Angst, im Umgang mit Frauen ungeschickt zu bleiben. Den Prahlereien seiner gleichaltrigen Studienkameraden (Kotov, Kapitel 3; Miron, Kapitel 4) hat er nichts entgegenzusetzen. 3.) Er hat Angst, wegen nicht angepaßten Verhaltens denunziert zu werden. Der Name des Vermieters seines Schlafplatzes, Valerij Izmajlovič, der ihn denunzieren wird, ist in Kapitel 3 bereits genannt.

Innerpsychische Räume der Unbestimmtheit versetzen Antipov in einen mentalen Zustand dreifach begründeter Angst, der von einer punktierten Linie umrissen wird, die sich u. a. in zwei Träumen konkretisiert. Der erste ist ein Alptraum, in dem sich Antipovs sexuelle Be- und Verklemmungen ausformen: Antipov, der sich in die Zirkusartistin Nataša verliebt hat, wehrt die sich ihm übermächtig aufdrängende Susanna ab, aber auch den Schnurrbart und die Baßstimme, mit der "sie" spricht, die zu dem langen Kerl im Matrosenhemd, Natašas Kompagnon, gehören. Der zweite Traum, der Teil einer längerwährenden Krankheitsphase ist, läßt in wirrer Verbindung alle Personen auftreten, die derzeit in Antipovs Gemüt Beängstigung auslösen, ohne daß der Betroffene die rationale Kraft fände, die ineinander verschmolzenen Dinge zu ordnen und zu klären.

In allen drei Bereichen - dem Avancement als Schriftsteller, der Liebeserfahrung und dem Umgang mit Denunziationen - überschreitet Antipov psychologische Schwellen. In allen drei Bereichen spielt Susanna Vladimirovna die entscheidende Rolle. - Susanna, die ihm aufdringlich begegnet und seine erotische Phantasie bis in Träume verfolgt, nicht die Artistin Nataša,

S. 289. 
die er aufrichtig liebt, wird die erste Frau sein, mit der Antipov durch eine zufällige Geschehnisfügung zu intimem Umgang kommt. - Susanna fängt die Denunziation ab, die Valerij Izmajlovič an die Direktion gerichtet hatte. Zwar hatte sich Antipov bezüglich der Heimreise der Mutter nicht durch seine Eintragung ins Notizbuch verraten, aber der Schlafplatzvermieter konnte in der Gemeinschaftswohnung auch ohne das feststellen, daß es sich bei seiner Mutter um eine Person ohne Aufenthaltsgenehmigung für Moskau handelte, und es konnte ihm bei der "Durchsicht" von Antipovs Sachen nicht entgehen, daß dieser verbotene Bücher las, wie den Emigranten Bunin. Die ordnungsgemäße Weiterleitung des Briefes hätte Antipov den Studienplatz gekostet. Der Denunziant, der - wie Susanna richtig vermutet hatte - "Resultate sehen will", wird die Anzeige wiederholen. Beim zweiten Mal - was Antipov erst 10 Jahre später erfährt - wird das Schreiben von Kijanov persönlich zurückgehalten. ${ }^{54}$ - Und Susanna vermittelt durch ihre allseits generösen Liebesdienste auch Antipovs erste Publikation im Feuilleton einer Zeitung, wenngleich nicht der Erzählung, die Antipov für seine beste hielt. Rojtek aber (im Text neu eingeführt), Abteilungsleiter der Zeitungsredaktion und aus Antipovs Sicht "ein sympathischer Mann mit Sachkenntnis und Autorität", ist - was Antipov jetzt noch nicht wissen kann - der negative Konvergenzpunkt in Kijanovs Lebenslinie, und zwar sowohl der der Vergangenheit als auch der der Gegenwart und der der Zukunft. Der ins Vertrauen gezogene Studienfreund Miron (im Text neu eingeführt), Antipovs wohlwollender Berater in allen Lebensfragen, bei dem Antipov nach der Kündigung seines Schlafplatzes erste Zuflucht findet, rät ihm, er solle Kijanov bitten, betreffs der ersehnten Publikation an Rojtek ein paar Zeilen zu schreiben. Kijanov aber reagiert bei dem Namen Rojtek höchst allergisch, wofür weder Miron noch Antipov eine Erklärung haben, wohl aber - unausgesprochen Susanna. "Das haben Sie unüberlegt gemacht. Mit Rojtek spreche ich. Zwischen den beiden ist das kompliziert."55 Obgleich Antipov die zwischen Kijanov und Rojtek bestehende Konfliktsituation nicht kennt, gerät er bei einer erneuten Begegnung mit dem "sympathischen Mann mit Sachkenntnis und Autorität" selbst in eine ähnliche allergische Abwehrhaltung wie eben noch Kijanov, nämlich als jener von ihm fordert, er möge seine Erzählung "Der Fluß und das Boot", offenbar die Darstellung einer Stimmungslandschaft, zu einem Text umarbeiten, der ins Schema des sozialistischen Rea-

54 S. u., Kapitel 10. Dazu auch Anm. 109.

S. 300 . 
lismus paßt. Antipov aber verkauft seine Überzeugung nicht: "Es gibt Dinge, die kann man nicht umändern." Rojtek: "Unsinn! Alles kann man ändern. Merken Sie sich, junger Mann, alles Echte kann man umarbeiten, und das, was sich nicht umarbeiten läßt, ist Blödsinn und faules Zeug. Gutes Material kann man immer wenden." Antipov, nachdenklich: "Nein. Da bin ich anderer Meinung." 56

Der zeitgeschichtliche Hintergrund wird auch in Kapitel 4 nicht ausgeführt, aber die Szene illustriert exemplarisch: Rojtek, Anfang 1947, ein Vertreter der offiziellen Kulturpolitik der eben beginnenden Ždanov-Zeit. Ein herausgegriffener Punkt, der erste für Antipov erlebbare typische Punkt aus der Lebenslinie eines skrupellosen Opportunisten der auf Kosten anderer seine Karriere betreibt. Mit einem zynischen Gruß an Kijanov empfiehlt Rojtek, Antipov möge sich von seinem Lehrer berichten lassen, wie oft dieser seinen Roman "Wermutsstern" umgeschrieben habe! Antipov kann ab jetzt wissen, daß zwischen Kijanovs und Rojteks Biographie ein unguter Zusammenhang besteht, wenn er auch noch nicht wissen kann, welcher und daß dabei der im dritten Kapitel beiläufig erwähnte Teterin eine wichtige Rolle spielt. Ob Kijanovs Bereitschaft zum Umschreiben von Rojtek persönlich erzwungen war, bleibt offen, die Veranlassung kann auch durch andere geschehen sein, aber sie entspricht der von Rojtek vertretenen offiziellen Order, und Rojtek als einer der verläßlichen Kulturfunktionäre weiß Bescheid.

Kijanovs punktierte Lebenslinie wird an dieser Stelle in der Charakteristik seiner Person vertieft. Es ist die Linie eines im persönlichen Umgang um Solidität bemühten Menschen, der den Zwängen des Gesellschaftssystems aber offenbar nicht bis zum letzten widersteht. Diese Haltung, das soll später deutlich werden, hatte ihn früher gegenüber Teterin einerseits und gegenüber Rojtek andererseits in ein ambivalentes Verhältnis gebracht: Weil er damals nicht zum Märtyrer werden wollte wie sein Frcund Teterin, sich aber vom "Volksfeind" Teterin auch nicht losgesagt hat, wird er für Rojtek, der an der Denunziation von ehemaligen Redaktionskollegen, vermutlich auch an der Teterins, wesentlichen Anteil hatte, in der Ždanov-Zeit aufs neue erpreßbar. Der beklagenswerte Zustand, in dem sich Kijanov im Vorjahr befand (Kapitel 3) und der ihn anderen gegenüber auch jetzt noch als krank, wortkarg und gereizt erscheinen läßt und den persönlichen Umgang mit ihm 
schwierig macht, kann seine Begründung eben darin haben, jedoch auch darin, daß er nicht bereit war, sich von Schülern aus "anrüchiger Familie" wie Antipov zu distanzieren, obgleich man ihm das geraten hatte (s. u., Kapitel 10). Für beides geben das dritte und das vierte Kapitel zwar erste Anhaltspunkte, wichtige Zwischenglieder, die für das Verstehen des Zusammenhangs erforderlich wären, fehlen jedoch noch. Diese werden erst durch Kijanovs Selbstdarstellung im zehnten Kapitel nachgetragen.

Antipov, anders als Kijanov, schreibt nicht um, deshalb wird auch seine ihm wichtigste, am Stile Bunins und Paustovskijs geschulte Erzählung nicht gedruckt, sondern statt dessen nur - das ist offenbar eine Konzession Rojteks an Susannas Liebesdienste - eine Humoreske aus dem Studentenleben, die durch Zufall Antipovs Autodafé seiner schriftstellerischen Fehlprodukte vom Vorjahr entgangen war. Auf diese Weise kommt Antipov zwar zu seiner Erstveröffentlichung, aber, von der Ironie des Schicksals gelenkt, mit einem banalen Text, der für ihn selbst keine Bedeutung mehr hat. "Er freute sich [als er in der Zeitung seine Erzählung gelesen hatte], aber nicht lange." (On obradovalsja, no nenadolgo. $)^{57}$

Wichtig bei der Weiterführung von Antipovs Lebenslinie ist im vierten Kapitel die Bewährung der charakterlichen Festigkeit, die in seiner Weigerung gegenüber Rojtek ebenso zum Ausdruck kommt wie in der Zurückweisung des Schlafplatzvermieters, der sich nach seiner Denunziation wieder anbiedern will. Damit wird an Kapitel 6 (= 1943/1944) angeknüpft, wo Antipov erstmals in Bewährungsproben seines Charakters gezeigt wird.

Neben Susanna, die Antipov durch konkret tätiges Eingreifen in allen drei Bereichen seiner Lebensangst über Schwellen hinweghilft (wenn auch nicht ganz uneigennützig), sind für Antipov zwei weitere Begleitpersonen von Bedeutung: der lebenserfahrenere Studienfreund Miron und weiterhin Kijanov. Miron, der liebenswürdige Petzer, der Antipov gern vor anderen provoziert und in Verlegenheit bringt, aber eben doch als Freund, in hilfreicher Absicht, steht Antipov beratend und mitdenkend bei allen Problemen bei. Kijanov, der bei aller Unnahbarkeit einigen seiner Studenten doch persönlich zugetan ist, bleibt auch Antipov gewogen und ist offenbar bereit, ihn weiter zu fördern. Das vierte Kapitel schließt damit, daß er, ohne über Antipovs "Publikationserfolg" ein Wort zu verlieren, seinen Schüler berät, was bei der schriftellerischen Bearbeitung einer eben erlebten ungewöhnli- 
chen Geschichte, der brutalen Abrechnung zweier Banden aus dem Halbweltmilieu, zu beachten wäre: die Motivkette der Zusammenhänge ergründen, versuchen, die Ursachen dafür zu erkennen, weshalb sich Menschen in der gegenwärtigen Gesellschaft so verhalten. "Wie sind wir zu einem solchen Leben gelangt? Alles hat Ursachen, meistens unsichtbare. Aber Sie müssen die Kette sehen."58 Das zu bedenken, wird für den Schriftsteller Antipov auch und gerade in bezug auf Kijanovs Leben wichtig sein, das er später in seinen Roman "Das Nikiforov-Syndrom" (s. u., Kapitel 11, = 1971) einbeziehen wird, von dem er aber jetzt erst nur unzusammenhängende Bruchstücke sieht.

Das vom ersten Kapitel an angelegte Strukturprinzip des Kontrastes derer, die an der Zeit und den Zeitereignissen leiden und derer, die Leiden verursachen, tritt im vierten Kapitel wieder deutlicher hervor, wenngleich auch hier die großen Verursacher verdeckt im Hintergrund bleiben. Beleuchtet werden auch hier nur punktuell einzelne Repräsentanten des gesellschaftlichen Geschehens: Antipovs Schlafplatzvermieter Valerij Izmajlovič, ein Vertreter der Staatsräson auf unterster Ebene, der aus seiner Denunziation vermutlich noch nicht einmal persönlichen Nutzen ziehen kann; Rojtek Vertreter der Staatsräson auf oberer Ebene im wichtigen Bereich der Kulturpolitik, der karrieristische Funktionär, auf dessen einflußreiche Wirksamkeit - wie später einsichtig wird - persönliche Schicksale projizierbar sind. Auf der Gegenseite erlebt Antipov in der Vielzahl einzelner Szenen die stillschweigende Solidarität derer, die nicht zu den Nutznießern der Gesellschaft gehören: seine nächsten Verwandten in der Gemeinschaftswohnung (Mutter, Schwester, Tante und Cousine) gegenüber dem "unhygienischen Kerl"; Miron und seine Eltern, die Antipov mit Selbstverständlichkeit aufnehmen. ("Das waren gute Menschen. Und als Antipov zu ihnen kam, spürte er diese besondere Güte armer Leute, die hundertmal wohltuender ist als die Güte von Reichen."\$9); Susanna und Kijanov im gegenseitigen Verstehen wie auch gegenüber Antipov.

58 Diese Sätze enthalten eine Anspielung auf Cechovs Erzählung Student, die Trifonov in seinem Aufsatz Pravda i krasota mit eben dieser Passage zitiert: "I student podumal, cto 'proß̌loe svjazano s nastojaščim neopredelennoj cep'ju sobytij, vytekavß̌ich odno iz drugogo. I emu pokazalos'. cto on tol'ko cto videl oba konca étoj cepi: dotronulsja do odnogo konca, kak drognul drugoj'." - Trifonov (= Anm. 3). Bd. 4. S. 524.

S. 293. 


\subsection{5.) Kapitel 5: Jakimanka (Ende Oktober 1941)}

Im zeitlichen Rückgriff hinter die Tverskoj Boulevard-Kapitel I und II (= Kapitel 3 und 4), die Antipovs Lebenslinie fortsetzten, nimmt der Ich-Erzähler im fünften Kapitel die eigene im Anschluß an das zweite wieder auf, dessen zentraler Teil, die Geschichte von Agnija, in die Zeit von 1938/1939 fiel. Nach Agnijas Tod kam Stanislav wieder ins Krankenhaus, der ehemalige Schulfreund Levka, den er seither nie wieder gesehen hat, soll im Krieg gefallen, Agababov, der Frauenheld, ordensgeschmückt daraus zurückgekehrt sein. "Während des Krieges war der Park leer und still." (Ende Kapitel 2) Die Handlung des fünften Kapitels kehrt in die Nähe des Parks, wo der Erzähler auch zwei Jahre später noch wohnt, zurück. Der Erzähler erinnert sich an zwei Tage seines Lebens aus dem ersten russischen Kriegswinter zur Zeit der Belagerung Moskaus, während der er als 15jähriger zum militärischen Hilfsdienst eingezogen war. Die erzählte Gegenwart ist absorbiert vom Gegenwartsgeschehen, das alle Einwohner in äußerste Anspannung versetzt, denn die deutsche Armee steht $40 \mathrm{~km}$ vor der Stadt. Der Erzähler - im fünften Kapitel wird sein Vorname, Andrej, genannt - erinnert sich zwar, dem hektischen Treiben mit persönlicher Gelassenheit begegnet zu sein, 60 in der Erinnerung aber reiht sich für ihn das Erlebte zu einer Vielfalt turbulenter Einzelszenen. Die Panik des Aufbruchs in einem großen Wohnhaus, in dem man sich auf Teilevakuierung vorbereitet: Markuša, der Bücher retten will, hier und jetzt schon, Kapitel 5 (= 1941), der "später", Kapitel 3 (= 1946) bei Kijanov "wieder" auftaucht; die Frage, wo soll man den Kater unterbringen, wo das Aquarium lassen, soll man den Fleischwolf mitnehmen?; die Balgerei der noch unbelasteteten Jungendlichen in der Kaserne; die nächtlich verdunkelten Fahrzeuge im Stadtverkehr und die gespenstischen Marschkolonnen der Landwehrleute.

Durchbrochen wird die dynamische Linie des vordergründig additiven Gegenwartsgeschehens von statischen Linien der Erinnerung zweier Vertreterinnen der alten Generation, die in wenigen markanten Punkten den zeitgeschichtlichen Hintergrund bis in die Jahre nach der Oktoberrevolution, in denen schon die Weichen für die Geschehnisse von 1937 gestellt wurden, und noch weiter zurück bis in die vorrevolutionäre Zeit skizzieren. Dabei werden Freiräume in der Lebenslinie des Erzählers aufgefüllt. Die in Kapitel 2

60 "Počemu-to ja byl sovsem spokoen i ne ponimal vsej ètoj sumatochi." S. 315. 
erwähnte, doch nie ins Blickfeld des Lesers getretene Großmutter Andrejs, bei der der Junge damals zwar offiziell wohnte, aber offensichtlich nicht lebte, ist jetzt im Gespräch mit dem Enkel persönlich zugegen und trägt Punkte aus der Biographie seiner Eltern nach. Der Vater hatte früher anscheinend der Gewerkschaftsbewegung angehört, war dafür bereits 1920 von staatlicher Seite angegriffen und 1937 dann in einem der politischen Prozesse verurteilt worden. Schuldhaft verwoben in das Schicksal der Eltern ist aus der Sicht von Andrejs Großmutter die mit ihnen über drei Generationen verbundene Familie Pletnev. Die Großmütter beider Familien waren aus der Zeit gemeinsam erlebter Verbannung in zaristischer Zeit eng befreundet; die Eltern beider Familien - möglicherweise noch inspiriert vom gleichen Geist eines notwendigen gesellschaftlichen Umbruchs, aber nicht eben im Sinne der Etablierung einer Diktatur, verhalten sich im nachrevolutionären Zeitgeschehen unterschiedlich. Während sich Andrejs Vater offenbar exponierte, zeigten sich die Pletnevs bereits 1920 "allzu vorsichtig", im Jahre 1937 aber, das klingt andeutungsweise an, bewirkte ihre übermäßige Vorsicht, daß sie Andrejs Eltern nicht beistanden (...sie vielmehr desavouiert, vielleicht sogar verraten haben?...in einer Situation, in der es möglich gewesen wäre, das Schlimmste noch zu verhindern?...). Der Enkel indessen zeigt sich nicht sonderlich an den biographischen Andeutungen der Großmutter interessiert. Den ominösen Satz: "Die Pletnevs haben ihre Prüfung nicht bestanden" - will er nicht bis ins letzte ergründen, wenngleich für ihn hier der Schlüssel zum Verständnis des Schicksals seiner Eltern liegen könnte. Und der auch im Moment noch spürbare Zorn der Großmutter gegen die Elterngeneration der Pletnevs beeindruckt ihn kaum: "Ich erriet dunkel, was sie meinte, wollte das aber nicht präzisieren, es war unangenehm, Gott mit ihnen, ich habe ihnen verziehen."61 Der Enkel lebt in der Gegenwart. Und die Gegenwart des Krieges zwingt zum Vergessen, aber eben jeden das Seine. Die Großmutter den Verrat der Pletnevs: "Natürlich hatte das jetzt keine Bedeutung (mehr). Nikolaj war an der Front, Ol'ga [seine Frau] quält sich mit Elizaveta Gavrilovna [der kranken Großmutter der Pletnevs], und alles frühere muß man vergessen."62 Der Erzähler, der Enkel selbst, wenn er zur gleichen Zeit an "Verrat" denkt und von "Vergessen" spricht, meint etwas ganz anderes, nämlich, daß ihn die gleichaltrige Tochter der Pletnevs vor einem halben Jahr mit einem anderen Liebhaber brüskiert hatte, wofür er ähnliche Worte 
wie die Großmutter gebraucht: "Ol'ja hatte natürlich Verrat begangen. Aber das war Ende Mai. Und jetzt hatte das keine Bedeutung (mehr). Alles ist vergessen. Nein, nicht vergessen, aber es hatte keine Bedeutung."63 Elementare Betroffenheit kann jeweils nur das unmittelbare Erleben auslösen. Und das ist für die Großmutter immer noch das Verschwinden von Andrejs Eltern. Der Junge hingegen, der die Eltern viel zu lange "auf Dienstreise" wähnte, kann aus der zeitlichen Distanz die Erschütterung, die ihm die Großmutter seinerzeit ersparen wollte, jetzt nicht mehr nachvollziehen. Er ist statt dessen vom Erleben seiner Gegenwart betroffen. So bleibt eine Leerstelle zwischen dem Bestreben der Großmutter, dem Enkel die Zusammenhänge seines Lebens zu erhellen und dessen mangelnder Verständnisfähigkeit in der gegebenen Situation. Für den Leser aber konkretisiert sich punktuell das Jahr 1937 als schicksalsträchtiges Jahr der Eltern-Generation.

Die Generation der Großeltern war anders und dachte anders als die ihrer Kinder. Bei den Pletnevs trifft Andrej nicht nur auf die im Aufbruch begriffene Mutter und Tochter Ol'ja, denen er beim Packen helfen soll, sondern auch auf deren gelähmte Großmutter Lasik, die nicht mehr weg will, weil sie ihr Leben innerlich abgeschlossen hat. Dem hektischen Treiben ihres Umfeldes, das auf sie banal wirkt, dem Lebenskampf einer alten Bolschewistin fremd, sieht die alte, sprachlos gewordene Frau schweigend zu und stellt ihm in inneren Monologen die plastische Erinnerung an ihr früheres Lcben in der Verbannung gegenüber, das trotz aller Gefährdung faszinierend und schön war, eine Erlebniswelt, die Tochter und Enkelin in ihrer derzeitigen Alltagsbefangenheit nie kennen werden.

Dem Kontrast zwischen der zeitlichen Erzählweise, die in vielen einzelnen Momenten gegenwärtiges Geschehen festhält und dem zeitlosen Erzählen, das Vergangenheit erinnert, entspricht der Kontrast zwischen der Ethik der alten Leute, die in der Zeit vor der Revolution ihr Leben für gesellschaftliche Ideale eingesetzt haben und auch danach nicht bereit sind. moralische Prinzipien preiszugeben, und der der nächst jüngeren Generation, die eigennützig denkt und in erster Linie das eigene Leben retten will.

Der 15jährige Junge aber, den die Anspielungen seiner Großmutter auf die frühere Verflochtenheit der Pletnevs in das Schicksal seiner Eltern gleichgültig ließen, er wird in der turbulenten Aufbruchsszene, in die er involviert ist, auch Lasiks innere Monologe nicht an Ort und Stelle nachge-

63

S. 314. 
dacht haben, diese sind vielmehr ein Eintrag des Erzählers aus späterer Zeit, basierend auf früheren Berichten seiner Großmutter oder Lasiks selbst. Für den Leser kaum bemerkbar überbrückt der Erzähler hier Leerstellen zwischen seinem damaligen augenblicklichen Erleben und einer Kommentierung aus einem anderen zeitlichen Kontext, in bezug auf eine Person, deren Wesen sich dem äußerlichen Augenblickserleben ganz offensichtlich entzog.

$\mathrm{Da}$ der seinerzeit 15jährige ganz auf die empirische Wahrnehmung des Gegenwärtigen ausgerichtet war, unterstreicht noch einmal die Schlußpassage des Kapitels. Eingeprägt hatte sich ihm damals unter anderem das impressionistische Bild einer nächtlichen Landwehrkolonne. Zur Zeit des Erzählens aber erhält die Erinnerung eine andere Dimension: "Von dieser schwarzen, ungeordnet dahinstampfenden Menge nichtmilitärischer Menschen ging eine windartige überirdische Kraft aus, die ich damals nicht empfand. Sie hat mich jetzt erreicht, fast vierzig Jahre später."64 Das ist im Nachtrag das Nachempfinden von Aleksandr Bloks mystischer Schau einer historischen Szenerie.

\subsection{6.) Kapitel 6: Die Gasse hinter dem Belorussischen Bahnhof (1943/1944)}

Der spätere Erzähler Andrej und sein späterer Romanheld SaŠa Antipov, die beiden in ihrem Schicksal und ihrer Mentalität ähnlichen, mittlerweile 18jährigen Jungen begegnen sich jetzt zum ersten Mal, bei der gemeinsamen Arbeit in einem kriegswichtigen Betrieb. Der Erzähler erzählt in erster Person ein Stück mit Antipov gemeinsam erlebter Geschichte im Zeitraum von etwa einem Jahr. Es ist ihrer beider Geschichte, durch die aber in besonderer Weise Saša Antipovs Charakterentwicklung veranschaulicht wird. - Wie in den Kapiteln 2 und 5 wird auch hier ein neuer Personenkreis eingeführt, der speziell zum Geschehen dieses Kapitels gehört und später keine Rolle mehr spielt.

Nachdem Kapitel 5 einen Ausschnitt aus der ersten Phase des Krieges wiedergegeben hatte, nämlich Moskau, Ende Oktober 1941, zur Zeit der deutschen Belagerung, hält Kapitel 6 einen Ausschnitt aus der zweiten Phase fest. Moskau - zwar noch verdunkelt, das Leben in der Stadt noch gedämpft, aber "der Krieg war überwunden und zog sich wie ein die Erde verwüstender 
Gletscher nach Westen zurück."65 Im November 1943 feiert man in Moskau. auch im Betrieb des Erzählers, die Befreiung Kievs. Mit der Verlagerung des Krieges nach Westen öffnet sich der bisher total vereinnahmte Lebensraum wieder für persönliche Freiräume. Die Menschen atmen wieder auf, haben wieder das Bedürfnis auch privat zu feiern, z. B. Geburtstage. Doch die Auswirkungen des Krieges bleiben präsent. Ljudas fröhliche Geburtstagsfeier mißlingt am Ende, weil ihr kriegsinvalider Bruder, Nadjas Ehemann, sich durch die Anwesenheit Zenins, Nadjas Liebhaber, beleidigt fühlt. Der Krieg bleibt als Horizontlinie erhalten, und seine Auswirkungen sind gegenwärtig, wenngleich der Abstand zwischen den Geschehnissen an der Front und den Einwohnern der Hauptstadt größer geworden ist. Die agierenden Figuren sind noch von Anspannung gezeichnet, sie haben Angehörige verloren, mancher ist zum Krüppel geworden. Sie leben in einer Mangelsituation und erleben im gegebenen Ausschnitt die Last eines 12stündigen Arbeitstages in einem wichtigen Ressort der Kriegsindustrie. Der leitmotivisch wiederholte Satz "Wir bauten Flugzeugkühler" - unterstreicht die Dringlichkeit und Bcdeutung des Unternehmens.

Eine zweite anonyme Horizontlinie verläuft auf der Ebene der staatlichen Instanzen, die neben dem zurückweichenden realen, äußeren Feind einen irrealen, inneren konstruieren, den es zu bekämpfen gilt. In der erzählten Situation ist für alle eine bis zur Hysterie verdichtete Atmosphäre der Mutmaßungen und des Argwohns spürbar. Dies fällt insbesondere an den Personen auf, die im Betrieb in irgendeiner Weise Verantwortung tragen und deshalb mit der Befürchtung leben, für Mißerfolge, Fehlleistungen und vorsätzliche Sabotageakte verantwortlich gemacht zu werden. Zenin, der Leiter des Werkes, auf die Erfüllung einer bestimmten Norm verpflichtet, erhofft sich, durch den über mutmaßliche verwandtschaftliche Beziehungen zur Hauptverwaltung neu ins Werk eingewiesenen Antipov zwei Werkbänke zu erhalten. Als sich herausstellt, daß die Mutmaßung unzutreffend war, reagiert er seine enttäuschte Hoffnung mit Schikanen an dem ab, der sie unbeabsichtigt erweckt hatte. - Terent'ič, der Verwalter des Werkzeuglagers, argwöhnt. daß Antipov von Zenin geschickt sei, um ihn zu observieren und übt sich deshalb in patriotischen Posen; und weil er argwöhnt, daß ihm sogar der Vorgesetzte selbst Werkzeug entwenden könnte, heftet er sich stets an dessen Fersen. Außerdem argwöhnt er schließlich, daß der Erzähler mit der 10 Jahre

Ebd. 
älteren Arbeiterin Nadja während seiner Abwesenheit in der Werkstatt ein Liebesverhältnis pflegt. Auf der Personalebene entstehen so im Umfeld der Verantwortlichen Leerräume, in denen jeder jedem suspekt erscheint, in positiver wie in negativer Hinsicht. Durch eine bestimmte Person (Antipov) könnte sich Erfreuliches (aus Zenins Sicht) oder Unerfreuliches (aus Terent'ičs Sicht) ereignen. Der so in Vermutungen gehüllte Antipov ahnt selbst von alledem nichts. Und der auf seine Weise involvierte Freund konstatiert aus der nüchternen Erlebnisdistanz des 18jährigen: "Der Alte [Terent'ic] war borniert und argwöhnisch, und der Argwohn bornierter Leute ist unerträglich. Alle ringsum verdächtigte er mit irgendwas. [...] Der Alte war ein Idiot." 66

Erzähltechnisch wird die punktierte Linie der "Mutmaßungen, an jeder Realität vorbei" über Terent' ič, in dem sich das Prinzip in besonderer Weise inkarniert, bis zu der im Hintergrund agierenden Instanz des Staatssicherheitsdienstes weitergeführt, - exemplarisch veranschaulicht an einer groteskkomischen Szene, in deren Mittelpunkt wiederum Antipov gerät und deren auslösendes Moment diesmal der argwöhnische Terent' ič selbst ist. Terent' $i c ̌$, der sich die plötzliche Aversion seines Vorgesetzten Zenin gegen Antipov zunutze machen will, veranlaßt Antipov zu einem verbotenen, "nach Kriegsrecht zu ahndenden Akt", nämlich einen Kohlkopf gegen gestohlenen Tabak zu tauschen, der für die Front bestimmt war. Der beim Tauschgeschäft erwischte Antipov, begriffsstutzig wie schon der 11 jährige Junge im ersten Kapitel, läuft nicht weg, was er hätte tun können, sondern läßt sich arretieren und wird vom Staatssicherheitsbeauftragten des Betriebs einen Tag lang verhört, ohne daß er seinen Auftraggeber verrät. Dies ist ein herausragender Punkt in Antipovs früher Personencharakteristik: Antipov denunziert nicht, auch nicht den, der ihn eben zu schikanieren suchte und ihn in die mißliche Lage gebracht hat, aus der ihm höchste Unannehmlichkeiten erwachsen konnten. Weil er aber Terent'ičs Namen nicht preisgibt, rekonstruiert Smerin, ein Mann mit Stalins Attributen, ${ }^{67}$ Antipovs Biographie und legt dem an seiner Statt am nächsten Tage verhörten Freund ein Bild von Antipovs Vater, dem 1937 verurteilten "Volksfeind" vor, mit dem Hinweis, daß dem Sohn ein ähnlicher Schauprozeß gemacht werden könnte. Als aber auch Andrej dem Verhörenden "nicht weiterhelfen kann", entgleitet die Szenerie ins Paranoische, denn der Anlaß des Ganzen, das illegal gegen Tabak

66 S. 329 und 330.

67 Schwarzer Schnurrbart, schwarze Brauen, manchmal in Majorsuniform. 
getauschte Kraut, ist mit einem Mal völlig belanglos. Der Sicherheitsbeauftragte argwöhnt plötzlich in allen Belegschaftsmitgliedern Verschwörer gegen den Staat, insbesondere aber im Werksleiter Zenin, dem er eine vorsätzlich subversive Personalpolitik unterstellt.

Die Strukturlinie der sich steigernden staatlichen Hysterie kontrastierend und ihr entgegenwirkend bildet sich in Antipovs Umfeld eine Strukturlinie der persönlichen Solidarität aus. Die beiden Frauen Nadja und Ljuda, die den beiden Jungen, dem Erzähler und Antipov auch erotisch zugetan sind, vor allem aber Nadja, die durch ihre Liebesbeziehung zu Zenin auf diesen Einfluß ausüben kann, erwirken im stillen Einvernehmen kollegiale Geschlossenheit. Nadja veranlaßt Zenin erfolgreich, bei der nächsthöheren Instanz für Antipov einzutreten. Und in der Balance der staatlichen Interessensphären behält in der gegenwärtigen Situation der für das Funktionieren eines kriegswichtigen Betriebs Verantwortliche schließlich größeres Gewicht als der Beauftragte der Staatssicherheit.

Der spätere Erzähler, der anfangs zahlreiche biographische Ähnlichkeiten registriert, die er an sich und an Antipov entdeckt hatte, und der sich insgeheim durch das "Pendant Antipov" neben sich um die eigene Originalität betrogen sah, entwickelt in dem Maße für Antipov Sympathie, wie es ihm gelingt, Unterschiede festzustellen: Antipov lehnte keine Arbeit ab. Er beschwerte sich bei niemandem darüber, daß ihn Zenin (nach der enttäuschten Erwartung) drangsalierte und ihm die schwersten und schmutzigsten Arbeiten auflud. "Sein Gesicht - grau, ohne zu murren, war dennoch stolz. [...] Und Terent'ič, der den Stimmungsumschlag beim Vorgesetzten bemerkte, wurde auch gehässig und bösartig, und je deutlicher das wurde, um so schneller verschwand meine frühere Feindseligkeit, und Saša begann mir zu gefallen. Mich wunderte, wie ruhig und friedlich er das alles ertrug. Nein, ich hätte das nicht gekonnt. Ich hätte Zenin längst gründlich Bescheid gesagt und den Alten für seine Meckerei und seine Schikanen zum Teufel geschickt. Mich hätte Terent'ič auch nicht dazu gebracht, Tabak zu holen, schon gar nicht, Tabak gegen Kraut zu tauschen. Das hätte gerade noch gefehlt!"68 Andrej bekundet die wachsende Freundschaft zu Antipov im kameradschaftlichen Verhalten während seines Verhörs durch den Staatssicherheitsdienst und ist beeindruckt davon, daß Antipov anscheinend auch noch im größten Wirbel gelassen in sich ruht. "Saša aber lebte in einer seltsamen Ruhe, ohne zu 
wissen, daß sich die Stürme um ihn herum und um uns alle nicht gelegt hatten." 69

In den vielfältigen Szenen des Kapitels erweist sich Antipov als ein geradliniger, integrer Charakter und als ein arglos gutmütiger Mensch, der sich nicht nur in Anspruch nehmen, sondern auch mißbrauchen läßt, weil er im Unterschied zu seinem Freund manche Zusammenhänge zu spät versteht. So ahnt Antipov offenbar als einziger nichts von Zenins und Nadjas Liebesverhältnis. Und weil er sich Zenin für dessen Beistand in der glimpflich überstandenen Affaire zu Dank verpflichtet fühlt, läßt er sich von ihm als einziger am arbeitsfreien Tage zum Kartoffelholen aufs Dorf schicken, was angeblich für Nadja und deren kriegsinvaliden Mann, tatsächlich aber für ihn, Zenin selbst, geschah. Die unglücklich verlaufende Geschichte mit dem zu schleppenden Kartoffelsack und der nachfolgende Überraschungseffekt, daß Zenin seine Gutmütigkeit skrupellos ausgenutzt hatte, machen Antipov am Ende des Kapitels zur komischen Figur. Auch das wäre seinem Freund, dem späteren Erzähler, der ihn noch gewarnt hatte, nicht passiert.

\subsection{7.) Kapıtel 7: Tverskoj Boulevard III (Frühjahr - Sommer 1947)}

Exkurs. Aus der Nachkriegszeit des vierten Kapitels $(=1947)$ greift das Erzählverfahren mit den Kapiteln $5(=1941)$ und $6(=1943 / 44)$ zurück in die Zeit des Krieges und schließt damit punktuell den Leerraum zwischen den Kapiteln $2(=1938 / 39)$ und $3(=1946)$. Die zeitliche Parallelführung der Biographien der beiden 11/12jährigen Jungen, Antipovs (Kapitel 1) und des späteren Erzählers (Kapitel 2) wird einige Jahre später in eben der Kriegszeit im rückgreifenden Kapitel 6 noch einmal praktiziert, und zwar so, daß jetzt beide in einem ersten Abschnitt ihrer persönlichen Begegnung dargestellt werden. Trotzdem stellt sich die Frage, warum der Autor die Chronologie des Erzählens unterbricht, also das fünfte und sechste Kapitel nicht an das zweite anschließt und die zeitlich aufeinanderfolgenden und sachlich zusammengehörenden vier Tverskoj Boulevard-Kapitel nicht in der chronologischen Folge der erzählten Zeit beläßt.

Zum einen ließe sich der erzählstrategische Eingriff in die Chronologie als thematischer Reflex auf den Vorgang des Erinnerns erklären. Dem sich 
etwa 40 Jahre später rückerinnernden Erzähler fallen bei der Niederschrift die Dinge "punktuell", nach und nach, und eben nicht in chronologischer Folge ein. Auf diese Weise kann er, der ja Antipovs Geschichte aufzeichnen will, noch einen Abschnitt aus der eigenen Biographie einfügen (Kapitel 5), ohne selbst gegenüber der Zentralfigur zu dominant zu werden. Andererseits aber wäre der direkte Anschluß des dritten an das zweite Tverskoj Boulevard-Kapitel eine zu einfache Weiterführung von Antipovs privater Lebenslinie gewesen, denn Antipov ist jetzt hauptsächlich damit befaßt, der verschwundenen Nataša nachzugehen, bis er sie (zu Ende Kapitel 7) schließlich gefunden hat. Kapitel 4 (= Tverskoj Boulevard II) schloß mit dem Satz: "Kann etwa jemand erklären, warum sie erschienen und warum sie verschwunden ist?" Kapitel 7 (= Tverskoj Boulevard III) beginnt mit den unmittelbar anschließenden Sätzen: "Sie verschwand im Frühjahr, war weg wie der Schnee und nirgendwo, nirgendwie, nirgendwann zu finden. [...] Der Sommer kam, und sie blieb verschwunden." Nach zwei eingeschobenen Kapiteln aber muß sich der Leser im Text neu orientieren, muß überlegen, von wem jetzt eigentlich die Rede ist, denn Natašas Name wird nicht gleich zu Beginn genannt (zunächst nur der ihrer Freundin und der ihrer Straße). Das Erzählverfahren kompliziert den Nachvollzug des Verstehens vorsätzlich, indem es Zusammengehörendes trennt und den Leser zwingt, sich über lange Zwischenpassagen hinweg zu erinnern und Vorstellungen zu verknüpfen, die im Erzählvorgang weit voneinander entfernt liegen. Das gilt in noch bedeutenderem Maße für die mit den beiden ersten Tverskoj BoulevardKapiteln neu in Antipovs Leben eingeflochtene biographische Linie seines Literaturlehrers Kijanov, zu dessen persönlichem Umfeld in für Antipov noch nicht durchschaubarer Weise dessen verschollener Freund Teterin und der Kulturfunktionär Rojtek gehören. Kapitel 7 (= Tverskoj Boulevard III) bringt neue Elemente der Klärung, die die Leerräume um Kijanovs Person in Antipovs (und des Lesers) Verstehen zunehmend schließen. Aber auch hier soll der Leser beim Nachvollzug Mühe haben. Während für Antipov, der selbst ja alles in ununterbrochener, enger Zeitfolge erlebt und erfährt, die Leerstellen nur auf der Ebene der Semantik, d. h. der noch zu erschließenden Bedeutung des Angedeuteten liegen, liegen sie für den Leser zusätzlich auf der Ebene des Textaufbaus. Der Leser wird, wenn er Kapitel 7 nicht als völligen Neuansatz des Erzählens um Kijanovs Person hinnehmen, sondern bisher Gesagtes in sein Verständnis der epischen Figur integrieren will, den großen Leerraum zurück zu den Kapiteln 3 und 4 "über-denken" und sich 
Details, die dort bereits mitgeteilt worden sind, erneut "zusammenlesen" müssen.

Ab Kapitel 7 nimmt der Erzähler die eigene Biographie bis zum Schlußkapitel des Romans ganz zurück und bleibt beim Erzählen von Antipovs Leben, dessen Linie im zeitlichen Anschluß an Kapitel 4 (= Februar 1947) auf der privaten wie der beruflichen Ebene fortgesetzt wird.

Der inzwischen dank Susanna Vladimirovna liebeserfahrene Antipov ist von der Sehnsucht nach seiner geliebten Zirkusartistin, die nach dem Lynchmord an ihrem Partner Moskau verlassen hat, umgetrieben. Bei der Suche nach ihrer derzeitigen Adresse tauchen punktuell Personen wieder auf, die auch im vierten Kapitel zugegen waren: Natašas Freundin Vika und der zur Zirkusclique gehörende Levočka; desgleichen der sich im Halbweltmilieu herumtreibende Bücherhändler Markuša (Kapitel 3 und 5). Beim Versuch, das Private mit dem Beruflichen zu verbinden, kommt Antipov mehr oder minder zwangsläufig wieder mit Susanna und mit Kijanov zusammen, um für die beabsichtigte Reise ins Kubangebiet eine Dienstbescheinigung zu erhalten. Und obgleich er Susanna seit der Liebesnacht gemieden hatte, wird er von ihr zu seinem Erstaunen spontan wieder in die Arme geschlossen, ungeachtet der Tatsache, daß an ihrem Tisch mittlerweile schon der Student Guß̌cin, das nächste Opfer ihrer Liebeslust, Platz genommen hat. Doch die sexuelle Begierde dieser Frau beeindruckt Antipov jetzt nicht mehr ("Susannas Geheimnis war ziemlich schnell verflogen, wie Morgennebel überm Fluß"70), allein ihre Kameradschaftlichkeit und Hilfsbereitschaft nimmt er auch jetzt dankbar an. Und er wird anerkennen, daß er seit Susannas Zuwendung seine frühere Befangenheit im Umgang mit Frauen verloren hat, wie die Tagesbekanntschaft mit Hortensia auf dem Weg zu Kijanovs Sommerhaussiedlung zeigt.

Antipovs Gang zu Kijanov hatte indessen nicht nur den Zweck, eine Empfehlung für eine Dienstreise zu erwirken. Bei seiner in Kapitel 4 beiläufig erwähnten Tante Margarita, bei der er nach seiner zeitweiligen Aufnahme in Mirons Familie Unterkunft fand, war er der Frau des in Kapitel 3 durch den Studenten Kotov wie auch durch Kijanov selbst erwähnten früheren Schriftstellers Teterin begegnet, ohne noch über deren verwandtschaftliches Verhältnis informiert zu sein. Tat'jana Robertovna, in schlechtem Gesund- 
heitszustand, ringt jetzt mit sich darum, ob sie die Tagebücher ihres (vermeintlich) umgekommenen Mannes Kijanov übergeben soll. Antipov erfährt nochmals - wie schon in Kapitel 3 durch Kijanov - von der früheren Freundschaft der beiden Männer. Er erfährt nochmals - wie schon in Kapitel 3 durch den Studenten Kotov -, daß Teterin seinerzeit durch seinen Roman "Das Aquarium" berühmt wurde und Kijanovs Ansehen als Schriftsteller übertroffen hat, worauf dieser mit Mißgunst reagiert habe. Von dem aber, was Tat'jana Robertovna die spätere "Tragödie" nannte, konnte Antipov (und mit ihm auch der Leser) noch nichts wissen: Kijanov habe bei der Aufführung eines im Jahre 1934 gemeinsam verfaßten Stückes - wahrscheinlich auf Druck von oben - den Namen ihres Mannes weggelassen und ihr nur die Tantiemenanteile geschickt. Kijanov sei deshalb nun zwar nicht als Verräter, nicht als Feind anzusehen, aber eben auch nicht als Gentleman, mit dem man zwanglos verkehren könnte. ${ }^{71}$ Doch hier bleibt eine bedeutsame Leerstelle bei der Interpretation der Fakten, die erst durch Kijanov selbst (Kapitel 10) behoben wird. Denn der von Tat'jana Robertovna vorgetragene Sachverhalt ist zwar richtig, aber er ist insofern verkürzt, als sie nicht weiß, daß ihr Mann vor seiner Verhaftung Kijanov selbst darum gebeten hatte, so zu verfahren. Konkretisiert wird somit neben der bestätigten einstmaligen Freundschaft Kijanovs und Teterins lediglich das bis in die Gegenwart hineinwirkende, für Antipov ungeklärte Spannungsverhältnis, was dieser bei seinem nachfolgenden Besuch Kijanovs auch persönlich zu spüren bekommt. Antipov merkt sofort, daß er mit der Übermittlung von Tat'jana Robertovnas Anfrage, ob Kijanov bereit sei, Teterins Tagebücher zu übernehmen, "etwas Unerlaubtes berührt" hatte, was die gesamte Gesprächssituation mit einem Mal zunichte machte. Kijanov reagiert verlegen, seine Frau rigoros ablehnend: "Du darfst keine Schriften annehmen!"72 Der in die Hintergründe nicht eingeweihte Antipov muß den Eindruck gewinnen, daß von dem verschollenen und von seiner Frau als tot erachteten Teterin für Kijanov gegenwärtig noch eine Gefährdung ausgehe. Und Kijanov ist in der Tat gefährdet. Er war soeben wovon Antipov auch nichts wußte - in einem Artikel der Literaturnaja gazeta als dekadenter Schriftsteller verleumdet worden. Antipov, dem das nicht sonderlich auffiel, wurde von Ehepaar Kijanov in einer Situation der Depression (er) und der Empörung (sie) empfangen. Beide Teile des Gesprächs, der aktuelle Zeitungsartikel und Teterins Tagebücher, stehen für

$\begin{array}{ll}71 & \text { S. } 361 / 362 . \\ 72 & \text { S. } 367 .\end{array}$ 
ihn unverbunden nebeneinander. Zwischen beiden bleibt semantisch eine Leerstelle, die wiederum erst Kijanov (Kapitel 10) persönlich schließt. Aus Antipovs gegenwärtiger Erlebnissicht stellt sich Kijanov - wie schon beim Besuch im dritten Kapitel - auch jetzt als ein an den Zeitumständen leidender Mensch dar. Das aber sind die Zeitumstände der Ždanov-Zeit, mit deren Hinterhältigkeiten Antipov eben erst vertraut wird. Irgend jemand aus dem Kreise der Einflußreichen ist Kijanov mißgünstig gesonnen und hat ein Interesse an seiner Diffamierung. Rojtek, auf dessen Namen Kijanov im vierten Kapitel allergisch reagierte und der ihm seinerseits durch Antipov einen zynischen Gruß ausrichten ließ, wird im Gespräch mit Antipov jetzt zwar nicht namentlich erwähnt, aber das Ehepaar Kijanov weiß, wer sich hinter der Verleumdung, mit dem Pseudonym Pravdenko unterzeichnet, verbirgt: "Dieser Mensch hat in unserem Haus verkehrt! Ich bin entsetzt über die Schamlosigkeit der Leute!"73 Und damit ist Rojtek indirekt, wie sich später aus Kapitel 10 rückfolgern läßt, als Konvergenzpunkt angesprochen: Rojtek, der in den 20er Jahren "zu ihnen", d. h. zu dem Redaktionskollegium einer Zeitschrift gehört hatte, der in den 30er Jahren zur Verhaftung von Kollegen beigetragen hat und den zwischen den Fronten stehen gebliebenen Kijanov für seine zwiespältige Haltung im "Komplott mit dem Volksfeind Teterin" jetzt, in der Ždanov-Zeit, ebenso belangen kann wie Ende der 30er Jahre. - Obgleich Antipov aufgrund des von ihm selbst schon Erfahrenen Kijanov nach Rojtek als möglichen Denunzianten hätte fragen können, stellt er diese Beziehung nicht her und wird am Ende des Tages, nachdem er auf dem Heimweg durch eine Verwechslung noch eine Tracht Prügel bekommen hatte, nur resümieren, daß er persönlich dafür prädestiniert scheint, in unangenehme Geschichten anderer Leute verwickelt zu werden.

Im Unterschied zu Kijanov hatte der 21 jährige Antipov noch keine Gelegenheit, sich zu kompromittieren. Seine bisher beste, aber "unzeitgenäße" Erzählung war von Rojtek zurückgewiesen, die statt dessen publizicrte banale Humoreske von diesem selbst für die Zeitung vorgeschlagen worden. Somit hatte er der Kritik noch keine Angriffsflächen bieten können.

Die Dienstreise ins Kubangebiet zeigt Antipov als angehenden Schriftsteller, der sich im Sammeln und Sichten von Material übt und dabei zwischen Brauchbarem und Unbrauchbarem zu unterscheiden sucht. Daß das faktisch Triviale aus dem Kolchosalltag, mit dem er der offiziellen Erwar-

73 S. 366. 
tung gemäß die Notizbücher füllt, schriftstellerisch nicht verwertbar sein wird, ist ihm ebenso bewußt wie die Tatsache, daß die tragische Lebensgeschichte des kriegsblinden Jakim ein darstellungswürdiger Stoff ist. Kijanovs Leitsatz, alle Geschehnisse von ihren Ursachen her in ihren inneren Zusammenhängen zu ergründen, "die Kette" zu sehen (Ende Kapitel 4), begleitet ihn auch weiterhin, aber er muß zugleich erkennen, daß die Empfehlung nicht zur Erklärung aller Ereignisse taugt. Gerade bei dem für ihn wichtigsten Erlebnis, der kurz vor seiner Abreise durch eben den blinden Jakim zufällig wiedergefundenen Nataša, erweist sie sich als untauglich. Schon damals, als Kijanov den Leitsatz aussprach, empfand er die Aporie: "Kann etwa jemand erklären, warum sie [Nataša] erschienen und warum sie verschwunden ist?"74 Antipovs Frage bezog sich auf den Sinn des Erlebten für die eigene Person. Diese aber ist durch das Aufzeigen von Kausalzusammenhängen nicht zu beantworten. Am Ende des siebenten Kapitels, ein reichliches halbes Jahr später, steht Antipov vor der gleichen Frage: "Was hatte sie beide für kurze Zeit miteinander verbunden? Und was hat sie auseinandergerissen? Und warum das jetzt noch einmal? Und liegt in all diesem Flüchtigen und Merkwürdigen ein Sinn?"75 Die Frage nach dem Sinn einer als schicksalhaft empfundenen Liebe, die ohne Erfüllung bleiben muß, erhält keine Antwort und eröffnet auf der Ebene der Bedeutungen einen Leerraum, der vom Text nicht geschlossen und dem Leser zur Interpretation übergeben wird.

\subsection{8.) Kapitel 8: Tverskoj Boulevard IV (Februar 1950 - April 1951)}

Zwischen Kapitel 7 (Tverskoj Boulevard III) und Kapitel 8 (Tverskoj Boulevard IV) beläßt das Erzählverfahren einen zeitlichen Freiraum von etwa drei Jahren, in den als für Antipov wichtigstes Ereignis der Abschluß des Studiums am Literaturinstitut fällt. Dieser biographische Höhepunkt bleibt im Erzählvorgang unerwähnt. Die Einleitung des achten Kapitels zeigt Antipov bereits im Kreise früherer Studienkollegen (Miron, Viktor Kotov, Tolja Kvašnin, neu: Prjachin), mit denen er den Empfang seines ersten Honorars (einen Vorschuß auf seinen ersten, noch nicht abgeschlossenen Roman) feiert. Sie alle haben inzwischen berufliche Tätigkeiten im schriftstelleri- 
schen oder redaktionellen Bereich aufgenommen, jeder von ihnen hat inzwischen etwas publiziert. Der Umgang, den die jungen Autoren miteinander pflegen, ist einerseits durch kameradschaftliche Nähe, andererseits aber auch durch Gereiztheiten gekennzeichnet, die aus der je eigenen Unsicherheit und aus Rivalitätsdenken entspringen und sich in Prahlsucht und Geltungsbedürfnis äußern. Antipov wirkt in ihrem Kreis auffallend zurückhaltend und von ausgeglichenem und ausgleichendem Temperament. Die bisher aufgezeigte Linie seiner Charakterentwicklung wird auf der Ebene einer sich selbst prüfenden moralischen Sensibilität und Geradlinigkeit wie auch der einer ursprünglichen Arglosigkeit weiter ausgeführt. Diese Eigenschaften sollen ihn im folgenden mit einer Gesellschaft konfrontieren, in der eben diese Werte zur Disposition stehen und die den einzelnen als "Funktionär" im System oder aber als ihr "Objekt" begreift. Der 24/25jährige Antipov, der mittlerweile Gelegenheit gehabt hat, die Diskrepanzen zwischen der eigenen Lebenshaltung und offizieller Erwartung als Konfliktfeld zu verstehen, läßt sich dessen ungeachtet weiterhin von der Überzeugungskraft der persönlichen Aufrichtigkeit leiten und trägt sich, weil er die Konsequenz einer Entscheidung zunächst nicht absehen kann und als er sie absehen sich von der Entscheidung nicht distanzieren kann, die bisher größte Kalamität seines Lebens ein.

Die unüberlegte Zusage an einen Rechtsanwalt (Mirons Vater), ein literarisches Gutachten zu erstellen, bringt ihn ungewollt in Konflikt mit dem neuen Verlagsredakteur Sajasov, der für die Veröffentlichung seines Romans zuständig ist, weil dessen Bruder als Kläger gegen den Klienten seines auftraggebenden Anwalts auftritt. Sajasovs Bruder (nur) stellvertretender Direktor jenes Verlages, in dem Dvojnikov Direktor ist, strengt gegen diesen einen Prozeß wegen Plagiats und Amtsmißbrauchs an, wobei das eigentliche Motiv aber im karrieristischen Kalkül und im Machtstreben des Klägers zu sehen ist, das eifersüchtige Werben um eine einflußreiche Frau inbegriffen. Antipovs Auftrag, in einem Gutachten darzustellen, daß die von Dvojnikov im Jahre 1949 herausgegebenen Texte einer literarischen Reihe kein Plagiat an Texten des Jahres 1936 seien, scheint sachlich einfach zu bewerkstelligen. "Er überzeugte sich schnell davon, daß von Plagiat überhaupt keine Rede sein konnte, denn Graues war grau umgeschrieben worden. [...] Es war einfach eine Vermehrung von Stuß. Schund hat immer das gleiche Gesicht."76 
Doch um die Sache selbst ging es dem Betreiber des Prozesses nicht, der Prozeß war für ihn nur Mittel zum Zweck, einen Rivalen aus dem Amt zu drängen. In Antipovs Verstehen der Zusammenhänge müssen sich Leerräume schließen. Zum einen muß er eben das durchschauen und zum anderen begreifen, daß die Publikation seines eigenen Romans sehr direkt davon abhängen wird, daß er in seinem Gutachten die Position von Sajasovs Bruder vertritt. Möglicherweise - das wird nicht ausgesprochen, aber angedeutet, hatte man (d. h. Sajasov dem Gericht und dieses dem Anwalt des Beklagten) "den Schriftsteller Antipov" mit dieser hinterhältigen Berechnung als Mittel der Zweckerfüllung anempfohlen, und zwar so, daß weder der Anwalt noch Antipov nachhaltigen Argwohn hegen.

Immerhin muß Antipov einsehen, daß es sich bei der Angelegenheit nicht, wie er anfangs meinte, um eine reine Formsache handelt, denn er sieht sich alsbald im Zentrum des Interesses beider Parteien, die ihn, jede auf ihre Weise, mit allen Mitteln der Einflußnahme (der Bestechung, der Beschwörung von Mitleid, der Hervorhebung gesellschaftlicher Verdienste des einen gegenüber sozialer wie moralischer Minderwertigkeit des anderen, bis hin zur offenen Drohung, daß der Fall Dvojnikov keine normale Strafsache, sondern ein politischer Fall sei) zu vereinnahmen suchen. "Das Leben warf ihn in einen jener unerwarteten Strudel, die einem plötzlich die Kräfte, das Gedächtnis und zeitweilig auch den Atem rauben." 77

Zeitgleich mit den parteilichen Versuchen der unlauteren Vereinnahmung dringen auf Antipov aber auch Stimmen der Warnung ein, die ihm schlicht und wohlgesonnen nahelegen, sich selbst mit dem Verfahren nicht zu schaden, so daß für ihn vor Prozeßbeginn über die Konsequenzen seiner Haltung keine $\mathrm{Zweifel}$ mehr bestehen konnten. Und nachdem er bei genauerer Prüfung zudem noch erkennen mußte, daß es sich bei Dvojnikov keinesfalls - wie ihm sein Anwalt wiederholt versichert hatte - um einen "in jeder Hinsicht anständigen Menschen" handelt, sondern, dem Namen entsprechend, durchaus auch im vorliegenden Fall, um eine Person mit zwei Gesichtern, hätte er erst recht keinen Grund mehr, diesen durch sein Gutachten in Schutz zu nehmen. Ausschlaggebend war für ihn in der Vielfalt der Stimmen dann wohl letztlich die junge Verlagssekretärin Tanja, mit der er sich angefreundet hatte, weil ihn deren Sinn für Korrektheit und persönliche Lauterkeit beeindruckten. Sie hatte ihm - trotz späterer eindringlicher War-

77 S. 387. 
nung vor Sajasovs Hinterhältigkeit - anfangs nahegelegt, sich von diesem nicht erpressen zu lassen. Und Antipov will - wenn überhaupt einer anderen Person, dann ihr - beweisen, daß er sich vor Leuten wie Sajasov nicht fürchtet und daß für ihn die Gewissenhaftigkeit in der Sache den Vorrang gegenüber allen privaten Nützlichkeitserwägungen hat. Weil aber nun die Sachlage auch für ihn am Ende zweideutig geworden ist, gibt für seine Bewertung bezeichnenderweise eine moralische Kategorie den Ausschlag: "Dvojnikov konnte auch großmütig sein."78 So ist seine Stellungnahme vor Gericht dann letztendlich nicht als eine sachliche Parteiergreifung für Dvojnikov, sondern als eine moralische gegen Sajasov zu verstehen. - Ungeachtet der inneren Zerreißprobe, in die er gestellt war und trotz aller persönlichen Nachteile, die er sich einhandelt, bedauert Antipov seine Entscheidung im nachhinein nicht. Er sieht seine Art der Konfliktbewältigung als persönliche Bewährungsprobe an (für die er - in einer Situation, in der er mittellos dasteht - nur sein Honorar, nicht aber Dvojnikovs zusätzliche 1000 Rubel entgegennimmt). "Und ihm schien, daß diese ganze Geschichte nur für einen Menschen von Interesse war, für ihn selbst."79

Aus zeitlicher Distanz betrachtet, erweist sich Antipovs Erleben als Schmierenkomödie der Ždanov-Zeit in ihrer spätstalinistischen Phase, wobei sich der zeitgeschichtliche Hintergrund wiederum nur punktuell konkretisiert, im übrigen aber ausgespart bleibt. Das Motto des Romans klingt nochmals auf, denn wie zur Zeit der 30er Jahre verschwinden auch jetzt wieder Personen; in Antipovs Umfeld - der Direktor und der Redakteur des Verlags, der vertragsgemäß seinen Roman publizieren sollte. An deren Stelle erscheint mit einem Mal als kommissarischer Direktor ein kleinwüchsiger Mann mit Stalins Attributen und Attitüden, ${ }^{80}$ den alle fürchten und als neuer Redakteur jener Sajasov, dessen vornehmstes Bestreben - wie für Antipov erlebbar nicht in der Förderung anvertrauter Literatur, sondern in der Durchsetzung

78 S. 410.

79 S. $410 / 411$.

80 "Er trug eine khakifarbene Jacke, bis obenhin zugeknöpft, so wie sie die Direktoren der Rüstungsindustrie trugen. Sein blasses, vertrocknetes Gesicht war hochmütig erhoben, und obgleich er klein war, schien es, daß er auf alle Entgegenkommenden von oben herab blickte. Die Entgegenkommenden aber schienen merkwürdigerweise zu ihm aufzuschauen." - S. 403. - Bereits in Kapitel 5 war von einer unangenehmen Zwergin die Rede, die vom Erzähler in Stalins Nähe gerückt wird. Sie hatte dort der Familie Pletnev eine Rede des Genossen Stalin angekündigt, der Befehl erlassen werde, Moskau zu räumen. Am folgenden Tag aber, nach dem Wegzug der Pletnevs, hatte sie deren Wohnung umgehend in Besitz genommen (S. 318 und 328). 
privater Interessen besteht. Die Vertreter der Vermittlerschicht werden beim staatlich sanktionierten Mißbrauch ihrer neuen Ämter in anschaulicher Aktion gezeigt.

Für Antipov erreicht die Konfrontation eine neue Qualität. Er erleidet sie nicht mehr nur unbewußt wie in Kapitel 1, wird nicht nur zufällig durch eine marginale Banalität in sie verwickelt wie in Kapitel 6, er verabschiedet sich nicht mehr aus ihr mit einer schlichten Verzichtserklärung wie gegenüber Rojtek in Kapitel 4 und nimmt sie auch nicht mehr nur als neutraler Beobachter passiv zur Kenntnis wie in den Begegnungen mit Kijanov (Kapitel 3 und 7), sondern er begibt sich jetzt bewußt in den Konflikt, um diesen Konflikt exemplarisch auszuhalten. Seine neu gewonnene Lebenserfahrung: Zivilcourage des einzelnen gegen die gesellschaftliche Korruption ist möglich und punktuell wirksam, wenngleich um den Preis eines großen persönlichen Schadens.

$\mathrm{Zu}$ den offiziellen Verhaltensnormen und -praktiken verläuft kontrastiv weiterhin eine punktierte Linie der Solidarität mit der charakterlichen Solidität. - Miron und Prjachin (im übrigen nicht nur mit positiven Attributen versehen) üben sie aus. Mutter und Schwester leisten Antipov moralischen Beistand. Sie glauben an sein Werk. - Kijanov, ohne die Zusammenhänge des Konflikts zu kennen und ohne zu wissen, daß die Absetzung von Antipovs Roman aus dem Verlagsprogramm nicht auf sachlichen Einwänden des Redakteurs gegenüber dem Text beruht, erweist sich ein weiteres Mal für Antipov als "guter Geist", indem er ihm am Ende des Geschehens seine Hilfe anbietet und sich das Manuskript bringen läßt. - Die schönste Selbstbestätigung aber erfährt Antipov durch Tanjas Liebe: "Ich habe mich an dem Tage in dich verliebt, als du ihn [Sajasov] zum Teufel schicktest. Du wußtest doch, was daraus wird? Du hast es doch gewußt?"8I Und sie hatte Grund, sich mit Antipov über dessen moralischen Sieg zu freuen, denn sie war selbst zuvor von Sajasov mit der Kriegsgefangenschaft ihres Vaters erpreßt worden. Die beiderseitige Zuneigung und baldige Eheschließung beruht auf der beiderseits empfundenen wesensmäßigen Ähnlichkeit: Jeder erfährt im anderen eine Entsprechung der eigenen Wertmaßstäbe.

Analog zu den Leerräumen, die das Erzählverfahren zwischen den nicht dargestellten gesellschaftlichen Instanzen und den sie in ihren Auswirkungen erlebenden einzelnen Personen beläßt, treten diese Leerräume wie bisher 
auch auf der Personalebene zwischen den handelnden Figuren in Erscheinung. In das Leben des einzelnen hinein wirken weiterhin Vorgänge und Verhängnisse, die man zwar ergründen könnte, über die man aber besser auch jetzt nicht spricht. Auch das findet im Erzählverlauf seine Fortsetzung. Antipov fragt nicht nach. Wie er nicht nach den Erlebnissen der Mutter in der Zeit ihrer zwangsweisen Trennung von der Familie noch nach dem Schicksal des Vaters gefragt hat (zumindest nicht auf der veröffentlichten Ebene des Romantextes!), so hat er auch die für ihn sichtbare Notlage Kijanovs nicht hinterfragt. Letzteres ließe sich zwar eben noch aus der respektvollen Distanz des Schülers zum Lehrer erklären, aber er vermeidet die Frage nach schicksalhaften Zusammenhängen auch gegenüber Personen, denen er nicht in ähnlicher Weise verpflichtet ist. Bei seiner Dienstreise an die Wolga, die er angetreten hatte, um seine finanzielle Misere zu überbrükken, wohnt er in der Nähe Kujbyševs bei einem Bojenwärter, der früher Direktor eines Sovchoz gewesen ist. "Warum es so kam und er vom Direktor zum Bojenwärter wurde, war Antipov nicht ganz klar. Er wollte aber auch nicht fragen."82 Auf einfaches Desinteresse des Schriftstellers an einem vermutlich konfliktreichen Lebensschicksal kann sich Antipovs Zurückhaltung nicht gründen, eher schon auf das Vorauswissen, daß das, was er zu hören bekäme, zwar interessant und literarisch darstellbar, aber - im Jahre 1951 nicht publizierbar sein würde. (Er hatte schließlich den Auftrag, eine Reportage über den Bau des Kujbyšever Wasserkraftwerkes zu schreiben!) Antipov weiß, daß Menschen der Generation seiner Eltern von zeitbedingten dunklen Umfeldern umgeben sind. Und so wenig er davor zurückscheut, die eigenen Konflikte persönlich auszutragen, so wenig ist er geneigt, sich mit der Problematik anderer zu belasten.

\subsection{9.) Kapitel 9: Das Ende des Winters am Trubnaja Platz (6. März 1953)}

Das neunte Kapitel ist das symbolträchtigste des Romans. Das Handlungsgeschehen umfaßt nur einen Tag, den Tag nach Stalins Tod. ${ }^{83}$ Der Tote liegt ab dem frühen Nachmittag im Gewerkschaftshaus am Trubnaja Platz aufgebahrt, gegenüber dem Wohnhaus, in dem Antipov jetzt mit seiner schwangeren Frau Tanja und dem Sohn Stepan in einer Gemeinschaftswohnung lebt.

82 S. 413.

83 Stalin war am Abend des 5. März 1953 an den Folgen eines Schlaganfalls verstorben. 
Zum vorausgehenden Kapitel 8 besteht ein zeitlicher Zwischenraum von etwa zwei Jahren, in den die Geburt des Sohnes fällt. 84

In Verbindung mit der neuen Gemeinschaftswohnung tritt namentlich ein neuer Personenkreis auf: Tanjas Tante Ksenja, die Antipov und Tanja ein Zimmer abgetreten hatte; die bei Ksenja übernachtende Ekaterina Gur'evna, die Antipov schon kannte, nämlich als eine Leidensgefährtin seiner Mutter, die gleichfalls ohne Aufenthaltsgenehmigung in Moskau lebt und deshalb häufig das Quartier wechseln muß; die alte Frau Veretennikova, die nach der Oktoberrevolution als einzige aus ihrer Familie in einem Zimmer der großen Wohnung zurückgeblieben war und - ähnlich dem 140 Jahre alten Haus -, wenn sie auf ihrem kleinen Balkon sitzt, den Charakter eines Denkmals hat; der erwartete Arzt Ivan Vladimirovič, ein Freund von Antipovs Vater aus früherer Zeit. Das ist der Personenkreis, der aufgrund gleicher mitmenschlicher Gesinnung eine stillschweigende Solidargemeinschaft gegenüber den staatstreuen Parvenüs der Familien Varganov und Irakliev bildet.

Das Erzählverfahren indirekter Darstellung durch Leerräume präsentiert sich jetzt in einer Nahaufnahme. Ganz nah herangeholt steht jetzt der große Verursacher erstmals persönlich, wenn auch als Toter, im Mittelpunkt. Doch auch jetzt wird sein Name nicht genannt, es wird nicht einmal gesagt, da $B$ er gestorben ist und daß die Leute, die in Scharen zum Trubnaja Platz ziehen, dies tun, um den aufgebahrten Toten zu sehen. Dargestellt wird "er" wiederum nur durch die Wirkung, die von ihm ausgeht. "Der Winter ging zu Ende, die Luft war eisig. Und ein eisiger Wind trieb die Menschen zum Trubnaja Platz. Es hieß, daß man ab zwei Uhr ins Gewerkschaftshaus eingelassen würde, aber die Leute strömten schon jetzt. Antipov wäre sicher mit allen anderen gelaufen, das, was sich ereignet hatte, regte ihn schrecklich auf, eisige Kälte durchfuhr ihn und brachte ihn zum Zittern, aber er konnte nicht von zu Hause weg." 85 In der Stadt herrscht Chaos, der Verkehr ist zusam-

84 Hier unterläuft dem Autor ein Zeitfehler im Erzählverfahren. Aus den Ausführungen des achten Kapitels ging hervor, daß sich Antipov und Tanja in den ersten Monaten des Jahres 1951 näher kennenlernen, und es läßt sich folgern. daß der Sohn Ende des Jahres 1951 zur Welt kam. Dann wäre er aber nicht, wie Kapitel 9 eingangs berichtet, jetzt zwei Jahre und drei Monate alt, sondern ein Jahr jünger. "Als Antipov vor zwei Jahren mit Tanja und dem drei Monate alten Stepka hierher zog..." (S. 415) - müßte richtig heißen: "Als Antipov vor einem Jahr... hierher zog." - Merkwürdig bliebe desgleichen, daß der Umzug in die neue Wohnung. der dem Bericht des neunten Kapitels entsprechend in die erzählte Zeit des achten gehören würde, dort nicht erwähnt wird.

S. 415. 
mengebrochen. Menschen ziehen einzeln und in Gruppen, mit unterschiedlichem Gesichtsausdruck - traurig, feierlich, verweint, finster - zum Trubnaja Platz. Und "in allem spürte man das, was Antipov empfand, irgendeinen Halbwahnsinn. Und er dachte, daß die Menschen, die in 100 Jahren leben, niemals das Zittern unserer Seelen an jenem eisigen März verstehen werden."86

Auf engstem Raum, im kleinsten Zeitabschnitt eines Tages, komprimiert sich "gegenüber" dem Toten, der den Lebenden nie so nahe war wie jetzt, in dem Haus, in dem Antipov mit Tanja wohnt, noch einmal die Tabusphäre, die der Tote verursacht hatte, deren zentralstes Wesensmerkmal die Verbreitung von Angst ist. - Antipov kann sich der Menge nicht anschließen, weil er auf einen Arzt wartet, und zwar nicht deshalb, weil jemand erkrankt wäre, sondern - der Erzähler beläßt auch hier vor dem Leser einen Leerraum, der sich erst im Laufe des Erzählvorgangs mit Bedeutung füllt - weil sich Tanja und Antipov in einer Situation gesteigerter Lebensangst, deren Entwicklung in die nicht dargestellte Zeit der zurückliegenden zwei Jahre fällt, nach langer Überlegung für diesen Tag zur Abtreibung ihres zweiten Kindes entschlossen hatten. Antipov, der gegenüber konkreten Personen meist furchtlos war und das zwei Jahre zuvor noch in seiner Auseinandersetzung mit Sajasov demonstriert hatte, ist mittlerweile offenbar zutiefst verunsichert, denn der Verlag hatte nach jenem Gerichtsprozeß (Kapitel 8) anscheinend nicht nur seinen Roman, sondern nachfolgend auch noch anderes abgewiesen, zuletzt eine Erzählung, mit der Begründung, daß dies der hier unerwünschte Stil Ivan Bunins sei. Antipov war also, seit Rojtek vor sechs Jahren (aus dem gleichem Grund) seine ihm wichtigste Erzählung verworfen hatte, seiner Schreibart treu geblieben, hatte sich damit aber offenbar ein Etikett eingehandelt, das ihm seither anhaftet und zu seiner Diskriminierung als Schriftsteller gebraucht wird. Die weitergeführte Lebenslinie Antipovs mündet in eine existentielle Befindlichkeit der Angst vor dem Leben, wie es geworden ist. In diesem Kontext erhält die Entscheidung ihre Begründung. "Das, wozu ihre verzagte Seele neigte, war die Errettung von der Angst (izbavlenie ot stracha). Von der Angst, daß das neue Wesen von den gleichen Dingen gequält würde, von der gleichen Ungewißheit. Aus Angst, daß sie dann schon nicht mehr auf der Welt sein würden und Stepka sich mit Gottes Hilfe allein 
durchschlägt, neigten sie immer mehr dazu..."87 Einbezogen ist - unausgesprochen - die Vorstellung von Verhaftung, Verbannung und Tod, wie es schon die Eltern erlebt haben. In diese Lebensatmosphäre hinein sollte nicht noch ein weiteres Kind geboren werden.

In der neuen "kommunal'ka" geben die Vertreter der neuen Gesellschaft, die die alteingesessenen Eigentümer und Mieter des großen Hauses aus der Napoleonischen Zeit entweder gänzlich vertrieben oder aber in die letzte Ecke gedrängt haben, den Ton an. Sie tun das nicht mehr heimlich und genant (wie noch Valerij Izmajlovič, Antipovs Schlafplatzvermieter im Jahre 1947, in Kapitel 4), sondern, im Wissen, daß sie die Macht auf ihrer Seite haben, offen, aggressiv, mit der ausgesprochenen Absicht, "staatsfeindliche Elemente" anzuzeigen, z. B. Ekaterina Gur'evna wegen illegalen Aufenthaltes in der Wohnung; Antipov, Tanja und den bestellten Arzt für die gesetzwidrige Handlung der Abtreibung. Frau Varganova, "das dickärschige Biest" (Antipov), nutzt ihre Kenntnisse, um Ekaterina Gur'evna mit unentgeltlichen Schneiderarbeiten zu erpressen. Als Antipov, den die Courage durchaus nicht verlassen hat, diesem unschönen Treiben durch einen handgreiflichen Akt im Badezimmer ein Ende setzt, löst er auf der anderen Seite nur zusätzliche Angst aus: "Die beiden Frauen, Tante Ksenija und Ekaterina Gur'evna, saßen im Zimmer, von Angst ergriffen. [...] Beide schwiegen, aber an ihren gebeugten Rücken, den niedergeschlagenen Gesichtern, daran, wie sie ihn anschauten, fühlte er mit seiner ganzen Haut, wie man Kälte spürt, die Anwesenheit von Angst im Zimmer. Ja, sie war überall, auf den Straßen, in der Luft."88 Antipovs beherzte Tat hatte zwar für einen Augenblick die Erpresserin zutiefst erschrecken lassen, aber damit das Problem nicht gelöst. In der Folgezeit wird sich Ekaterina Gur'evna nur weiter zurückziehen und sich nicht mehr getrauen, in der Wohnung zu übernachten, und er selbst wird künftig aufmerksamer observiert werden.

87 S. 423. - In Trifonovs noch unkorrigiertem Manuskript, das mir nicht zugänglich war. hatte ursprünglich eine kurze Passage gestanden, aus der hervorging, daB man auch Tanja wegen "systemfeindlichen Verhaltens" nirgends mehr zur Arbeit einstellte. Siehe die deutsche Übersetzung von Eckhard Thiele: Jurij Trifonow: Zeit und Ort. Suhrkamp Verlag Frankfurt am Main 1985. S. 239. (Thiele gibt an, nach der Erstausgabe in Družba narodov 9/10 1981 zu übersetzen, er fügt aber, ohne darauf hinzuweisen und ohne die Stellen entsprechend zu kennzeichnen, wiederholt, so auch hier, Passagen ein, die offenbar aus dem unkorrigierten Manuskript stammen.) 
In dieser zweiten, von Antipov erlebten Gemeinschaftswohnung sind die privaten Freiräume noch enger geworden, fast ganz verschwunden. Die Nutznießer des totalen Systems suchen die Konfrontation mit den Nonkonformisten, um ihr Reich skrupellos auszubauen, und es gelingt ihnen, die Atmosphäre der Angst in extremer Weise zu verdichten. Noch gelingt es ihnen, denn der Verursacher, der als Toter im Haus gegenüber aufgebahrt liegt, um den "man" weint, ohne ihn zu erwähnen, ist noch präsent, bei "ihnen" ebenso wie bei denen, die vor Schauder in Schweigen erstarrt sind.

Auf zwei Ebenen, die miteinander korrespondieren, drinnen und draußen, oben in der Wohnung und unten auf dem Platz, ereignet sich in der zeitlichen Erstreckung der allmähliche Zusammenbruch innerer Spannung. Antipov und Tanja hatten sich zwar nach langem Zögern zum bevorstehenden medizinischen Eingriff entschlossen, die Entscheidung selbst aber immer wieder bis zum gegenwärtigen Tag in Frage gestellt. Das Ausbleiben des Arztes, der im Verkehrschaos der Stadt steckengeblieben war, gibt dazu erneut Gelegenheit: "Vielleicht muß es doch nicht sein?"89 Die durch das Wartenmüssen bedingte Zeitdehnung ermöglicht erzähltechnisch den Einschub von Erinnerungen, durch die für den Leser Leerräume in Antipovs Lebenslinie aufgefüllt werden: Der erwartete Arzt, ein alter Freund von Antipovs Vater, hatte die Familie auch nach der Deportation der Eltern nicht im Stich gelassen und war seinerzeit bereit gewesen, die Kinder zu adoptieren. Aus dem Rückblick in Ekaterina Gur'evnas Biographie ist zu entnehmen, daß Antipovs Mutter zur Zwangsarbeit in Kasachstan gewesen ist, wo sich beide Frauen begegnet sind, und die Mutter zuletzt in einem Sovchoz gearbeitet hat. Weitere Zeit vergeht, weil auch der eingetroffene Arzt keine Eile zeigt, sondern statt dessen seinerseits anhebt, "Geschichten" zu erzählen. In der vergehenden Zeit aber vollzieht sich in Antipov das gleiche, wie in der lärmenden Menschenmenge unten auf dem Platz: die Befreiung von einer ungeheueren Last. Antipov begreift mit einem Mal, daß die "Erlösung von der Angst", deretwegen man den Arzt herbestellt hatte, mit dem Tod des Toten bereits geschehen war. Der zum anhaltend elementaren Tosen anschwellende Lärm der Menge zeigt die Peripetie an: "Der Strom der Zeit" hat mit eruptiver Kraft ein großes Hindernis aus dem Weg geräumt und den Weg wieder frei gemacht "für das Leben". "Ans Fenster tretend sah Antipov unten ein Gemenge von Mützen, Kragen und barhäuptigen Köpfen, zusam- 
mengedrängt im dichten Gewühl. Die Zeit wälzte sich donnerähnlich nach unten zum Trubnaja Platz."90 Und mit liebevoller Geste zu seiner Frau gewandt: "Es ist gar nicht nötig. Wir werden weiterleben."

Mit dem Tod des Verursachers bricht die Spannung zusammen, die die Menschen in einer Atmosphäre der Angst polarisiert hatte, wie es noch einmal im Ausschnitt der "Gemeinschaftswohnung", als Beispiel für das Leben im Lande, veranschaulicht wird. Am Trubnaja Platz erleben sie "das Ende des Winters", den sie miteinander überstanden haben, nicht zuletzt durch den solidarischen Zusammenhalt, mit dem man sich gemeinsam der honorierten Brutalität widersetzt hat: Die großen alten Leute, Frau Veretennikova und der Arzt, deren Lebenszeit die des Diktators überdauert,92 Antipov und Tanja, die sich den Willen zur persönlichen Integrität aus ihren leidgeprüften Familien bewahrt haben, Tante Ksenja und Ekaterina Gur'evna als Beispiele schlichten menschenfreundlichen Verhaltens in der Not - sie lassen sich in eine punktierte Linie einreihen, die sich zur geschlossenen Linie ausziehen läßt und mit der anderen, der der Varganovs und Iraklievs kontrastiert.

Der junge Antipov scheint erstmals zu verstehen, daß für die Generation der Eltern und der Älteren die Kunst des Überlebens wesentlich im Vermeiden von Konfrontation, in der Fähigkeit zur Distanz, dem Bewahren von "Leerräumen" bestanden hat. Die alte Veretennikova vefmag es trotL aller Schikanen, die sie hinnehmen mußte, sich still zu amüsieren. Auffallendstes Kennzeichen des Arztes - ständig zu lächeln und selbst in fatalen Situationen vor sich hinzusingen. Ekaterina Gur'evna hat gelernt, sich an dem Unrecht, das ihr widerfährt, nicht aufzureiben, die Mutter - was Antipov bisher zornig gemacht hat -, Konflikten auszuweichen. Jetzt scheint er einzusehen, daß man diese Haltung nicht unbedingt als Feigheit abtun muß, sondern daß man sie auch als Lebensweisheit begreifen kann.

Für die handelnden Figuren hat sich durch den Tod des Tyrannen ein neuer großer Raum der Unbestimmtheit eröffnet, von dem man noch nicht weiß, womit er sich füllt, von dem man aber hofft, daß er wesentlich im Zeichen der "Errettung von Angst" stehen wird.

90 S. 424.

91 S. 425.

92 Sie sind auch in ihrer körperlichen Statur als große Personen dargestellt und dies eindeutig mit symbolischer Funktion, nachdem im Text zuvor kleinwüchsige Gestalten in die Nähe Stalins gerückt worden sind (die Zwergin in Kapitel 5 und der kommissarische Verlagsdirektor in Kapitel 8). 
Mit dem neunten Kapitel erfährt das in Antipovs Leben vom Erzählbeginn an angelegte Thema der Angst seinen Höhepunkt und Abschluß. In Kapitel 1 (=1937) hatte der 11 jährige Junge - von unbegreiflichem Zittern erfaßt - versucht, den Vater am Finger festzuhalten. Kapitel $4(=1947)$ thematisierte durch Angstträume hindurch Antipovs dreifache Befreiung von der Angst, mit Susanna Vladimirovnas Hilfe - persönlich, beruflich und gesellschaftlich. In Kapitel $8(=1950 / 1951)$ überwindet Antipov noch einmal speziell eine durch gesellschaftliche Zwänge verursachte Angst, und es wurde hier überdimensional verdeutlicht, daß diese Angst eine institutionalisierte Realität ist, auch wenn sich Antipov bemüht, das anderen gegenüber zu ignorieren. Dem, der ihn mit jenem verhängnisvollen literarischen Gutachten beauftragt hatte, gestand er doch, daß er Angst habe, es mit dem Herausgeber seines Buches zu verderben. Und nach Tanjas eindringlicher Warnung holte ihn in einem nächtlichen Fiebertraum ein Entsetzen ein, daß sich nicht abschütteln ließ: In grellem Scheinwerferlicht sah er sich einem folternden Verhör ausgesetzt, hinter dem sich nicht, wie er vermutet hatte, lediglich der Redakteur Sajasov, sondern vielmehr der kleinwüchsige kommissarische Direktor mit Stalins Attributen verbarg. ${ }^{93}$

\subsubsection{0.) Kapitel 10:Bol'šaja Bronnaja (August 1957)}

Im zeitgeschichtlichen Hintergrund, vom Erzähler weiterhin als Leerraum belassen, spannt sich von den Kapiteln 1 und 2 des Romans ein großer Bogen zur Gegenwart der erzählten Zeit, der auch an seinem Endpunkt wiederum nur auf der Ebene der handelnden Personen zur Geltung kommt. "Es war eine Zeit unerwarteter Neuigkeiten, plötzlicher Veränderungen, unglaublicher Gerüchte"94, denn der Prozeß der "Entstalinisierung"95 hatte eingesetzt und zeigte Auswirkungen, die niemand für möglich gehalten hat. Die in den politischen Prozessen der 30er Jahre zu lebenslanger Haft Verurteilten wer-

93 S. 400 und 405/406. - Für andere Figuren des Romans bleibt das Thema der gesellschaftlich begründeten Angst weiterhin präsent. Für Kijanov, wie das folgende 10. Kapitel (= 1957) zeigt - eine Lebensangst, die ihre Wurzeln in den Erlebnissen der 30er Jahre hat. Für den Erzähler im abschließenden 13. Kapitel (= 1979/1980) - eine Angst. die zumindest teilweise den gesellschaftlichen Mechanismen der Gegenwart entspringt. S. 426.

95 Im Text wird weder der Ausdruck gebraucht, noch wird anderweitig konkret auf Umstellungen in der Regie der offiziellen Politik verwiesen. 
den, sofern sie die Tortur überstanden haben, aus den Lagern entlassen. Verschwundene tauchen plötzlich wieder auf. Zu ihnen gehört auch Kijanovs alter Freund Teterin, der für alle unerwartet nach 20 Jahren Zwangsarbeitslager aus Kasachstan nach Moskau zurückkehrt.

Antipov hatte früher von Teterin gehört, beiläufig von seinem Studienkameraden Kotov und von Kijanov selbst, als er seinen Lehrer 1946 erstmals zu Hause besuchte (Kapitel 3: "Tverskoj Boulevard I") und ein Jahr später, als er Kijanov im Auftrag von Teterins Frau Tat'jana Robertovna fragen sollte, ob dieser bereit sei, Teterins Tagebücher zu übernehmen (Kapitel 7: "Tverskoj Boulevard III"). Er hatte dabei punktuell etwas von der früheren Freundschaft der beiden Männer erfahren wie auch von dem zwischen beiden verbliebenen Spannungsverhältnis. Auf der Ebene des Verstehens werden sich jetzt für ihn Leerräume schließen, denn er wird wiederum zum Vermittler bestellt und erhält dabei Einblick in die tieferen Zusammenhänge der problematischen Beziehung. Im Mittelpunkt des zehnten Kapitels steht aber nicht er, Antipov, sondern Boris Kijanov, sein Literaturlehrer aus den ersten Jahren nach dem Krieg. Kijanovs Lebenslinie wird zu Ende geführt, seinetwegen und aus seiner Sicht wird hauptsächlich erzählt.96

Kijanov greift das Thema selbst auf, denn er kann nicht verstehen, warum ihn sein ältester und bester Freund nicht besuchen kommt, ihn nicht einmal anruft. Die Tatsache aber, daß sich Teterin gleichgültig zeigl, während er sehnsüchtig auf ein Wiedersehen wartet, zwingt ihn zum Nachdenken über das, was zwischen ihnen aus der Zeit vor 20 Jahren mißstimmig geblieben ist. Das Nachdenken bewegt sich zwischen moralischer Anfrage an das derzeitige Verhalten des anderen und dem Versuch einer eigenen Rechtfertigung, aus dem Empfinden, vor Teterin für irgend etwas schuldig zu sein, und es verliert sich schließlich in einem irrationalen Geflecht der Angst. "Die Rückkehr Michails, von der ich früher so stark und innig geträumt habe, hat sich für mich in eine quälende, zunehmend grausame Folter verwandelt. Die Qual liegt darin, daß ich meine Schuld vor ihm fühle. Aber worin besteht die

96 Dies ist das einzige Kapitel des Romans, in dem der Erzähler aus der internen Sicht einer dritten Person (nicht der eigenen und nicht nur der Antipovs, der sein Gewährsmann für den Erzählstoff ist) darstellt. Da Kijanov die hier vorgetragenen Gedanken. seinen Traum. seine Tagebuchaufzeichnungen, weder Antipow noch dem Erzähler direkt mitgeteilt hat, müßte eine weitere Vermittlerperson zwischen ihm und Antipov bzw. dem Erzähler hinzugedacht werden, entweder ein dem Ich-Erzabder hebengeordneter auktorialer Erzähler oder eine andere epische Figur, z. B. Susanna Vladimirovna. 
Schuld?"97 Die Antwort auf diese Frage hat Kijanov verdrängt, nur ein nächtlicher Alptraum präsentiert ihm in Bildern den Schlüssel dazu. In diesem Traum erlebt sich Kijanov in einem trübe beleuchteten, unterirdischen Raum aus Beton, in dem er sich angstvoll hinter einer Säule versteckt, während er über sich das bedrohliche Geräusch einer aufgestoßenen Tür und einer vom Luftzug über den Betonboden gefegten Menge von Papieren wahrnimmt. Anschließend sieht er, wie eine gedrängte Schar weißgekleideter, barfüßiger Gestalten mit verbundenen Augen, etwas in den Händen haltend treppabwärts kommt und an ihm, der sich angsterstarrt im Schatten der Betonsäule verbirgt, vorüberzieht. "Wohin sie so zielstrebig und einmütig laufen und was sie in den Händen halten, kann man nicht erkennen, aber Angst lähmt das Herz."98 - Kijanov entsinnt sich, diesen Traum, den er in sein Tagebuch für Träume einträgt, ähnlich schon vor 20 Jahren geträumt zu haben. Warum träumt er ihn jetzt noch einmal, und was haben die Bilder zu bedeuten? Und er gibt sich selbst eine Antwort: "Todesangst. [...] In mir sind die alten Zeiten nicht gestorben. Sie sind mit Mišas Erscheinen in Bewegung geraten. Sie sind in meinen Adern, in meinem Fleische, das noch auf etwas wartet."99 - Bei der Interpretation stellt sich zunächst die Frage, ob der Traum tatsächlich eine einfache Wiederholung ist oder ob die für Kijanov anscheinend identischen Bilder, die ja doch durch unterschiedliche Situationen ausgelöst wurden, nicht auch unterschiedliche Bedeutung haben. Im realen Bezug zur zeitgeschichtlichen Situation damals (1937) könnten die Bilder bedeuten: In dem bunkerartigen Raum - vielleicht das Souterrain eines Gerichtsgebäudes oder Gefängnisses, vielleicht eine Hinrichtungsstätte - gelang es Kijanov, sich vor Stalins blindwütenden Schergen, denen ein Wust von Haftbefehlen vorauswehte, zu verstecken; es gelang ihm anders, als es den seinerzeit Ergriffenen und Verurteilten gelungen ist, zu denen er eigentlich auch gehört hätte. Im realen Bezug zur zeitgeschichtlichen Situation jetzt (1957), in der Kijanov voll Unruhe darauf wartet, daß ihn sein zurückgekehrter Freund Teterin besucht, könnten die Bilder zwar immer

97 S. 429.

98 S. 428. - In Trifonovs noch unkorrigiertem Manuskript hat ursprünglich gestanden: "...und in den Händen etwas, das wie ein Messer aussieht." So Eckhard Thiele in seiner deutschen Übersetzung. Thiele (= Anm. 87), S. 247. - Sigrid McLaughlin ubersetzt nach dem selben Manuskript ins Englische: "DAGGERS IN THEIR HANDS". In ihrem Aufsatz: Antipov's "Nikiforov Syndrome": The Embedded Novel in Trifonov's "Time and Place". In: Slavic and East European Journal. Bd. (32). 2/1988. S. 241.

S. 433. 
noch den unterirdischen Raum einer Gerichtsstätte bezeichnen, in dem sich Kijanov wiederum angstvoll versteckt, im übrigen aber: Das über ihm aufgestoßene Tor - das sich öffnende Gefängnistor, weil die Gefangenschaft der damals Verurteilten zu Ende ist; die vom Winde davongetriebenen Papiere die alten, revidierten Gerichtsakten; die bedrohlich nahe vorbeiziehenden, blinden Gestalten - die Schar der Entlassenen, die sich noch eng aneinander hält, weil sie noch nicht weiß, wohin sie gehen soll. Jetzt versteckt sich Kijanov vor ihnen, weil er Angst hat, sie könnten sich für sein früheres Fehlverhalten an ihm rächen.

Woran Kijanov jetzt anknüpfen möchte, wenn er sich nach dem Freund sehnt, das ist die gemeinsame Zeit am Gymnasium, die Zeit der ersten gemeinsamen Schriftsteller- und Herausgebertätigkeit in den 20er Jahren, in der man gegen Ende des Jahrzehnts auch erste kritische Situationen überstanden hat, als die Disziplinierung nonkonformistischer Autoren begann. Zwischen dieser als glücklich erinnerten Zeit und der Gegenwart liegt aber nicht einfach ein neutrales Feld, sondern es liegen wesentlich die verhängnisvollen Ereignisse der 30er Jahre, die zum Prüfstein für die Geisteshaltung des einzelnen wurden und schließlich zu Teterins, nicht aber zu Kijanovs Verurteilung führten. - Die Bruchstelle im Verhältnis der beiden früheren Freunde liegt im Jahre 1934, dem Jahr der Weichenstellung, das die Schriftsteller zur Entscheidung zwang. 100 Kijanov entschied sich zur Botmäßigkeit des Opportunisten, Teterin, der mit seinem (gesellschaftskritischen) Roman "Das Aquarium" Aufsehen und Anstoß erregt hatte, ${ }^{101}$ zur Unbotmäßigkeit. In der Zeit der politischen Prozesse zur Mitte der 30er Jahre verweigert Teterin die Aussage gegen andere Schriftsteller, zu der man ihn nötigen wollte, wohl wissend, daß er damit die eigene Verurteilung endgültig besiegelt. In seinem letzten, nächtlichen Gespräch mit Kijanov bekennt er sich, von Todesangst gezeichnet, zum Wert seiner persönlichen Würde: "Denke nicht, ich sei verrückt geworden. Ich habe nur plötzlich klar gesehen, was ist und was sein wird. Ich habe das Ende gesehen. Und ich will mich vor dem Ende nicht wie ein Schwein in der Suhle wälzen."102 Damit aber - so Kijanov auch heute

100 Nach der Auflösung aller literarischen Gruppierungen und ihrer zwangsweisen Vereinigung in einem Sowjetischen Schriftstellerverband im Jahre 1932 wurde auf dem Ersten Sowjetischen Schriftstellerkongre $B$ im Jahre 1934 die offiziell verbindliche Literaturdoktrin des sozialistischen Realismus verkündet.

101 Kijanov: "Ein talentvolles Buch, aber ätzend wie Vitriol, dafür mußte er sich verantworten, und er wußte, worauf er sich einlie B" - S. 430.

102

S. 431 . 
noch eher vorwurfsvoll als anerkennend - habe Teterin sein Schicksal selbst gewählt. Anders verhielt er sich in der gleichen Zeit. Seiner Tagebucheintragung ist zwar nicht zu entnehmen, daß er vorsätzlich denunziert hat, desavouiert aber hat er: "Auf einer Versammlung mußte man jetzt dieses kleine Journal [das nicht mehr existierte] als übles Muster der Ideologie der Poputčiki anprangern, sich von ihm lossagen [...] und zugleich von den früheren Kollegen, mit denen man schon jahrelang nicht mehr verkehrte. So waren die Regeln des Spiels des Schicksals. Er aber [Teterin] wollte aus den Regeln ausbrechen."103 Kijanov beruft sich mit euphemistischer Rhetorik wiederholt auf "das Schicksal" als ordnungsgebietende Macht, und er braucht diese Rationalisierung seines damaligen persönlichen Versagens offenbar auch jetzt, 20 Jahre später, noch dringend zur eigenen Rechtfertigung. Allein im Traum, den Teterins Heimkehr ausgelöst hat, wird die Verdrängung unwirksam. Im Traum holt Kijanov das unterdrückte Gewissen ein. ${ }^{104}$

Die unterschiedliche Haltung in der Entscheidungssituation der 30er Jahre, die Kijanov das Hierbleiben im zivilen Leben ermöglichte, Teterin aber in die Zwangsarbeit führte, bezeichnet den Divergenzpunkt im Leben der beiden alten Freunde. Deshalb bleibt für Teterin die Distanz zu Kijanov auch nach der Heimkehr, und zwar weniger, weil er ihm für etwas aus früherer Zeit Vorwürfe machen wollte, sondern weil ihn innerlich nichts mehr mit ihm verbindet. Dem in Vermittlungsmission erschienenen Antipov erklärt er das in zwei einfachen, bildhaften Sätzen: "Wir haben auf einer Eisscholle gestanden, die zerborsten und auseinandergetriftet ist. Und jetzt zurückzuspringen, habe ich keine Lust."105 - Dort überleben zu müssen, bedeutete für Teterin aber auch die Lösung anderer persönlicher Bindungen des bisherigen Milieus, insbesondere die seiner Ehe. Dort beim Überleben geholfen hat ihm eine andere Frau, nicht seine ihm zu Hause treu verbliebene Tat'jana Robertovna, die über der Nachricht, daß er jetzt mit dieser anderen Frau zurückge-

103 Ebd.

104 Es bleibt allerdings offen, ob für Kijanov speziell im Verhalten gegenüber Teterin in der damaligen Situation das gleiche gelten soll wie in Kapitel 5 für das Verhalten der Pletnevs gegenüber den Eltem des Erzählers, nämlich, daß er "allzu vorsichtig" war und deshalb - obgleich das für ihn möglich gewesen wäre - der Verurteilung des Freundes nichts entgegengesetzt hat (s. o., S. 41). - Sigrid McLaughlin behauptet das: "[...] Kijanov wanted to survive in 1937 and therefore did not dare to defend Teterin." McLaughlin (= Anm. 98), S. 240. Aus dem Romantext geht aber nicht hervor, daß für Kijanov eine solche Gelegenheit konkret bestanden hat, bei der er das hätte tun können.

105 S. 440. 
kehrt sei, zusammengebrochen ist. (Kijanovs moralische Wertung: 'Das hätte er nicht tun dürfen, aber rücksichtslos gegenüber Frauen war er auch früher', - verkürzt den psychologischen Sachverhalt.)

Zur Komplizierung des Verhältnisses der beiden Freunde hatte wesentlich eine dritte Person beigetragen, die damals eine ungute Rolle spielte und dies auch jetzt wieder tut: der in Kapitel 4 erstmals namentlich erwähnte, als Kontrahent Kijanovs eingeführte Rojtek. Der um ihn verbliebene große Raum der Unbestimmtheit füllt sich ab jetzt im Erzählvorgang mit Konkretion. Zunächst durch Kijanovs Erklärung im Tagebuch. Teterin hatte damals, im Zusammenhang mit den Prozeßaffairen, nachdrücklich vor Rojtek, der anscheinend auch sein Gegenspieler war, gewarnt: "Hütet euch vor Rojtek. Von ihm kommt Unheil." 106 Kijanov, zu dem sie gesagt war, aber hatte die Warnung nicht sonderlich ernst genommen und war nachfolgend in Rojteks unheilvolle Abhängigkeit geraten: Teterin hatte ihn bei jener letzten nächtlichen Begegnung befugt, das gemeinsam verfaßte Theaterstück auch ohne seinen, Teterins Namen aufführen zu lassen. (Dies ist der notwendig klärende Nachtrag zu Tat'jana Robertovnas Vorwurf, s. o., Kapitel 7.) Der damalige Chefdramaturg Rojtek aber wußte von der gemeinsamen Verfasserschaft und gebraucht seither dieses Wissen, um Kijanov zu drohen und zu erpressen. Und obgleich er selbst, um die Aufführung zu ermöglichen, Kijanov damals auch dazu gedrängt hatte, so zu verfahren, wie er es getan hat, nutzt er jetzt wiederum die Gunst der Stunde, sich Teterin anzubiedern und Kijanov öffentlich als Betrüger zu diffamieren. Das ist der wichtigste Grund, weshalb Kijanov, der sich gegenüber Teterin diesbezüglich keiner Unkorrektheit bewußt ist, umgehend an einem Treffen gelegen sein muß.

Antipov übernimmt den an ihn ergangenen Auftrag des Schriftstellerbüros, die Dinge klären zu helfen, zunächst nur ungern, begreift aber nach der Aussprache mit Kijanov, an der sich auch Susanna Vladimirovna beteiligt, wie wichtig für seinen früheren Lehrer in dieser Situation seine Rolle als Vermittler und Stifter von Versöhnung ist. Und es gelingt ihm tags darauf, an Teterins Mitleid zu appellieren und ihn zur Begegnung mit Kijanov zu bewegen, was den Leerraum, der zwischen beiden auf der Ebene des Verstehens entstanden war, durch die spontane Wiedersehensfreude überbrückt und eine Anknüpfung an die Zeit der alten Freundschaft, die zuvor über ein Vierteljahrhundert gedauert hatte, wieder möglich erscheinen läßt. Kijanov 
kann zu seiner eigenen Genugtuung die Treue zum Freund damit bestätigen, daß er als einziger in der Stadt seine Bücher aufbewahrt und sie entgegen der offiziellen Verfügung nicht vernichtet hat. Krank geworden sind sie indessen an ihrer Gesellschaft beide - der im zivilen Alltag verbliebene Kijanov, herzkrank durch die anhaltende gesellschaftliche Repression; der körperlich verschlissene, zur Trunksucht neigende Teterin - durch die Strapazen von 20 Jahren Lagerleben. Und nach der Wiederholung einiger freudig begangener Begegnungen erfolgt für Kijanov dann die jähe Katastrophe, denn auf die für ihn wichtige Frage, ob sich Teterin an jene letzte Nacht vor 20 Jahren erinnere, in der er ihm aufgetragen hatte, seinen Namen vom gemeinsam geschriebenen Theaterstück für die Aufführung wegzulassen, verweigert der betrunkene Teterin die Erinnerung. Sein wiederholtes "ich erinnere mich nicht” aber wirkt auf den gesundheitlich geschwächten Kijanov tödlich.

Mit Kijanovs Lebenslinie endet im Roman auch die von Susanna Vladimirovna, der es gelungen war, nach dem Tod von Kijanovs Frau deren Platz einzunehmen. "Sie hat erreicht, was sie wollte, wenn auch spät, kurz bevor sich der Vorhang senkt. [...] Wie sehr er sich auch seit 1946 gewunden und gesträubt hatte, das Morgenkleid hatte ihn eingeholt."107 Susanna, die große Liebende, ist ihrer unkompliziert direkten Rolle, zu der also schon ihre für Antipov auffällige Fürsorge (s. o., Kapitel 3, = 1946) gehörte, treu geblieben und hat dem kranken Kijanov die letzte Lebenszeit erleichtert.

Der Personenkreis Kijanov - Susanna - Teterin - Rojtek, dessen gemeinsame Geschichte seit dem dritten Kapitel des Romans in Antipovs Lebenslinie eingeflochten war, wird im folgenden, elften Kapitel ("Das neue Leben am Stadtrand", = 1970/1971) in Antipovs literarische Bearbeitung Eingang finden. Persönlich wird von ihnen nur Rojtek noch einmal in Erscheinung treten, und zwar als Streit- und Skandalobjekt auf einer öffentlichen Neujahrsfeier. Vermutlich hat er seine frühere ungute Rolle als Kulturfunktionär fortgesetzt, so daß es auch jetzt einige kategorisch ablehnen, seine Gesellschaft zu teilen. "Kolja Kubarskij sagte ihm damals ins Gesicht: Sie sind ein Mensch mit amputierter Moral. [...] Miron sagte, daß er bei Rojteks Anblick eine Allergie bekäme. Antipov war alles gleich."108 Letzteres kann besagen, daß Antipov selbst keine weiteren schlechten Erfahrungen mit Rojtek gemacht hat oder aber, daß er an unmoralischen Verhaltensweisen

107 S. 433.

108 S. 466 und 464. 
weniger Anstoß nimmt als früher, was ebenfalls zu seiner Situation des elften Kapitels passen würde.

Obgleich Antipov im zehnten Kapitel nur die Nebenrolle eines Vermittlers spielt, wird beiläufig auch seine Lebenslinie weitergeführt. Beim letzten Gespräch mit seinem Lehrer erfährt er unter anderem, daß er sein früheres Studium letztlich ihm, Kijanov, zu verdanken hatte, der ihn im Jahre 1946 trotz ergangener Denunziation (Antipov = eine unerwünschte Person aus anrüchiger Familie) stillschweigend als Studenten in seinem Seminar behalten hat. ${ }^{109}$ Für Antipov ist diese am Rande eingefügte Auskunft wichtig, sowohl für das eigene Selbstverständnis wie auch für das richtige Verständnis der Persönlichkeit seines Lehrers; für Kijanov war sie wichtig in einer Situation auf ihn niedergehender Diffamierung, als der bescheidene Versuch, das Zerrbild, das man eben in der Öffentlichkeit von ihm verbreitete, wenigstens bei einem Menschen zu korrigieren, dessen Lebenslauf ihm persönlich nicht gleichgültig war.

In seiner schriftstellerischen Laufbahn hat Antipov mittlerweile Erfolge aufzuweisen, wenngleich Kijanov wie auch Susanna seine Fähigkeiten als "ziemlich mäßig" (dovol'no umerennye) ansehen. In seiner Familie wurde ihm nach dem Sohn Stepan (*1951) im Jahre 1953 noch eine Tochter geboren. Doch in seiner Ehe ist die große Liebe der ersten Zeit in die Normalität eines Alltags mit Meinungsverschiedenheiten übergegangen, in der Gegenwart der erzählten Zeit deutlich an Tanjas Einwänden gegen seine Reise nach Jalta. Die Einwände werden nicht konkretisiert, legen aber zwei Gründe nahe: 1.) Tanja möchte nicht, daß er allein verreist und sich von ihr und der Familie trennt, 110 - oder/und - 2.) Er kann sich die Reise finanziell nicht leisten. (Schon nach kurzer Zeit hatte Antipov in Jalta sein Geld verbraucht und übernachtete auf der Parkbank.)

109 Gemeint ist vermutlich die in Kapitel 4 ("Tverskoj Boulevard Il") wiedergegebene Situation. Das dort dargestellte Handlungsgeschehen gehört allerdings zum Februar 1947. Denkbar wäre aber auch, daß der dort berichteten Denunziation Antipovs durch Valerij Izmajlovic bereits eine andere im Vorjahr vorausging.

110 Vielleicht war Jalta für sic zum gegebenen Zeitpunkt auch schon zum Inbegriff für eheliche Seitensprünge geworden. Sieben Jahre später, wie aus Kapitel 11 ersichtlich, wird sich Antipov dort mit Lucienne, Mirons Frau, vergnügen. 


\subsubsection{1.) Kapitel 11: Das neue Leben am Stadtrand (Herbst 1970 - November 1971)}

Kapitel 11 weist den größten zeitlichen Abstand zu einem vorausgehenden Kapitel auf, nämlich etwa 13 Jahre. Es ist zugleich das umfangreichste des Romans und unterscheidet sich von allen übrigen durch die Struktur einer Rahmenerzählung, wobei der Erzählrahmen vom Geschehen der Erzählgegenwart ausgefüllt wird (= November 1971), die in den Rahmen eingefügte Vorzeithandlung aber, die sich vom Herbst 1970 bis April 1971 erstreckt, nicht nur unmittelbar in die Gegenwart der erzählten Zeit einmündet, sondern zugleich deren Verständnisgrundlage darstellt."111

Der relativ große zeitliche Leerraum zum vorausgehenden zehnten Kapitel markiert den Abschluß einer vergangenen und den Beginn einer neuen Phase im Leben der Gesellschaft. Der zivile Alltag hat sich verändert. Die Atmosphäre der Angst und Depression ist der Atmosphäre einer neuen Freizügigkeit, auch der einer Konsolidierung im materiellen Bereich gewichen. In neu erschlossenen Gebieten werden Wohnungen gebaut. Antipov ist vor kurzem (Mitte 1971) mit seiner Frau Tanja und den beiden inzwischen erwachsen gewordenen Kindern (Sohn Stepan fast 20 Jahre und Tochter Marina 18 Jahre) aus der Enge der "kommunal'ka" in eine neue, geräumige Wohnung an die Peripherie der Stadt, in das Neubaugebiet des Flughafenviertels gezogen.

Die im Erzählvorgang als Freiraum belassene Zeit von 13 Jahren bezeichnet andererseits aber auch einen Abschnitt im privaten wie beruflichen Werdegang Antipovs, der nachträglich punktuell konkretisiert wird. Antipov hat sich im Laufe der Jahre soweit als Schriftsteller etablieren können, daß ihm die berufliche Tätigkeit eine Lebensgrundlage bietet. "Die Bücher Antipovs [nach eigener Auskunft sieben oder acht] drangen zwar nicht in die dicken Journale vor, wurden aber regelmäßig in Kinder- und

111 Der im neunten Kapitel aufgetretene Zeitfehler im Erzählverfahren wirkt hier, in Kapitel 11, noch an zwei Stellen nach. Von Antipovs Sohn Stepan heißt es S. 481: “...kaum, daß er im Jahre 1950 geboren war". Stepan, jetzt 19 Jahre alt, ist aber erst Ende 1951 geboren worden (s. o., Anm. 84). Deshalb und auch wegen der von Antipov selbst erwähnten Angabe des eigenen Alters mit 45 Jahren (er wurde im Mai - diese Präzisierung ist der Einleitung des zwölften Kapitels, s. u., S. 497, zu entnehmen - 1926 geboren) kann der bevorstehende Jahreswechsel nicht der von 1969 auf 1970, sondern es muß der von 1970 auf 1971 sein. "Das neue Jahr 1970 stand vor der Tür" (S. 466) muß heißen: "Das neue Jahr 1971...". 
Jugendbuch-Verlagen gedruckt."112 In der Reihe "Aus der Vergangenheit der russischen Kultur" kann er seit sechs Jahren Erzählungen über Reisende, Freidenker, Künstler und Sonderlinge des letzten Jahrhunderts publizieren, weil diese Art der Erzählung sowohl den Erwartungen des Verlags als auch einer bestimmten Leserschaft entspricht. Das auf der Einzugsfeier vorgebrachte Kompliment, zwei seiner Bücher seien "Meisterwerke der russischen Literatur", wird allerdings - zu Recht, wie der Erzähler vermerkt - ins Mokante gezogen. Die Summe der Andeutungen läßt folgern, daß Antipov ein einigermaßen bekannter Autor geworden ist, wobei der Unterhaltungswert seiner Werke vermutlich höher zu veranschlagen ist als deren künstlerischer Anspruch. Jetzt jedoch ist er seit längerem mit einem Roman befaßt, dessen zu gestaltenden Stoff er als eine Herausforderung an seine künstlerischen Fähigkeiten empfindet.

In einer Krise steht mittlerweile Antipovs Familienleben. Seine Ehe ist am Zerbrechen, so daß sich der äußere Höhepunkt im Handlungsgeschchen, mit der Familie endlich eine eigene Wohnung zu haben, ins Gegenteil verkehrt, weil er mit einem Tiefpunkt der persönlichen Beziehungen zwischen den Ehepartnern zusammenfältt. Tanja: "Was sollen wir mit der neuen Wohnung, wenn..." "Ich weiß nicht", sagte er. "Ich brauche sie nicht."113

Aber auch im Gesamtgefüge der anderen persönlichen Beziehungen Antipovs hat die vergangene Zeit "Fort-Entwicklung" im Sinne von Entfremdung gebracht. Die Einzugsfeier in der neuen Wohnung, von Antipov nach 20 Jahren wohlmeinend zugleich als Seminartreffen mit früheren Studienkameraden gedacht, gerät aus den Fugen, weil die weniger Erfolgreichen (Miron, Kotov) sich alsbald anschicken, mit den Erfolgreicheren (Kvašnin) "alte Rechnungen" zu begleichen und das Fest des Wiedersehens dadurch unversehens in einen handgreiflichen Skandal umschlägt. - Tanja hatte die Feier von Anfang an nicht gewollt. Sie hatte den Verlauf in etwa vorausge-

112 S. 469.

113 S. 450. - Ähnlich wie Teterin im vorigen Kapitel sein Verhältnis zu Kijanov mit einer Eisscholle beschreibt. auf der beide ursprünglich gemeinsam gestanden hatten, nun aber. nachdem sie in zwei Hälften geborsten ist, jeden in eine andere Richtung davon getragen hat, so gebraucht Antipov in diesem Kapitel analog dazu das Bild vom zerbrochenen Floß, dessen Wrackteile Tanja und inn unaufhaltsam in unterschiedliche Richtungen fortreiben. "Langsam trifteten dic: beiden Hälften des geborstenen Floßes voneinander weg, auf deren einer Antipov stand, auf der anderen Tanja, [...] Man kann nichts aufhalten, alles nießt, bewegt sich. entfernt sich von irgend etwas und nähert sich an irgend etwas an." S. 479. 
sehen und erlebt ihrerseits das Ganze als offene Demonstration von Antipovs Lieblosigkeit. Statt des Trubels mit fremdgewordenen Gästen hätte sie sich nichts weiter als familiäre Gemeinsamkeit gewünscht. Sie leidet darunter, daß ihr Mann sich von ihr abgewandt hat und sie mit einer anderen Frau hintergeht. 114 Die Darstellung dieser eben beendeten Liebesbeziehung, die in der Rahmenhandlung in ihrer Auswirkung auf die Erzählgegenwart gezeigt wird, bildet den zentralen Teil des Kapitels.

Zeitgeschichtlich gehört das private Geschehnis einer freizügigen Liebe zum Hintergrund der neuen gesellschaftlichen Freizügigkeit, die nach dem Tod des Diktators unter anderem auch Gruppenreisen in die Länder befreundeter Staaten ermöglichte. Anscheinend auf lange Sicht vorbereitet, wird eine solche Gesellschaftsreise in die Slowakei von Irina, "der stadtbekannten Hyäne" (Tanja: opasnaja chiščnica) genutzt, um sich Antipov zur Beute zu machen. Das exzessive Spiel mit der Liebe hält beide in beiderseits hysterischer Vereinnahmung auch in der Folgezeit, bis zum Frühjahr des nächsten Jahres fest. Irinas Erfolgsgeheimnis lag dabei nicht allein in ihrer erotischen Faszination, sondern wesentlich auch in ihrer Fähigkeit, Antipovs schriftstellerischer Begabung zu schmeicheln. Die Schmeichelei ist zwar primitiv (Antipov sei größer als Čechov, größer als Hemingway, als Tolstoj, als Homer), aber sie trifft psychologisch mit einer Phase der Depression in seinem Schaffen zusammen, und deshalb "glaubte, glaubte, glaubte er, bis zur Erschöpfung".115 Er gewöhnte sich an Sätze wie diesen, "daß er derzeit

114 Längere Zeit hatte sie das geahnt und an seinem Verhalten gespürt. Auf der Einzugsfeier bekommt sie es von Mirons Frau Lucienne, die auf jene andere eifersüchtig ist, bestätigt. Antipov hatte seinerseits zwar Tanjas Liebe immer zu schätzen gewußt. Noch vor einem Jahr, "als das alles anfing", war es für ihn nicht denkbar, sich von ihr zu trennen. "Zuviel hatten sie gemeinsam erlebt, fast 20 Jahre." (S. 459) Erste Risse hatte die eheliche Treue aber schon sieben Jahre zuvor erhalten, als eben dieselbe Lucienne, ohne Miron, und er, ohne Tanja, sich (zufallig?) in Jalta trafen und Lucienne ihn für zwei Nächte in Anspruch nahm. In der Erinnerung stellt sich die Szene für Antipov so dar, als habe das damals nicht in seiner Absicht gelegen, sondern ausschließlich in der Luciennes, von der er im übrigen keine gute Meinung hatte. (S. o., Kapitel 8: "Tverskoj Boulevard IV", (= 1950): "Eine Schönheit, eine Tänzerin, aber nur für eines gut und im übrigen langweilig." S. 395.) Ihre ersten Avancen vor 20 Jahren auf ihrer eigenen Hochzeitsfeier hatten Antipov abgestoßen. - Von sich selbst aus neigte Antipov wohl nicht unbedingt zu erotischen Abenteuern, er setzte ihnen aber, wenn er dazu verleitet wurde, auch nicht allzuviel Widerstand entgegen, wie diese Szene in Jalta und noch deutlicher die letzte Liebesgeschichte mit Irina zeigte, die zur Entfremdung von seiner Frau und der Zerruittung seiner Ehe geführt hat.

115 S. 458. 
der 'einzige Schriftsteller sei, über den man ernsthaft sprechen könne'. Zu Hause bekam er solches nicht zu hören."116 Er hat im Gegenteil den Eindruck, daß Tanja seine Arbeit bisweilen nicht ernst nimmt. Einmal hörte er sie zur Tochter sagen: "Dein Vater hat sich mit seinem Schamott festgesessen, deshalb können wir dieses Jahr nicht nach Jalta fahren."117 Die exaltierte Liebe zu Irina wirkt dem entgegen und erhebt Antipov sowohl über die eigenen Zweifel am Gelingen seines Werkes als auch über die seiner Familie. Sie versetzt ihn in eine kreative Spannung, die ihn anspornt, sein Schreiben fortzuführen.

Das innere Ringen um die Geliebte verläuft zeitlich parallel zum inneren Ringen um seinen Roman, von dem er selbst, auch nach Phasen der Überarbeitung, zunehmend überzeugt ist, daß er ihm mißlungen sei, und von dem er doch nicht lassen kann. Zum ersten Mal hat Antipov offenbar einen anspruchsvollen Erzählstoff gefunden, der ihn fasziniert, von dem er aber auch den Eindruck gewinnt, daß er sein schriftstellerisches Können überfordert.

Im Zentrum des Romans "Das Nikiforov-Syndrom" steht der Schriftsteller Nikiforov, mit dessen Darstellung Antipov versucht, die Lebensproblematik seines Literaturlehrers Boris Kijanov wiederzugeben. Das in sich komplizierte Verhältnis Kijanov (= Nikiforov), Susanna (= Georgina, Goga) und Rojtek (= Jarbor) bildet die Materialgrundlage, die Antipots dichterische Phantasie zwar umgestaltet, doch so, daß der kundige Leser die Personen im Text wiedererkennen kann. Nikiforov ist wie Kijanov, ein älterer, wenig bekannter und wenig anerkannter Moskauer Schriftsteller, der sich über Jahre hin mit der Abfassung eines Romans abquält, in dem er sowohl sein eigenes Leben der 30er bis 50er Jahre wie auch das Leben von Schriftstellern vorausgehender Generationen darstellen möchte, und der eines Tages an einem Herzanfall stirbt, nachdem er - wie es im unkorrigierten Manuskript zur Unterstreichung der Analogie mit Kijanov noch heißt - eine Überdosis Schlaftabletten eingenommen hatte. ${ }^{118}$ Jarbor - der Mann mit dem schrägen Nacken - das Pendant zu Rojtek, aber im Unterschied zu diesem in direkter Konfrontation gegenüber Nikiforov gezeigt, nämlich als der staatlich beauftragte Funktionär, der Nikiforov wegen der verschlüsselten Darstellung einer

$\begin{array}{ll}116 & \text { S. } 459 . \\ 117 & \text { S. } 469\end{array}$

118 Siehe die deutsche Übersetzung. Thiele (= Anm. 87), S. 310 wie auch im englischen Zitat von McLaughlin (= Anm. 98), S. 244. 
konterrevolutionären Person zur Rede stellt. Anders als Kijanov kann Nikiforov, nachdem er 20 Jahre (!) vor ihm Angst gehabt hat, über Jarbors Verschwinden triumphieren: "Ich freue mich, daß sie diesem Scheusal den Garaus gemacht haben. [...] Er war ein Scheusal, ein Scheusal, und hat es verdient, wie ein Hund zu krepieren!"119 Goga, Nikiforovs Frau - die selbst im Alter noch kokette - ist deutlich Susanna nachgebildet (nicht Kijanovs Frau, der Antipov nur einmal flüchtig begegnet war). Sie ist die Frau mit den vielen "Beziehungen", deren Liebesdienste, u. a. gegenüber Jarbor, ihrem Mann ohne dessen Wissen das Leben gerettet haben. - Eine "Analyse des Lebens, das sich nicht zusammengefügt hatte" 120 will Antipov am Beispiel Nikiforovs geben und dabei der Frage nachgehen: Warum scheitert jemand als Schriftsteller, und warum mißlingt sein Werk? Und er weiß, daß dies auch sein ganz persönliches Thema ist. "Aber die Arbeit am 'Syndrom' war etwas ganz anderes [als alles, was er bisher geschrieben hatte]. Hier hatte es den Anschein als operiere er an sich selbst."121

Das Wesen der Krankheit, an der Nikiforov (= Kijanov) litt, das Syndrom, war "die Angst vor der Realität des Lebens, ${ }^{122}$ [...] die Angst, zu sehen 123". Das bezieht sich auf den privaten Bereich (Nikiforov hat sowohl Angst davor, Goga zu verlieren als auch ihre "Beziehungen" näher zu ergründen) und erst recht auf den gesellschaftlichen, der Nikiforov veranlassen müßte, die eigene Problematik als Schriftsteller in der Gesellschaft seiner Zeit wie auch die seiner Zeitgenossen zu bedenken. Statt sich aber mit der unbequemen, gefährlichen Wirklichkeit auseinanderzusetzen, ordnet er sich der offiziellen Erwartungsnorm unter. In seinem, nicht zum Abschluß gebrachten Roman "wollte er sich selbst widerrufen" (chotel oprovergnut' samogo sebja), ${ }^{24} \mathrm{~d}$. h., "er wollte", weil man das offenbar von ihm verlangt hatte, mit seinem Werk Positionen, die er früher als Schriftsteller eingenommen hatte, dementieren. ${ }^{125}$ Doch nicht nur sich selbst, auch die Darstel-

119 Diese Passage wiederum nur in Trifonovs unkorrigiertem Manuskript, zitiert nach der deutschen Übersetzung von Thiele (= Anm. 87), S. 340.

120 S. 468.

121 S. $469 / 470$.

122 S. 469.

123 S. 474 und 488.

124 S. 468.

125 Hier steht Nikiforov stellvertretend für eine ganze Reihe namhafter und weniger namhafter zeitgenössischer Autoren, die in der Stalinzeit auf höhere Weisung hin Selbstkorrektur geübt haben, z. B.: Fedin, Fadeev, Ėrenburg, Leonov, Valentin Kataev, u. a. 
lung der ihm nächst wichtigen Figur, eines Schriftstellers aus der Revolutionszeit, muß er "zurücknehmen", und zwar soweit, daß die Wahrheit entstellt wird. (Aus dem ehemaligen Sozialrevolutionär, dem "Überläufer" Vsevolodov, der 1919 von Tschekisten erschossen wurde, wird der "rote" Valdaev, den Kolčaks Anhänger umbringen.) Nikiforov muß feststellen: Die Wahrheit ist im literarischen Werk nicht darstellbar. Und er selbst leidet an einer Gesellschaft, die ein Interesse daran hat, daß sie nicht zur Darstellung kommt. Er leidet an der Realität des Lebens, aber er hat zugleich Angst davor, sie in ihrer letzten Tiefe erkennen zu müssen, und deshalb kann er dieses Leiden - ähnlich wie Kijanov, der seinem Schüler Antipov ja selbst erklärt hatte, daß Literatur Leiden sei126 - schon rein sprachlich nicht vermitteln. Der Schriftsteller übt aus Gründen des Selbstschutzes Selbstzensur. ${ }^{27}$ Seine Krankheit äußert sich in der Verdrängung der eigenen, verhängnisvollen Lebensgegenwart und deren Substituierung durch Ersatzthemen. Und weil sein Zustand kein subjektiv zufälliger, sondern ein zeitbedingter ist, bedarf sogar das Ersatzthema bei einem Zeitsprung von nur 40 Jahren noch der Verschlüsselung, deren Dechiffrierung dem Verfasser zum Verhängnis werden kann. Nikiforov versucht das, was sein persönliches Thema wäre, durch epische Figuren zu ersetzen, durch Schriftstellergestalten, für die in der Vergangenheit das gleiche galt: das Scheitern ihres Lebens und ihres Werkes an den gesellschaftlichen Verhältnissen ihrer Zeit, im literarischen Text jeweils festgehalten an einem Autor der vorausgehenden Generation, rückwärtig bis zum 18. Jahrhundert. "Eine ganze Kette, oder besser gesagt, ein System von Spiegeln, das sich durch fast zwei Jahrhunderte hinzog..."128 Doch auch das darzustellen mißlingt offensichtlich. Nikiforov merkt, daß dic Glieder der "Kette" (Kijanovs von Čechov entliehener Ausdruck), wenn überhaupt, dann nur oberflächlich ineinander greifen und nicht das Wesentliche erfassen. Analysiert werden müßte das Krankheitsbild der jeweiligen Gesellschaft, und es müßte der Begründungszusammenhang aufgezeigt werden, warum Schriftsteller an ihrer Zeit krank geworden sind. Davor aber schrickt Nikiforov zurück, denn er hat instinktiv verstanden, daß unter der

126 S. o., Kapitel 3: "Tverskoj Boulevard I" ( = 1946), S. 287.

127 In Trifonovs noch unkorrigiertem Manuskript hatte Kijanov bezüglich seines Traumes (Kapitel 10), den er in sein Tagebuch einträgt, bemerkt: "Das Scheußlichste und anscheinend durch nichts zu Bezwingende: Sogar in diesem Heft unterwerfe ich mich einer unglaublichen Selbstzensur. Ich träume zensierte Träume." Zit. nach der deutschen Übersetzung. Thiele (= Anm. 87), S. 248.

S. 469. 
sichtbaren Oberfläche des gewöhnlichen Lebens unsichtbar verborgen, "tief drinnen irgendwo eine Zeitbombe tickte"129, so daß der analysierende Rückblick auf die Zeit der vergangenen Jahre dem Blick in einen Abgrund gleichkäme, den man tunlichst vermeiden muß, wenn man die Gegenwart ertragen will. An eben dieser Stelle aber entscheidet sich der Weg des Schriftstellers und das Schicksal seines literarischen Werkes. Der Schriftsteller müßte als Interpret des Lebens seiner Zeit nicht nur bereit sein, ständig in den Abgrund zu schauen, er müßte zugleich auch bereit sein, den Abgrund in seinem Werk zu thematisieren. Das aber konnte Nikiforov nicht, das konnte Kijanov nicht, und das kann auch Antipov nicht.

Nikiforov ist ein Analogon nicht nur zu Kijanov, sondern auch zu Antipov. Auch Antipovs Schreiben erstreckt sich mit Unterbrechungen über Jahre, bedingt durch ständige Korrekturen, durch Zweifel am Sinn seiner Arbeit und durch die Notwendigkeit, "dringend etwas [anderes] zu Ende zu bringen, um Geld zu verdienen." 130 Und Antipov leidet am gleichen Syndrom wie Nikiforov (= Kijanov), nämlich an der Angst davor, das Leben zu sehen, wie es wirklich ist und es in seinen tieferen Zusammenhängen verstehen zu müssen. Deshalb übt auch er Selbstzensur, und deshalb verliert auch er sich, statt zum Wesentlichen vorzudringen, im Labyrinth des Geflechts einer äußeren Verknüpfung seiner epischen Figuren. "Anfang April war klar, daß alle Änderungen nichts genützt hatten. [...] Als Antipov das Kapitel gelesen hatte, begriff er mit Schrecken, daß das Wichtigste nicht im Roman stand. [...] Und Mitte September kam er zu der endgültigen Schlußfolgerung, daß der Roman mißlungen sei. Das war eine schreckliche Wahrheit, aber aus irgendeinem Grund empfand er Erleichterung."131

Beim Verlag, der Antipovs bisherige Bücher ohne größere Einwände angenommen und gedruckt hatte, stieß der neue Roman schon in der ersten Fassung auf Befremden. Man versteht nicht, was das Ganze soll. Es fehle die optimistische Note, und der Autor hätte "die sozialen Wurzeln des Mißerfolgs [Nikiforovs] vor dem Hintergrund des Lebens im Lande zeigen müssen. - Antipov schien es, daß er Wurzeln und Hintergrund gezeigt habe. Aber man erwiderte ihm, daß der Hintergrund nicht der richtige sei, sondern

131 S. $488,494,495$. 
der von gestern."I32 Über einen Schriftsteller wie Nikiforov (= Kijanov) und dessen Scheitern zu schreiben, wäre damit gleichbedeutend, die Stalinzeit seit den 30er Jahren als Hintergrund und Ursache des persönlichen Versagens auszuleuchten und Kijanovs Frage nachzugehen: "Wie sind wir zu einem solchen Leben gelangt?"133 Das zu ergründen hatte vermutlich in Antipovs Absicht gelegen, sonst hätte ihn die Redaktion diesbezüglich nicht rügen können. Doch er schreibt sein Buch in den Jahren 1969-1971. Und zu diesem Zeitpunkt war in der Kulturpolitik des Landes die Phase des verhältnismäßig liberalen Klimas, in dem Stalins Erbe ansatzweise zur Kritik freigegeben wurde, schon wieder vorüber. ${ }^{134}$ Dieser zeitgeschichtliche Kontext wird im Roman nicht ausgeführt, sondern erscheint - wie auch der allen bisherigen Zeitgeschehens grundsätzlich - wiederum nur als Leerraum.

Antipovs Erklärung gegenüber der Mutter, daß das Darzustellende seine Kräfte übersteige, ist mehr als eine einfache Wiederholung seines Zweifels an den eigenen künstlerischen Fähigkeiten. "Ich kann es nicht ausschöpfen. Aber das muß man. Man muß es bis zum letzten ausschöpfen, bis zum Grund."135 Das besagt auch nicht nur, daß die Erschließung des Verständnishintergrundes seiner epischen Figuren im nachhinein kompliziert und schwierig ist, sondern es drückt auch die Einsicht aus, daß der Autor bei diesem Vorhaben staatlich sanktionierte Tabusphären betreten müßte. Die Mutter scheint eben dieses aus den Worten des Sohnes herauszuhören, wenn sie erwidert: "Weshalb bis zum Ende ausschöpfen? Das ist nicht nötig, ich bitte dich."136 Und sie hat persönlichen Anlaß dazu, das zu sagen, denn sie hat sich - wofür ihr

132 S. 468. - Das unkorrigierte Manuskript hatte ursprünglich noch den Zusatz enthalten: "Zu diesen Themen sollte man nicht zurückkehren, es sei schon alles gesagt, man brauche das nicht zu wiederholen." Zit. nach der deutschen Übersetzung. Thiele (= Anm. 87), S. 306. Im englischen Zitat von McLaughlin (= Anm. 98), S. 243: "THERE WAS NO POINT RETURNING TO THIS TOPIC; EVERYTHING HAD BEEN SAID ABOUT IT; NO NEED TO REPEAT IT."

133 S. 313.

134 Nach dem Sturz von Nikita Chrušcev im Oktober 1964 zwang die Kommunistische Partei die Schriftsteller alsbald wieder in ihre ideologische Botmäßigkeit. Solženicyn konnte zwar 1962 dank der engagierten Herausgebertätigkeit von Aleksandr Tvardovskij seine Povest' Odin den' I vana Denisovi ${ }^{\prime}$ a veröffentlichen, die beiden großen Romane Rakovyj korpus und $V$ kruge pervom aber wurden 1968 in der Sowjetunion endgültig verboten. Gegen andere nicht systemkonforme Autoren waren zwischenzeitlich drastische Verurteilungen zur Zwangsarbeit ausgesprochen worden: Iosif Brodskij 1964. Andrej Amal'rik 1965. Andrej Sinjavskij und Julij Danièl' 1966.

135 S. 496.

136 Ebd. 
die Tochter Vorwürfe macht - mit einem alten Bekannten näher angefreundet, der sich früher als Bauingenieur in den berüchtigten "nördlichen Gebieten" verdungen hatte. Das Aufgraben der Vergangenheit würde den Schriftsteller nicht nur zwingen, sich auf Gelände zu begeben, unter dem "die Zeitbombe tickt", es würde von ihm auch moralische Wertungen verlangen, die die Verflechtung von Schicksal und Schuld zeitgenössischer Personen im Innersten bloßlegen. Nach Ansicht der Mutter sollte man das nicht tun. "Wir sind so müde geworden, du weißt es." 137 Um selbst Ruhe zu finden, sollte man das Vergangene ruhen lassen. Der Sohn aber fühlt sich allem Selbstzweifel und allen Einwänden anderer zum Trotz nochmals von einer inneren Notwendigkeit zur Weiterarbeit angetrieben. "Er begriff, daß es keinen Ausweg gab. Niemand wird ihn retten. Er setzte sich an den Tisch, [...] legte ein sauberes Blatt Papier vor sich hin und schrieb darüber: Das Nikiforov-Syndrom. Roman."138 Das war im November des gleichen Jahres 1971.

Der Erzähler, aus späterer Zeit rückblickend, kennt den weiteren Verlauf: Antipov wird sich noch einige Zeit weiterquälen, bevor er endgültig resigniert (siehe Kapitel 12). "Manche Fliegen summen und zappeln noch lange mit den Beinen, wenn sie am todbringenden Papier kleben. So summte und zappelte auch Antipov mit den Beinen, verlangte immer neue Stellungnahmen und objektive Beurteilungen. [...] Die hartnäckige Fliege summte weiter und zuckte mit den Flügeln, bis sie im Leim verendete."139

Die nach dem Tod des Diktators im Lebensalltag eingekehrte "Normalisierung" erstreckte sich nicht auf den Bereich der öffentlichen Meinungsfreiheit. Die Instanzen der Zensur funktionieren nach wie vor und verwehren es dem Schriftsteller auch weiterhin, sich mit der eigenen Gesellschaft im literarischen Werk kritisch auseinanderzusetzen.

137 Ebd.

138 Ebd.

139 S. 468 und 488. 
Die beiden jeweils nur 10 Seiten umfassenden Schlußkapitel haben Resümeecharakter und schließen den Kreis zu den beiden Anfangskapiteln.

Der große Leerraum des zeitgeschichtlichen Hintergrundes konkretisiert sich punktuell in einer neuen politischen Qualität, der Öffnung für andere, auch westliche Länder: Für sowjetische Staatsbürger ist es möglich geworden, längerfristig in zivilen Berufen im Ausland zu arbeiten. Miron ist seit fünf Jahren in Bulgarien, Antipovs Sohn Stepan als Arzt in Algier tätig. Die auffälligste Markierung aber ist die namentliche Nennung zweier amerikanischer Präsidenten: John F. Kennedys, von dem Markuša schwärmt (Kapitel 12) und James E. Carters, von dem der Erzähler träumt (Kapitel 13). Das ist um so bezeichnender, als im gesamten Roman an keiner einzigen Stelle der Name auch nur eines sowjetischen Staatsmannes erwähnt wird!140

Die beiden früheren Freunde, deren Biographie im Kindheitsalter von 11/12 Jahren in den beiden Anfangskapiteln in kleinen Ausschnitten parallel geführt wurde, die sich während des Krieges bei gemeinsamer Fabrikarbeit kennenlernten, danach allmählich aus den Augen verloren haben, begegnen sich am Ende der Romanhandlung, nach Überschreiten der Lebensmitte wieder. Antipov ist mittlerweile geschieden, der Erzähler verwitwet. Beide erleiden sie in der Erzählgegenwart einen lebensgefährlichen Zusammenbruch ihrer Gesundheit, aber für beide geht das Leben, nachdem sie neue Gefährtinnen gefunden haben, weiter, und zwar nunmehr gemeinsam, wie die vom Erzähler verfaßte Lebensdarstellung Antipovs folgern läßt.

Der 52jährige Antipov erfährt seine derzeitige Lebenssituation als Zäsur. Seine Ehe ist gescheitert. Von Tanja seit fünf Jahren (=1973) getrennt, lebt er wieder im Zentrum der Stadt, in der Nähe des Tverskoj Boulevard und ist jetzt ernstlich herzkrank. Aus seinem Gesundheitszustand läßt sich schließen, daß die zurückliegenden Jahre von Anspannung und Überforderung geprägt waren, und dies sowohl familiär wie beruflich. Bis er seinen ersten schweren Infarkt erlitt - so ist Kapitel $13 \mathrm{zu}$ entnehmen -, habe ihm der Sohn, der ihn nach wie vor liebt und verehrt, lange Zeit nicht verziehen, $\mathrm{da} B$ er die Mutter verlassen hat. ${ }^{141}$

Nicht minder gravierend ist die Zäsur, die er in seinem Selbstverständnis als Schriftsteller erlebt. Er konnte seinen Roman "Das Nikiforov-

140 Die Handlung der beiden Schlußkapitel gehört in die Regierungszeit Leonid I. Brežnevs. 141 S. 513 und 514. 
Syndrom", an dem er mehrere Jahre gearbeitet hatte, offenbar nicht zum Abschluß bringen (...nach weiteren Fehlversuchen, mit kleineren oder gröBeren Konzessionen an die Staatsräson, das Konzept neu zu fassen und doch noch $z u$ retten?...). Antipov wird von seiner beruflichen Tätigkeit weiter leben können - als Unterhaltungs- und Gebrauchsschriftsteller, als Journalist, der, wie das Kapitel einleitend berichtet, z. B. in die Mongolei reist und anschließend eine Erzählung "Das Rascheln des Sandes" ("Šum peska") schreibt, aber er wird in der gegenwärtigen Gesellschaft nicht als Zeitzeuge, nicht als Künstler gefragt sein, der seine Zeit im literarischen Werk authentisch interpretiert. Die Gesellschaft, in der er lebt, versagt ihm das, was er als seine wichtigste Aufgabe begriffen hatte. Und in dem, was er nicht sein darf, sieht er spiegelbildlich das, was seine Zeit ist. Deshalb wandelt sich für ihn der ihm beiläufig überkommene Satz: "Alles hat seine Zeit und seinen Ort"142 in die bittere Einsicht: "Nichts ist furchtbarer, als seinen Ort und seine Zeit zu erkennen."143 Diese Einsicht steht in ursächlichem Zusammenhang mit seinem derzeitigen Krankheitszustand und wirkt in ihm nach. "Gedanken kamen und gingen, das waren irgend welche Bruchstücke, irgendeine Hülse von Gedanken, etwas Wesentliches und Tiefes vermochte er nicht zu denken. Und wenn er zufällig auf ein unvollendetes Werk stieß, ergriff ihn eine Art seelische Übelkeit, so daß er eiligst abschaltete, damit ihm nicht noch übler würde. Jeder Gedanke an die Arbeit war gefährlich, wie eine heftige Bewegung, wie eine traurige Nachricht."144 Die Situation der Lebenskrise ist für Antipov noch nicht überwunden, aber er hat sich offenbar durch alle Zerreißproben hindurch, in die er als Schriftsteller gestellt war, seinen Sinn für persönliche Integrität bis zuletzt bewahrt. Er hat nichts veröffentlicht, was er nicht vertreten kann. Wenn das Wesentliche nicht ausgesprochen werden darf, verzichtet er auf die Publikation. Im Unterschied zu Kijanov (= Nikiforov) läßt er sich nicht dazu verleiten, sich selbst und die eigene Überzeugung zu verleugnen und über seine Zeit die Unwahrheit zu sagen. Aber - er nimmt sich auch nicht das Leben.

Die Erzählgegenwart gibt das Spektrum der Gemütsschwankungen wie auch die Schwankungen des körperlichen Befindens, die Antipov in jüngster

142 S. 500. - Überliefen war Antipov dieser Satz von MarkuŠas Mutter - in ihrer Jugendzeit Musikstudentin, später Piroggenverkäuferin auf dem Moskauer Arbat, jetzt in Armut lebend.

143 S. 504.

144 S. 498. 
Zeit durchlebt hat, noch einmal in knapper Form wieder. Sie ist einerseits von einem großen Gefühl der Befreiung aus Abhängigkeiten gekennzeichnet, die ihn bisher belastet hatten: "von der Sorge um die Kinder, die groß geworden waren, von überflüssigen Möbeln, von den Qualen der Ruhmsucht, von der Macht der Frauen, dem Egoismus der Freunde, dem Terror der Bücher."145 Andererseits hat eben dieser Akt der Loslösung soviel an Lebenskraft gekostet, daß eine Reihe von Herzanfällen und nachhaltige Resignation die Folge sind. Kapitel 12 schließt damit, daß Antipov erneut auf der Bahre aus dem Haus getragen wird. Zwischen Anfang und Ende des Kapitels aber zieht sich wie eine Fieberkurve das Auf und $A b$ von Antipovs Wohl- und Unwohlbefinden.

Als ihn in einer längeren Phase der Rekonvaleszenz die Nachricht vom Tode des früheren Studien- und Schriftstellerkollegen Kotov (s. Kapitel 3, 4, $8,10,11)$ erreicht, sieht er sich unwillkürlich mit dem eigenen Ende konfrontiert. Das Ableben Kotovs, der zwar nicht viel getaugt, mit dem ihn aber "Freude, Unsinn und Hoffnung" verbunden hatte, der ein Teil seines Lebens war, versetzt ihn in Trauer und läßt unwillkürlich in der Erinnerung auch andere Personen vorüberziehen, die zu seinem Leben gehört haben. Geblieben sind ihm nur wenige. Nur noch gelegentlich erhält er derzeit Besuch von seiner Tochter und von seiner Schwester, häufiger allein von Markuša, dem Büchernarren, der beim letzten Umzug auch seine Bibliothek aufgelöst hatte. Durch den Wiederauftritt des komischen Kauzes schließt sich der Kreis zu Kapitel 3, wo Markuša bei Kijanov als Buchaufkäufer fungiert hatte und Antipov ihn zum ersten Mal sah und zu Kapitel 5, in dem er dem Erzähler bei den Pletnevs begegnet war. Markuša wird der beste und treueste Gesellschafter des kranken Antipov, der für ihn große Sympathie hegt, "weil sich in ihm Kindheit, Torheit und Güte bewahrt hatten. Alles das, was irgendwann auch Antipov eigen gewesen ist."146 Und mit ihm schließt sich der Kreis noch zu einer anderen Figur, zu Nataša, der Zirkusartistin, Antipovs erster großer Liebe (s. Kapitel 4 und 7), die Markuša jetzt als seine Lebensgefährtin entdeckt hat: "Eine ungewöhnliche Frau", - kennengelernt - "ganz normal, beim Friseur". 147 Weder Antipov noch der Leser kann aus Markušas geheimnisvoller Ankündigung erahnen, daß es sich bei dieser Person um jene Nataša aus früherer Zeit handelt. Das ergibt sich erst durch einzelne Anhalts-

145 S. 497.

146 S. 503.

147 S. 501 und 504. 
punkte aus Markušas weiterem Bericht. Nataša ist seinerzeit, wie in Kapitel 7 (= 1947) erwähnt, nach Saratov ans Theater gegangen, 148 war dann auch Filmschauspielerin und ist nunmehr in der Prosektur eines Krankenhauses beschäftigt. Mit Antipov verbindet sie nur noch eine oberflächlich banale Erinnerung, mit Markuša aber hält sie auf der gegenwärtig absteigenden Lebenslinie ihre manifeste Trunksucht zusammen. Markuša hatte Antipov nicht zuviel versprochen, als er ihm andeutete, daß er ihm "ein Sujet" liefern werde, und Antipov wird - wie schon zu Ende des vierten und zu Ende des siebenten Kapitels - erneut Gelegenheit haben, darüber nachzudenken, worin der Sinn schicksalhafter Liebesbegegnungen besteht. Das Geschehen vor 31 Jahren hatte der Erzähler, auf die jetzige Situation vorausdeutend, mit den Worten kommentiert: "Viele Jahre sollten vergehen, bis er [Antipov] begriff, daß jenes andere, was ihn drei Nächte in der Steppe erfüllt hatte, das ist, was keinen Namen hat und was der Mensch immer sucht."149 Jenes andere benennt jetzt sentenzhaft eine alte Frau, die sich Antipov bei einem seiner Spaziergänge am Boulevard auf einer Parkbank zugesellt hatte: "Der Mensch muß lieben. Und geliebt werden. Alles andere hat keinen Sinn."150 Und eine Phase körperlichen Wohlbefindens, die ihn in freudige Hochstimmung versetzt hat, suggeriert Antipov: "Man kann von neuem beginnen, kann noch probieren, kann hoffen."151 Der in Antipov trotz allem unbeschädigt gebliebene Wille zum Leben weist voraus in die Zukunft, denn Antipov wird die kritische Situation, die Kapitel 12 beschließt, nicht nur überstehen, er wird in Kürze noch einmal heiraten und noch einen Sohn haben.

Für den Erzählschluß des zwölften Kapitels aber, als man Antipov erneut (...auch ihn diesmal für immer?...) aus dem Hause trägt, ist es bezeichnend, daß in den zurückliegenden Tagen offenbar in ihm selbst ein Klärungsprozeß stattgefunden hat, der ihn seine tiefe seelische Erschütterung überwinden half und ihn sein Leben, so wie es war, bejahen läßt. "Es gab keine bessere Zeit, als die, die er durchlebt hatte. Und keinen besseren Ort als diese Treppe mit der abblätternden Farbe an den Wänden [...], mit den Stimmen und den Gerüchen des Lebens, dem offenen Fenster, hinter dem sich die feurige, nächtliche Stadt regte."152

\footnotetext{
148 S. o., S. 376.

149 S. $377 / 378$.

150 S. 502.

151 Ebd.
}

152 S. 507. - In literarischer Reminiszenz klingt in dieser Szene Boris Pasternaks Gedicht $V$ bol' nice (Sommer 1956) nach, wenngleich der "Atheist" Antipov, der zwar "an Vorzei- 


\subsubsection{3.) Kapitel 13: Diesen Winter überleben (Herbst 1979-Anfang 1980)}

Im Schlußkapitel erzählt nach den Kapiteln 2, 5 und 6 der Ich-Erzähler wieder in erster Person aus seinem, jetzt dem gegenwärtigen Leben. Die zwischenzeitlichen Ereignisse seiner Vergangenheit werden nicht nachgetragen, sie sind von den Erwähnungen der Gegenwart aus rückwärtig nur punktuell erschließbar.

Der verwitwete 53jährige Erzähler, Doktor der Mathematik, lebt mit seiner nervenkranken Tochter Katja, dem Enkel Vasja, verschiedenen Kinderfrauen, mit denen er sich seit Katjas Krankenhausaufenthalt die Pflege des etwa einjährigen Enkels teilt, sowie mit einer befreundeten jüngeren Frau Julija Fedorovna zusammen. Im Erzählverfahren schließt sich der Kreis zu Kapitel 2, denn Katja wird in eben dem Krankenhaus stationär behandelt, in dessen Umfeld mit dem angrenzenden "Zentral-Park" der Vater früher gelebt hat, zur Schule ging und seine Kindheit verbrachte. Die Figuren des zweiten Kapitels, Agnija, Stanislav und Levka Gordeev werden erinnert, aber der Erzähler verschweigt der Tochter die wichtigsten Begebnisse seines damaligen Erlebens, d. h. die Ereignisse, die ihn später veranlassen, das Kapitel so zu erzählen, wie er es erzählt hat. Insbesondere Agnijas Freitod und Stanislavs unbegreifliche Krankheit, seine Lethargie mit den schweren Depressionen und dem "Unwillen zu leben", spart er aus, denn auch Katja war suizidgefährdet, und ihr Krankheitsbild war dem von Stanislav ähnlich. Sogar die Ursachen ihrer psychischen Erkrankung sind vergleichbar: Auch ihr wurde zu Unrecht die Anerkennung einer erbrachten Leistung verweigert. (Zweimal fehlte ihr bei der Aufnahmeprüfung zur Universität ein halber Punkt.)

Der Geschehnisort "Krankenhaus" führt die Lebenslinie des Erzählers wieder mit der Antipovs zusammen, denn der die Tochter behandelnde Arzt, so stellt sich heraus, ist Antipovs Sohn Stepan Aleksandrovič, der in der zwischen Kapitel 12 und 13 liegenden Zeit aus Algier nach Moskau zurückgekehrt war. Durch Katja erfährt der Erzähler und mit ihm der Leser, was sich zwischenzeitlich in Antipovs Familie ereignet hat: Tanja ist im Laufe des vergangenen Jahres gestorben. Sohn Stepan war verheiratet; sein Kind lebt bei der geschiedenen Frau. Antipov selbst habe kürzlich wieder geheiratet, eine junge Ärztin, und habe einen anderthalbjährigen Sohn. Antipovs

chen glaubt", sich aber im übrigen "vielleicht einen Heiden nennen könnte" (S. 468), anders als Pasternaks Todkranker seine Dankbarkeit nicht dezidiert an den Schöpfer richtet. 
neue Eheschließung muß also bald nach seiner Einlieferung ins Krankenhaus stattgefunden haben, mit der die Handlung des zwölften Kapitels abschloß.

Das Stichwort "Schriftsteller Antipov" im Bericht der Tochter gab dem Erzähler den Hinweis darauf, daß es sich beim Vater des Arztes um seinen früheren Freund handelt, den er 30 Jahre nicht gesehen hat. Und noch einmal wird das Thema "Schriftsteller Antipov" punktuell konkretisiert. Katja: "Sein [Stepan Aleksandrovičs] Vater ist Schriftsteller. Aber wenig bekannt. [...] Ich habe nichts von ihm gelesen." Katjas Vater, der Erzähler: "Nein, ich habe etwas gelesen. [...] Irgend zwei kleine Bücher von ihm sind mir in die Hände geraten. Ich habe sie durchgelesen. Nicht schlecht. Für die Jugend. Aber ich bin nicht sicher, daß ich sie zu Ende gelesen hätte, wenn ich Saša nicht gekannt hätte."153 Den um 1970 einigermaßen populären Schriftsteller Antipov (s. o., Kapitel 11) kennt man zehn Jahre später anscheinend schon nicht mehr (...weil er nicht im gleichen Stil für die Unterhaltungsbedürfnisse einer bestimmten Leserschicht weitergeschrieben hat?...).

Analog zu Antipovs Zusammenbruch am Ende von Kapitel 12 erscheint nach physischer und psychischer Überanstrengung der des Erzählers im dreizehnten Kapitel. In nächtlichen Angstträumen verfolgt den Erzähler die "Grimasse des Schicksals", am Tage abgelöst von neuer, vager Hoffnung, die Zeit der Strapazen doch zu überstehen. Und die schwache Hoffnung bricht sich Bahn, denn in eben die Situation des Zusammenbruchs hinein ereignet sich Antipovs Telephonanruf und sein Angebot, ihm bei der Betreuung des Enkels zu helfen. Als danach auch der verschwundene Freund der Tocher wieder auftaucht, mit der freudigen Nachricht, für Katja einen Zugang zur Universität gefunden zu haben, weiß der Erzähler, daß er den "Winter" überstanden hat. ${ }^{154}$

153 S. 514 und 515.

154 Der Winter hat im Romantext fast durchgängig symbolische Bedeutung, so daß die jahreszeidiche Realität jeweils als eine Entsprechung zum seelischen Befinden der Menschen erscheint. Wie die Überschrift des Schlußkapitels so konnotiert auch die des neunten Kapitels "Das Ende des Winters am Trubnaja Platz", das in Antipovs Erlebnisausschnitt den Tag nach Stalins Tod wiedergibt, diesen Sachverhalt. - Höhepunkt des achten Kapitels "Tverskoj Boulevard IV" war der GerichtsprozeB im Februar 1951, in den sich Antipov durch jenes für ihn verhängnisvolle Gutachten hatte verwickeln lassen, der ihm zwar moralische Selbstbestätigung. zugleich aber die momentane Zerstörung seiner Existenzgrundlage und eine große innere Erschütterung einträgt, über die ihm schließlich seine Freundin Tanja hinweghilft. ("Sie wärmten einander in den kalten Nächten, den ganzen März und bis Mitte April." S. 411) - An einem Wintertag (1939/1940) hatte sich Agnija (= Kapitel 2) erhängt. - Anfang 1946 (= Kapitel 3) wird 
In Analogie gesetzt werden im Schlußkapitel ferner die Generationen der Väter und ihrer Kinder. Die Lebensproblematik wiederholt sich. Mittlerweile haben auch die erwachsen gewordenen Kinder unter geschiedenen Ehen und zerbrochenen Partnerschaften mit den sich daraus ergebenden familiären Lasten zu leiden. Ihre Väter aber brauchen sie als persönlichen Beistand nach wie vor oder aber aufs neue. Nach allen überwundenen Krisen scheinen dabei die Väter am Ende, trotz aller Kennzeichnung durch das Alter, sogar besser im Lebensgleichgewicht zu sein als die junge Generation. Mit gegenseitiger Hilfe wird man weiterleben, wenngleich das Leben mühsam bleibt und man es auch künftig nur in kleinen Abschnitten überblicken kann. Ohne panegyrischen Überschwang erhält der Ausklang einen optimistischen Ton: Antipovs neu erwachter Lebenswille wird dem Freund helfen, gleichfalls wieder festen Boden zu finden.

Der Tverskoj Boulevard als Ort des Wiedersehens der Freunde nach 30) Jahren läßt die Bedeutung dieser Straße in Antipovs Leben noch einmal in zweifacher Hinsicht aufleuchten. Und ein letztes Mal wird damit zugleich auch eine Analogie zwischen Antipov und seinem früheren Literaturlehrer Kijanov hergestellt, der an gleicher Stelle nach 20 Jahren Trennung das Wiedersehen mit seinem Freund Teterin feierte (s. o., Kapitel 10: "Bol'šaja Bronnaja", = August 1957). Es wird angedeutet, daß Antipov jetzt die gleiche bzw. eine ähnliche Funktion ausübt wie einst Kijanov. Auch er leitet jetzt Seminare (...für angehende Schriftsteller?...). Antipov: "Treffen wir uns doch am Tverskoj Boulevard. Gegen sechs komme ich aus dem Institut. Dann ist mein Seminar zu Ende."I55 Kijanovs Name wird nicht mehr erwähnt, aber die Parallelität der Situation ist deutlich.

Nach dem Gang durch die Zeit vom Jahre 1937 bis zur Erıählgegenwart im Jahre 1980, punktuell illustriert an Lebensausschnitten zweier Figuren, Saša Antipovs und seines Freundes, des Erzählers seiner Biographie, apostrophiert der Erzähler abschließend noch einmal den Ort des Erlebens, die Stadt Moskau. Während des gesamten Erzählvorganges war er darauf bedacht, den

Antipovs Mutter aus der Zwangsarbeit entlassen und erfährt zu Hause, in Moskau, wo sie zu leben keinen Anspruch hätte, die Fremdheit ihrer erwachsen gewordenen Kinder. Im gleichen Kapitel, zur gleichen Zeit, erlebt Antipov erstmals seinen Literaturlehrer Kijanov als unglücklichen, kranken Menschen. - Im Februar 1947 (= Kapitel 4) überwindet Antipov durch Alp- und Fieberträume hindurch seine dreifache Angst. - Winter ist es Ende Oktober 1941(= Kapitel 5) zur Zeit der Belagerung Moskaus, als Privilegierte im letzten Augenblick versuchen. die Stadt zu verlassen.

S. 518. 
Leser durch die namentliche Nennung von Straßen, Plätzen und Stadtteilen in die Welt des realen Moskau zu versetzen und mit der Romanhandlung die Illusion eines in der außerliterarischen Realität konkret nachvollziehbaren Geschehens zu erwecken. Die Hervorhebung am Ende unterstreicht noch einmal die Bedeutung des Ortes als Stätte der Stiftung persönlicher Identität. ${ }^{156}$

"Bist du es?" - "Nun ja", sage ich, wir umarmen uns, schlendern zum Boulevard, irgendwo setzen wir uns hin, Moskau umgibt uns wie ein Wald. Wir haben ihn durchquert. Alles andere hat keine Bedeutung. ${ }^{157}$

Der Vergleich der Stadt mit einem Wald, der Menschen umgibt, spricht vom Schutz, den die Anonymität der Stadt in den Verhängnissen des Zeitgeschehens gewährt hat. Andererseits konnotiert der Vergleich aber auch: überwundenes Hindernis, überstandene Gefährdung, dem Dunkel eines Labyrinths, in dem man sich lebensbedrohend verirren konnte, glücklich entkommen zu sein - jeder auf seine Weise, bis man sich zufällig wiederbegegnet ist.

\section{4.) Schlußbetrachtung}

Die punktierte Linie des Romangeschehens weist über den Erzählschluß hinaus, denn Antipov wird dem wiedergefundenen Freund bei den nachfolgenden Begegnungen seine Lebensgeschichte erzählen, und zwar - so darf man annehmen - vollständig, ohne Auslassungen. D. h., beide werden sich so ist anzunehmen - jetzt auch über das unterhalten, worüber sie bei ihrer ersten Begegnung im Jahre 1943/1944 aus Verlegenheit geschwiegen haben, nämlich über das Schicksal ihrer Eltern in der Stalinzeit. Antipov wird dem Freund vom problematischen Lebensweg seines Lehrers Kijanov und dessen

156 Das erinnert an den Erzählschluß von Pasternaks Dokıor Živago, wo sich die Freunde Gordon und Dudorov vor der Kulisse des abendlichen Moskau in die Schriften Jurij Živagos vertiefen und es heißt: “Moskau kam ihnen jetzt [...] wie die Hauptheldin einer langen Geschichte (povest') vor, an deren Ende sie angelangt waren, mit dem Heft in den Händen an diesem Abend." (Boris Pasternak: Doktor Živago. Milano 1957. S. 530.) Pasternak hebt allerdings anders als Trifonov bei seinem Romanschluß die historische Dimension des gemeinsamen Erlebnisortes Moskau hervor.

157 S. 518. 
Scheitern als Schriftsteller crzählen wie auch von den Schwierigkeiten in seiner eigenen Schriftstellerlaufbahn, insbesondere vom Mißlingen seines Romans "Das Nikiforov-Syndrom". Dieser aber wird sich nicht nur entschließen, Antipovs Lebensgeschichte, die z. T. auch die seine ist, in einer Prosaerzählung aufzuzeichnen, er wird (wie sein Autor Trifonov), bevor er zu schreiben beginnt, der Frage nach den möglichen Ursachen des Scheiterns eines Schriftstellers in seiner Zeit gründlicher nachgehen, als es Antipov getan hat, denn er will vermeiden, daß er das, was er geschrieben hat. anschließend nicht publizieren kann. Das bedeutet aber, daß er zuallererst die Mechanismen der Gesellschaft, in der er lebt, als das begreifen muß, was sie wirklich sind, nämlich als die einer Diktatur, die akribisch darüber wacht, in ihrem Wesen nicht kompromittiert zu werden, insbesondere nicht von ihren Dichtern und Schriftstellern. "Die Angst des Schriftstellers, zu sehen" (das galt für Kijanov wie für Antipov) entsprang letztlich der Angst vor Bestrafung, die den ereilte, der geneigt war, das, was er gesehen und begriffen hatte, auch öffentlich auszusprechen. Die Angst vor Strafe aber bewirkte eine Selbstzensur, die nicht nur davor bewahrte, das Unbotmäßige zu sagen, sondern die - in einem weiteren Stadium der Verinnerlichung - dem Erlebenden die Fähigkeit nahm, es überhaupt noch begrifflich zu fassen, d. h., es mit dem Namen zu benennen, den es im normalen Sprachgebrauch hat. Kijanovs Selbstzensur reichte am Ende seines Lebens bis in seine Träume (s. o., Anm. 127). Antipov beschrieb diesen Krankheitszustand Kijanovs (= Nikiforovs) in einem Vergleich: "Er sieht alles klar und sieht absolut gar nichts, der Mechanismus der Angst macht blind wie der graue Star die Augen."158 Am Ende des Prozesses steht die Verflachung und schließlich der Verlust der schriftstellerischen Kreativität. 159 Kijanovs letztes Werk, an dem er acht Jahre gearbeitet hatte - ein langweiliger Roman aus der Revolutionszeit, der die Wirklichkeit entstellte, die Wahrheit verschwieg, den "niemand zu Ende lesen konnte" (Antipov) und der den aus der Zwangsarbeit zurückgekehrten Teterin zu sagen veranlaßte: "Borja, entschuldige, [...] ich finde, das ist Schund. Ich finde, um einen solchen Roman zu schreiben, hättest du nicht... [hierbleiben müssen]."160

158 S. 488.

159 "Their [d. i. Kijanovs/Nikiforovs] worst punishment was not a vague sense of guilt and failure. It was the loss of their ability to write." - McLaughlin (= Anm. 98), S. 244.

160 S. 442. 
Auch Antipov übt Selbstzensur, aber er ist sich im Unterschied zu seinem Lehrer Kijanov noch der Tatsache bewußt, daß er es tut. Er weiß, daß das, worüber er in seinem Roman nicht sprechen darf, eben das ist, worüber er schreiben müßte. Das wird an seinem Umgang mit dem Erzählstoff deutlich. Er versucht zunächst, mit dem zu beginnen, was unverfänglich ist, und das auszusparen, was offiziellen Anstoß erregen könnte, anscheinend aus der Überzeugung, daß sich "das Wichtigste" auf irgendeine Weise dann doch noch in den Text eintragen ließe. Ein Irrtum, wie er nach mehrjähriger vergeblicher Weiterarbeit eines Tages mit Schrecken erkennen muß. "Das Wichtigste" läßt sich ohne Konflikt mit der Zensurbehörde nicht zu Papier bringen.

Schließlich stehen der Erzähler und sein Autor Trifonov ihrerseits erneut vor der Frage, wie ein Zeitroman, dessen Stoff die eigene Erlebnisgegenwart ist, geschrieben werden kann, wenn man über das, was diese Zeit im wesentlichen geprägt hat, schweigen muß. Die praktizierte Antwort: Man muß eine Darstellungsform finden, die es ermöglicht, das, was nicht gesagt werden darf, indirekt auszudrücken und den Leser in hohem $\mathrm{Ma} B$ in die Sinnerschließung des Textes einzubeziehen. Von dieser Grundüberlegung geht die Erzählweise der punktierten Linie aus. ${ }^{161}$ Die "nedogovorennost" das "Prinzip der künstlerischen Ökonomie" und das "Prinzip der gemeinsamen schöpferischen Arbeit des Autors und des Lesers" (Zamjatin) - ist also bei Trifonov nicht nur als ein Erzählverfahren anzusehen, das rein formal um der größtmöglichen wirkungsästhetischen Effektivität willen angewandt wird, es ist in seinem letzten Roman aufgrund des Gesamtthemas wesentlich auch durch äußere Sachzwänge bedingt. Die äußere, gesellschaftliche Situation zwingt den Erzähler, Worte und Gedanken zu reduzieren, 162 und zwar

161 Abwegig ist Woodwards Auffassung, die in der Erzählmethode der punktierten Linie lediglich das vereinfachte Verfahren der Darstellung einer großen Zeitspanne sehen will, reduziert auf Episoden im Leben eines Helden, weil dem letztlich "ungeeigneten" Erzähler (dem Mathematiker), das tiefere Verständnis für historische Zusammenhänge ermangele und er deshalb auch das Leben eines Schriftstellers nur "punktuell" (= unangemessen) wiedergeben könne. Deshalb müsse nun der Leser übernehmen (was an sich Aufgabe des Erzählers wäre), die zwischen den Punkten fehlenden Bindeglieder selbst zu ermitteln. - James B. Woodward: The 'Dotted Line' of Jurij Trifonov's Lasi Novel. In: Die Welt der Slaven. (36). 1991. S. 332, 334ff.

162 Nach Auskunft von McLaughlin (= Anm. 98), S. 248, Anm. 3, hat Trifonov sogar sein abgeschlossenes Manuskript bei einer letzten Korrektur noch einmal um 10 Seiten gekürzt, und dies wohl deutlich mit Rücksicht auf die Zensur, wie man insbesondere an Passagen aus dem neunten Kapitel ("Das Ende des Winters am Trubnaja Platz"). 
soweit, daß deren Sinngehalt einerseits als durchaus mehrdeutig erscheint, andererseits aber dem geschulten Leser zugleich eine bestimmte Interpretation dadurch nahelegt, daß die Synopse der einzelnen Andeutungen zu bestimmten Konvergenzpunkten hinführt.

Die Leerräume die der Autor durch seinen Ich-Erzähler im Erzählvorgang verfügt, liegen auf verschiedenen Ebenen und haben - abgesehen davon, daß sie grundsätzlich die Aufmerksamkeit des Lesers konzentrieren sollen unterschiedliche Funktionen. Hauptsächlich, so ließ sich beobachten, liegen sie im Bereich des Erzählverfahrens, und zwar sowohl auf der Ebene des äußeren Textaufbaus wie auch auf der der inneren Struktur.

la) Die Segmentierung des Romans in 13 einzelne "Novellen" (Trifonov) setzt zeitliche Abstände zwischen die Kapitel, in deren Freiräume bisweilen wichtige Ereignisse des Romangeschehens fallen (z. B. die Verurteilung von Antipovs Mutter zur Zwangsarbeit, zwischen Kapitel 1 und 3; Antipovs Studienabschluß am Literaturinstitut, zwischen Kapitel 7 und 8; die Existenz- (= Publikations-) Schwierigkeiten des nicht angepaßten Schriftstellers Antipov, zwischen Kapitel 8 und 9.) Die Einschnitte in das Kontinuum der erzählten Zeit unterstreichen die erklärte Absicht des Autors, jedes Kapitel als eine in sich geschlossene Erzähleinheit anzusehen.

Ib) Leerräume ergeben sich ferner dadurch, daß die Kontinuität der Darstellung von Antipovs Lebenslinie durch Einfügungen des Ich-Erzählers aus seinem eigenen Leben unterbrochen wird (Kapitel 2, 5 und 13). Das zeitlich analoge Erleben des Erzählers vergrößert den Erlebnisausschnitt, der einen bestimmten Punkt im Zeitgeschehen markiert, und verstärkt den Anspruch auf Objektivität des subjektiv Erlebten einer einzelnen Person.

Ic) Die erst nachträgliche Auffüllung von zunächst eingeräumten Leerstellen kompliziert den Aufbau des Textes und vermittelt durch die Vermeidung eines nur chronologisch additiven Erzählverfahrens den Eindruck von Komplexität. (Die Kapitel 5 und 6 stehen zeitlich vor den Kapiteln 3 und 4.) - Später im Erzählverlauf auftretende Figuren, wie Ekaterina Gur'evna und der Arzt Ivan Vladimirovič in Kapitel 9, schließen für den Leser Freiräume in Antipovs Biographie.

2) Eine weitaus größere Herausforderung an den Leser bringen die Räume der Unbestimmtheit auf der Ebene der inneren Textstruktur mit sich.

Kijanovs Traum (Kapitel 10) und Antipovs Arbeit an seinem Roman (Kapitel 11) ersehen kann. 
Es war durchgängig zu beobachten, daß das Zeitgeschehen, die großen Ereignisse der Epoche selbst nicht zur Darstellung kommen. Sie bleiben Hintergrund und werden nur indirekt und "punktuell" in ihren Auswirkungen auf einzelne Erlebende gezeigt. In einem betont personalen Erzählmilieu der Autor bedient sich durchgängig der "Nesobstvenno-prjamaja rex'" bzw. des "Nesobstvenno-avtorskoe povestvovanie" 163 - sind die epischen Figuren agierende Personen, die immer auch reagierende auf ein ausgespartes Hintergrundgeschehen sind, das der Erzähler verschweigt, als ob er nicht Bescheid wüßte. Daß er Bescheid weiß, ist jedoch der Tatsache zu entnehmen, daß der einzelne "Punkt", die einzelne Andeutung sehr präzis gesetzt ist, adressiert an einen Leser, der der weiteren Information (anscheinend) nicht bedarf, weil er seinerseits (vermutlich) schon im Bilde ist und das Wesen der Epoche, das die Romanfiguren erleben und erleiden, schon kennt. Das bedeutet aber: Der Text setzt beim Leser ein Höchstmaß an Ansprechbarkeit und Korrespondenzfähigkeit über die nicht ausgeführte außerliterarische Realität voraus. Und: Der kundige Leser kann die Konvergenzpunkte der Stalinzeit und der nachfolgenden Jahrzehnte zwar aus dem Text erschließen, doch bleibt er in extrem anspruchsvoller Weise aufgefordert, das weite semantische Umfeld zwischen der einzelnen Andeutung und dem Zielpunkt selbständig, vom eigenen Wissen und Erleben her mit Konkretion zu füllen.

Das Wichtigste nicht sagen zu dürfen, bedingte in gleicher Weise auch Leerräume auf der Personal- und Handlungsebene, zwischen den epischen Figuren und der Horizontlinie des Textes wie auch zwischen den epischen Figuren selbst. Die zeitgeschichtliche Situation, deren Kommentierung der Autor ausspart, wird auch für die epischen Figuren nicht zum Gegenstand von Reflexion und Gespräch. Auch sie verdrängen und verschweigen das, was man offiziell nicht aussprechen darf, was aber zu verstehen wichtig ist, wenn man die Vorgänge begreifen will, die schicksalhaft auf das Leben der Menschen einwirken, und was zu verstehen wichtig ist, wenn Verständigung zwischen den Personen stattfinden soll. Das verordnete Schweigen über wichtige Geschehnisse bewirkt, daß die epischen Figuren, statt in wechselseitige Kommunikation zu treten, vorwiegend als vereinzelte dastehen, zumal jede von ihnen von einem eigenen Erleben und deshalb auch von einem eigenen Verständnis der Zusammenhänge herkommt. Mit der Generation der

163 Zur Definition der Begriffe s. N. A. Koževnikova: $O$ sootnošenii rexi avtora i personaža. In: Jazykovye processy sovremennoj russkoj chudožestvennoj literatury. Proza. Moskva 1977. S. 7-98. 
alten Leute, der Eltern, der Jugendlichen, der Kinder, verbinden sich unterschiedliche Ausschnitte der Welterfahrung, die dem jeweils anderen, wenn überhaupt, dann nur partiell zu vermitteln sind. Die Kinder im Alter von 1112 Jahren (Kapitel 1 und 2) wissen nicht, warum ihre Eltern verschwinden, und man kann es ihnen auch nicht erklären. Einige Jahre später wagen es die befreundeten Jugendlichen nicht, miteinander über ihre ähnlichen familiären Schicksale zu reden (Kapitel 6). Antipov erkundigt sich - "in Gegenwart des Lesers" - nicht nach den Erlebnissen seiner Mutter während der Zwangsarbeit und nicht nach dem Verbleib seines Vaters. Der 20jährige Student ahnt zwar, daß sein Lehrer unter den Zeitumständen zu leiden hat, aber er weiß nicht, was ihn konkret belastet. Er kennt die Hintergründe und die Verhängnisse von Kijanovs Biographie nicht, und er getraut sich auch nicht, danach zu fragen. Weil aber aus Antipovs Erlebnissicht erzählt wird, ergeben sich in der situativen Zusammenfügung der beiden Lebenslinien, Antipovs und Kijanovs, Räume der Unbestimmtheit auf der Ebene der Semantik, die Antipov mit dem Leser gemeinsam in einen Prozeß des Verstehens eintreten lassen, den erst Kijanovs eigene Erklärungen am Ende seines Lebens (Kapitel 10) zum Abschluß bringen.

Trifonovs thematischer Schwerpunkt hatte seit seinen Moskauer Erzählungen auf der Darstellung einfacher, meist intellektuell geprägter Menschen des städtischen Alltags der sowjetischen Gesellschaft gelegen, eines Alltags, der sozialpsychologisch gesehen von egoistischem Pragmatismus und zuweilen zynischer Selbstbehauptung gekennzeichnet war. ${ }^{164}$ Die Konfliktsituationen ähneln und wiederholen sich. Kustanovich resümiert zum Thema von Trifonovs Anti-Helden: "The plot of his works is always concerned with a moral decision or decisions that the protagonist has to make under pressure. He [ resp.: she] has to make a choice between his own interests and the fate of others and he makes it always in favour of his own interests, though not without doubts, hesitations and a struggle with his own conscience. Some time (usually many years later) the protagonist tries to vindicate in retrospect his decision and justify his betrayal. The main excuse is that the pressure, or

164 "Perhaps the most prominent figure in Russian literature in this period whose works concentrate on the phenomena of pragmatism and cynicism in Soviet society is lurii Trifonov." - Konstantin Kustanovich: Monologue of the Anti-Hero. Trifonov and the Prose of the Last Decade. In: Slavic Revien. (50) Spring 1991. S. 978. 
'the ruthlessness life' is to blame, not the protagonist himself."165 Galina Belaja vertritt sogar die Ansicht, Trifonov wolle sagen, der wesentliche Grund für die Verwüstung des Lebens liege darin, daß in Entscheidungssituationen nicht der einzelne Mensch selbst, sondern die Zeitumstände für ihn entscheiden, die es ihm verwehren, eine Persönlichkeit zu sein, die zu freien Entscheidungen fähig wäre. 166 - Daß Trifonov die personzerstörende Wirkung, die die Mechanismen der sowjetischen Gesellschaft auf ihre Menschen ausüben, mit Bitterkeit betrachtet, ist immer wieder konstatiert worden. Trotzdem bleibt die Frage, ob er seine epischen Figuren angesichts der belastenden Umstände entschuldigen und aus der persönlichen Verantwortung entlassen will. Als Autor stellt er zunächst nur dar. Er verurteilt seine Figuren nicht und überläßt die Bewertung dem Leser. ${ }^{167}$ Die Tatsache aber, daß moralisch fragwürdiges Verhalten als solches thematisiert wird, bleibt bestehen, und zwar ausgeführt von einem Autor, der in einem seiner letzten Interviews noch einmal die Maxime ausgesprochen hat: "Der Mensch muß nach dem Gewissen leben."168 Und dieser Leitsatz geht von der Überzeugung aus, daß der einzelne - auch in Situationen von hoher Belastung - ethisch verantwortbar handeln kann.

In seinem letzten Roman Zeit und Ort skizziert Trifonov mit Saša Antipov eine Person, die im Unterschied zu früheren Protagonisten diesem Appell zu folgen versucht. ${ }^{169}$ Antipov, mit moralischer Sensibilität begabt, wird in einer Zeitspanne von über 40 Jahren in einzelnen Lebensausschnitten gezeigt, die man als typisch für das Zeitgeschehen ansehen kann. Das Zeitgeschehen spiegelt sich in seinem Erleben als dem eines Teilhabers, der in einer

165 Ebd., S. 979.

166 Galina Belaja: Nepovtorimoe odnazdy. In: Literaturnoe obozrenie. 1/1983. S. 11: "Tak, osmysljaja problemu 'Celovek i vremja' (inače: 'celovek i obstojatel'stva'), Trifonov prichodit $k$ vyvodu: do tech por, poka za Celoveka resajut obstojatel'stva, on ne predstavljaet soboju lix̌nost', on slabodušen, ego żizn' razrušitel'na dlja nego i okružajušxich."

167 S. auch Kustanovich (= Anm. 164), S. 987: "The objectivization of the narration in Trifonov and the later authors may indicate that Russian literature, or at least some part of it, is moving away from traditional Russian didacticism toward the art of simply showing, leaving the ultimate judgement to the reader."

168 "Celovek tem otliðaetsja ot volka, Cto neset $v$ sebe načalo, kotorogo priroda ne znaet: sovest'. [...] Čelovek (...) dolžen Žit' po sovesti. Ėto budet ego otliðat' ot volka." - Ju. Trifonov: "Kak naše slovo otzovetsja..." In: Novyj mir. 1//1981. S. 233 und 235.

169 Auf den Paradigmawechsel ist hingewiesen worden, z. B. von Arkadij Ėl'jaševið: Gorizontali $i$ vertikali. Sovremennaja proza - ot semidesjatych $k$ vos'midesjatym. Leningrad 1984. S. $342 f$. 
Reihe von Erlebnisstationen den Prozeß seines "Selbstbewußtwerdens" (samosoznanija) erfährt. Episodenhaft nachvollzogen und aufgezeichnet wird die durch Zeit und Ort bedingte Biographie dieser einen Person. ${ }^{70}$ Dabei sind die einzelnen Stationen zwar keine Grenz- oder Extremsituationen, die Antipov erlebt, sondern Situationen eines normalen sowjetischen Alltags, aber sie verlangen oftmals Entscheidungen, die, jede für sich gesehen, eine Weichenstellung für das weitere Leben des Betreffenden bedeuten können. ${ }^{171}$

Antipov läßt sich die "Regeln der Zeit" nicht aufreden (wie Kijanov), er folgt weder der Staatsideologie noch den Richtlinien der Kulturpolitik, sondern geht, sich selbst prüfend, den Weg seines Gewissens. Er schreibt seine beste Erzählung nicht um (Kapitel 4), er denunziert nicht (Kapitel 6), er verkauft als Gerichtsgutachter nicht seine Überzeugung (Kapitel 8), er publiziert nichts, was er nicht vertreten kann (Kapitel 11), er be- und verurteilt nicht nach fremden Maßstäben, sondern versucht zu verstehen und zu vermitteln, insbesondere im Umfeld seines Lehrers. Das trägt ihm bisweilen schmerzliche Erkenntnisse und tiefe Erschütterungen ein, aber auch Selbstbestätigung und ein Wertempfinden für die eigene Person, was ihn befähigt, sein Leben anzunehmen und zu bejahen, auch wenn es von außen betrachtet als wenig glanzvoll erscheint. "Trifonov gelangt [in Zeit und Ort ] zur Bestätigung des Selbstwertes, der Bedeutsamkeit des einzelnen Menschenlebens und des Lebens grundsätzlich." 172

Auch das "neue Leben", das sich für Antipov am Ende der Romanhandlung nach seiner Rekonvaleszenz noch einmal eröffnet, wird nicht das erträumte "andere Leben" der noch ungenutzten großen Möglichkeiten sein, wie sie in anderen Werken Trifonovs (meist illusorisch) anklingen, sondern

170 Nicht die von Antipovs Generation schlechthin. So die Ansicht von Eremina/Piskunov: "V obraze Antipova Ju. Trifonov v serii zakončennych épizodov vossozdaet biografiju svoego pokolenija, obuslovlennuju vremenem i mestom." - Eremina. S. und V. Piskunov: Vremja i mesto prozy Ju. Trifonova. In: Voprosy literatury. 5/1982. S. 54/54. Andere Zeitgenossen Antipovs haben sich in vergleichbaren Erlebnissituationen anders verhalten.

171 Natal'ja Ivanova [= Anm. 51]. S. 272, spricht von einer Krisenkette, aus der sich die Zeichnung von Antipovs Leben zusammensetze. - Anders dagegen El'jaševic l= Anm. 169]. S. 276: Trifonov stelle seine Figuren selten in Extremsituationen dar. "Extrem" sei das durchschnittliche Leben, in dem sich der einzelne zu bewähren habe. So auch OvCarenko: Nicht in Ausnahmesituationen, sondern im Alltagsleben werden Trifonovs Personen geprüft. - A. I. Ovcarenko: $O$ psichologizme i nor Xestie Jurija Trifonova. In: Russkaja literatura. 2/1988. S. 45.

172 Eremina/Piskunov [= Anm. 170], S. 65. 
das durch Ernüchterung gereinigte Leben jenseits aller Illusionen, deren größte, von Antipov überwundene, die irrtümliche Annahme war, in der Gesellschaft seiner Zeit als Schriftsteller zu persönlicher Entfaltung kommen zu können. 173

173 McLaughlin [= Anm. 98], S. 246, resümiert Antipovs Einsicht in sarkastischer Kurzform: "All the artist may accomplish is to remain an honorable human being." 


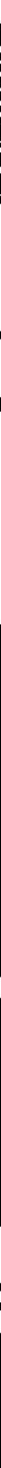

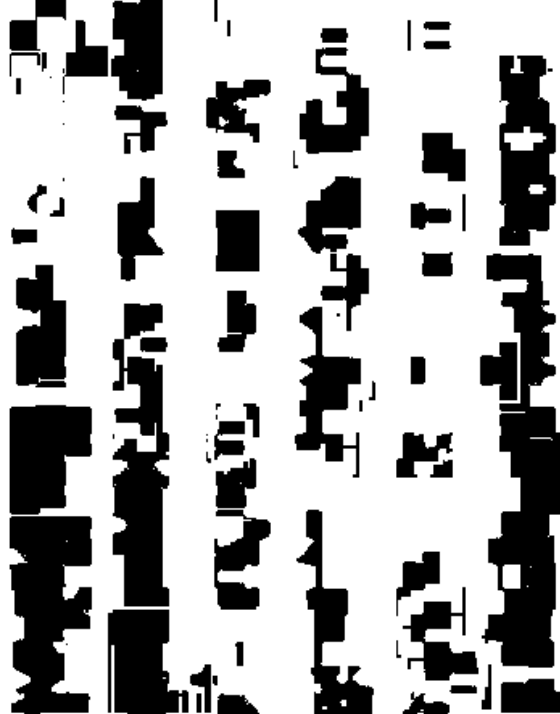

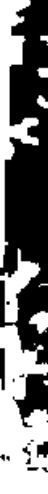

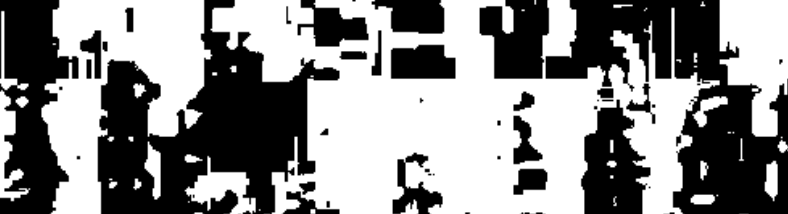

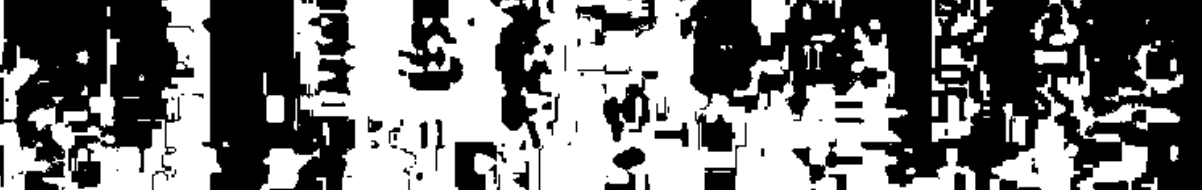

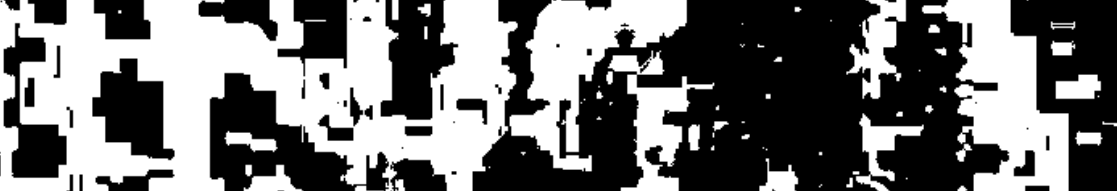

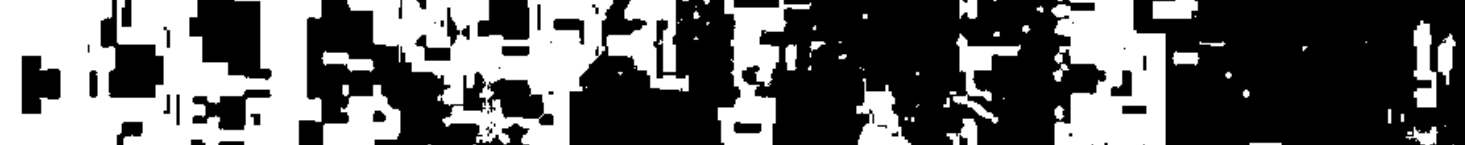

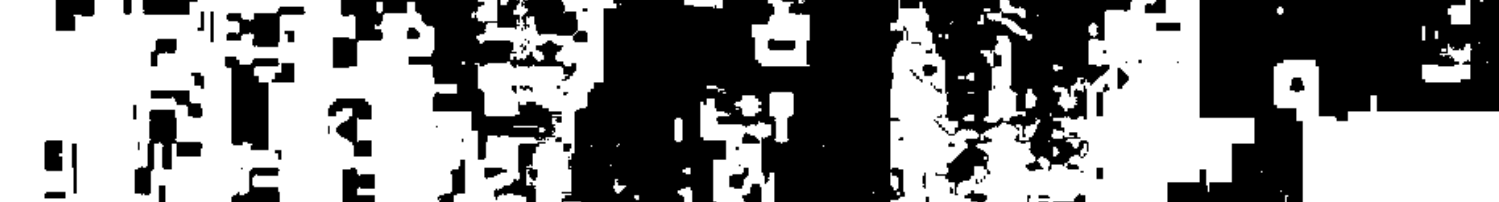 $=$ 


\section{LITERATURVERZEICHNIS}

Belaja, Galina: Nepovtorimoe odnaždyj. Filosofsko-ètičeskaja tema v proze Jurija Trifonova. In: Literaturnoe obozrenie. 1/1983. S. 7-12.

Bočarov, A.: Jurij Trifonov: V kratkom - beskonečnoe. (Besedu vel A. Bocarov). In: Voprosy literatury. 8/1974. S. 171-194. (Deutsch: In der Kürze das Unendliche finden. In: Kunst und Literatur. 23/1975. S. 612-629).

Bulgakov, Michail: Master i Margarita. Frankfurt/Main 1969.

Čechov, A. P.: Pis'ma. In: Sobranie socinenij v dvenadcati tomach. Moskva 1960-1964. Tt. 11 und 12.

Čukovskaja, Lidija: Opustelyj dom. Paris 1965.

Dalton-Brown, Sally: Creating a Sense of Time: Some Aspects of Style in lurii Trifonov's Mature Prose. In: The Modern Language Review. (88). 3/1993. S. 706-717.

Dedkov, Igor': Vertikali Jurija Trifonova. In: Novyj mir. 8/1985. S. 220-235.

El'jaševič, Arkadij: Gorizontali $i$ vertikali. Sovremennaja proza - ot semidesjatych $k$ vos'midesjatym. Leningrad 1984. (Darin über Trifonov $S$. 255-366.).

Eremina, S. und V. Piskunov: Vremja i mesto prozy Ju. Trifonova. In: Voprosy literatury. 5/1982. S. 34-65.

Hughes, Anne C.: "Bol' §oj mir" or "zamknutyj mirok": Departure from Literary Convention in Iurii Trifonov's Recent Fiction. In: Canadian Slavonic Papers. (22). 1980. S. 470-480.

iser, Wolfgang: Die Appellstruktur der Texte. Unbestimmtheit als Wirkungsbedingung literarischer Prosa. - Konstanzer Universitätsreden (28). Hsg. von Gerhard Hess. - Konstanz 21971.

Ivanova, Natal'ja: Proza Jurija Trifonova. Moskva 1984.

Kolesnikoff, Nina: Yury Trifonov. A Critical Study. Ann Arbor 1991.

Koževnikova, N. A.: O sootnošenii reči avtora $i$ personaža. In: Jazykovye processy sovremennoj russkoj chudožestvennoj literatury. Proza. Moskva 1977. S. 7-98.

Kustanovich, Konstantin: Monologue of the Anti-Hero: Trifonov and the Prose of the Last Dekade. In: Slavic Review. (50). Spring 1991. S. 978-988.

McLaughlin, Sigrid: Antipov's "Nikiforov Syndrome": The Embedded Novel in Trifonov's "Time and Place". In: Slavic and East European Journal. (32). 2/1988. S. 237-250.

Ovčarenko, A. I.: O psichologizme $i$ tvorčestve Jurija Trifonova. In: Russkaja literatura. 2/1988. S. 32-57.

Pasternak, Boris: Dokıor Živago. Milano 1957.

Rasputin, Valentin: Povesti. 3. Aufl. Moskau 1980.

Schlögel, Karl: Ein Garten für den neuen Menschen. [Heraus zum 1. Mai! Doch nicht nur auf der Straße, auch im sozialistischen Park sollte sich die kollektive Kraft manifestieren. Das Modell war Moskaus Gorki-Park.J Die Chronik einer monströsen Idylle. In: Die Zeit. 2. Mai 1997 (= 1997 Nr. 19). S. 44.

Schröder, Ralf: Zum Schaffen Juri Trifonows. In: Weimarer Beiträge. 8/1981. S. $155-169$.

Ders.: Gespräch mit Juri Trifonow. Ein "Roman mit der Geschichte". Ebd. S. 133-154. 
Ders.: Jurij Trıfonov: Roman s istoriej. (Besedu vel Ral'f Šreder). In: V'oprosy. literatury. 5/1982. S. 66-77.

Ders.: "Moj god ešče ne nastupil...". - Ral'f Šreder. Iz hesed s Jurien Trifonovym. In: Literaturnoe obozrenie. 8/1987. S. 96-98.

Schultze, Brigitte: Jurij Trifonovs "Der Tausch" und Valentin Rasputirs "Geld für Maria". Ein Beitrag zum Gattungsverständnis von Povest' und Rasskaz in der russischen Gegenw'artsprosa. Göttingen 1985.

Shneidman, N. N.: The New Dimensions of Time and Place in lurii Tifonov's Prose of the 1980s. In: Canadian Slavonic Papers. (27). 2/1985. S. $188-195$.

Trifonov, Jurij: Sobranie sočinenij v četyrech tomach. Moskva 1985-1987.

Ders.: Vremja i mesto. Roman v trinadcati glavach. In: Drusha narodov. September 1981, S. 72-148 und Oktober 1981, S. 22-108.

Ders.: Zeit und Ort. - Deutsche Übersetzung von Eckhard Thiele. Berlin 1982.

Ders.: Kak naše slovo otzovetsja... In: Novyj mir. 11/1981. S. 233-244.

Woodward, James B.: The 'Dotted Line' of Jurij Trifonov's Last Novel In: Die Welt der Slaven. (36). 1991. S. 330-346.

Zamjatin, Evgenij: Sočinenija v četyrech tomach. München 1970-1988. 


\section{PERSONENREGISTER}

Abramov, F. A. 12

Amal'rik. A. A. 78

Arakceev, A. A. 12

Belaja, Galina 93

Belov, V. I. 12

Biron. E. J. 12

Blok. A. A. 43

Bočarov, A. 11

Brežnev, L. I. 80

Brodskij, I. A. 78

Bulgakov, M. A. 23

Bunin, I. A. 36, 38, 59

Carter, James E. 80

Čechov, A. P. 11-14, 39, 73, 76

Chrušcev, N. S. 78

Cukovskaja, L. K. 24

Daniel', J. M. 78

Dedkov, Igor' 34

Dostoevskij. F. M. 29

Ėl'jaševix̌, Arkadij $93 f$.

Eremina, S. 94

Ėrenburg, I. G. 75

Fadeev, A. A. 75

Fedin, K. A. 75

Gogol', N. V. 29

Gorbunov-Posadov, I. 1.12

Gor'kij. Maksim 9, 11, 27
Hemingway, Ernest 73

Homer 73

Hughes, A. C. 15

Iser, Wolfgang 16

Ivanova, Natal'ja 34, 94

Joyce, James 16

Kataev, V. P. 75

Kennedy, John F. 80

Kolcak, A. V. 76

Koževnikova, N. A. 91

Kustanovich, Konstantin 92f.

Leonov, L. M. 75

McLaughlin. Sigrid 65, 67, 74, 78, 88f., 95

Možaev, B. A. 12

Napoleon I. Bonaparte 60

Ovčarenko, A. I. 94

Pasternak, B. L. $83 f ., 87$

Patera. Tat'jana 15

Paustovskij, K. G. 38

Piskunov, V. 94

Plešeev, A. N. 12

Rasputin, V. G. 10, 12, 15

Schlögel, Karl 27 
100

Schröder, Ralf 9, 12, 14, 16, 19

Schultze, Brigitte 15

Shneidman. N. N. 9

Sinjavskij, A. D. 78

Solženicyn, A. I. 78

Stalin, I. V. 11, 19, 23, 45, 55, 57, 62f., $65,75,78,85,87,91$

Sukšin, V. M. 12

Suvorin, A. S. 11

Thiele, Eckhard 60, 65, 74-76, 78

Tolstoj. L. N. 73

Tvardovskij. A. T. 78

Woodward, James B. 89

Zamjatin. E. I. 13f., 89

Ždanov, A. A. 9, 37, 51, 55 


\section{VORTRÄGE UND ABHANDLUNGEN ZUR SLAVISTIK}

- herausgegeben von Peter Thiergen (Bamberg) -

Verzeichnis der bislang erschienenen Bände

(W. Schmitz Verlag, Gießen)

Band 1: Peter Thiergen

Turgenevs "Rudin" und Schillers "Philosophische Briefe".

(Turgenev Studien III)

1980, 66 S., broschiert, DM 19,80

Band 2: Bärbel Miemietz

Kontrastive Linguistik. Deutsch-Polnisch 1965-1980.

1981, 132 S., broschiert, DM 25,-

Band 3: Dietrich Gerhardt

Ein Pferdename. Einzelsprachliche Pointen und die Möglichkeiten ihrer Übersetzung am Beispiel von A. P. Čechovs "Losadinaja familija".

1982, 69 S., broschiert, DM 20,-

Band 4: Jerzy Kasprzyk

Zeitschriften der polnischen Aufklärung und die deutsche Literatur.

1982, 93 S., broschiert, DM 20,-

Band 5: Heinrich A. Stammler

Vasilij Vasil' evic Rozanov als Philosoph.

1984, 90 S., broschiert, DM 20,-

Band 6: Gerhard Giesemann

Das Parodieverständnis in sowjetischer Zeit. Zum Wandel einer literarischen Gattung.

1983, 54 S., broschiert, DM 19,-

Band 7: Annelore Engel-Braunschmidt

Hebbel in Rußland 1840-1978. Gefeierter Dichter und verkannter Dramatiker.

1985, 64 S., broschiert, DM 20,-

Band 8: Suzanne L. Auer

Borisav Stankovičs Drama “Koštana". Übersetzung und Interpretation. 1986, 106 S., broschiert, DM 25,- 
(Otto Sagner Verlag, München):

Band 9: Peter Thiergen (Hrsg.)

Rudolf Bächtold zum 70. Geburtstag.

1987, 107 S., broschiert, DM 22,-

Band 10: A. S. Griboedov

Bitternis durch Geist.

Vers-Komödie in vier Aufzügen. Deutsch von Rudolf Bächtcld.

1988, 101 S., broschiert, DM 20,- (vergriffen)

Band 11: Paul Hacker

Studien zum Realismus I. S. Turgenevs.

1988, 79 S., broschiert, DM 20,- (vergriffen)

Band 12: Suzanne L. Auer

Ladislav Mñačko. Eine Bibliographie.

1989, 55 S., broschiert, DM 16,-

Band 13: Peter Thiergen

Lavreckij als "potenzierter Bauer". Zu Ideologie und Bild:prache in I. S.

Turgenevs Roman "Das Adelsnest".

1989, 40 S. Text plus $50 \mathrm{~S}$. Anhang, broschiert, DM 18,-(vergriffen)

Band 14: Aschot R. Isaakjan

Glossar und Kommentare zuV. Astafjews "Der traurige Det?ktiv".

1989, 52 S., broschiert, DM 10,-

Band 15: Nicholas G. Žekulin

The Story of an Operetta: Le Dernier Sorcier by Pauline Vistot and Ivan:

Turgenev.

1989, 155 S., broschiert, DM 18,-

Band 16: Edmund Heier

Literary Portraits in the Novels of F. M. Dostoev'skij.

1989, 135 S., broschiert, DM 18,-

Band 17: Josef Hejnic (u. Mitarbeiter)

Bohemikale Drucke des 16.-18. Jahrhunderts.

1990, 65 S., broschiert, DM 8,-

Band 18: Roland Marti

Probleme europäischer Kleinsprachen: Sorbisch und Bündn!rromanisch.

1990, 94 S., broschiert, DM 17,- 
Band 19: Annette Huwyler-Van der Haegen

Goncarovs drei Romane - eine Trilogie?

1991, 100 S., broschiert, DM 20,-

Band 20: Christiane Schulz

Aspekte der Schillerschen Kunsttheorie im Literaturkonzept Dostoevskijs.

1992, 258 S., broschiert, DM 40,-

Band 21: Markus Hubenschmid

Genus und Kasus der russischen Substantive: Zur Definition und Identifikation grammatischer Kategorien.

1993, 134 S., broschiert, DM 20,-

Band 22: France Bernik

Slowenische Literatur im europäischen Kontext. Drei Abhandlungen.

1993, 75 S., broschiert, DM 16,-

Band 23: Wemer Lehfeldt

Einführung in die morphologische Konzeption der slavischen Akzentologie. 1993, 141 S., broschiert, DM 30,-

Band 24: Juhani Nuorluoto

Die Bezeichnung der konsonantischen Palatalität im Altkirchenslavischen. Eine graphematisch-phonologische Untersuchung zur Rekonstruktion und handschriftlichen Überlieferung.

1994, 138 S., broschiert, DM 25,-

Band 25: Peter Thiergen (Hrsg.)

Ivo Andric 1892-1992. Beiträge des Zentenarsymposions an der Otto-

Friedrich-Universität Bamberg.

1995, 161 S., broschiert, DM 25,-

Band 26: Sebastian Kempgen

Russische Sprachstatistik. Systematischer Überhlick und Bibliographie.

1995, 137 S., broschiert, DM 25,-

Band 27: Peter Thiergen (Hrsg.)

Ivan S. Turgenev - Leben, Werk und Wirkung. Beiträge der Internationalen Fachkonferenz aus Anlaß des 175. Geburtstages an der Otto-FriedrichUniversität Bamberg, 15.-18. September 1993.

1995, 282 S., broschiert, DM 44,- 
Band 28: A. A. Donskov (Hrsg.)

L. N. Tolstoj i M. P. Novikov. Perepiska.

1996, 120 S., broschiert, DM 20,-

Band 29: A. A. Donskov (Hrsg.)

L. N. Tolstoj i T. M. Bondarev. Perepiska.

1996, 142 S., broschiert, DM 25,-

Band 30: V. Setschkareff

Die philosophischen Aspekte von Mark Aldanovs Werk.

1996, 80 S., broschiert, DM 18,-

Band 31: Galina A. Time

Nemeckaja literaturno-filosofskaja mysl' XVIII-XIX vekov v kontekste tvorčestva I. S. Turgeneva (Genetičeskie i tipologičeskie aspekty').

1997, 140 S., broschiert, DM 30,-

Band 32: L. D. Gromova-Opul'skaja/Z. N. Ivanova (sost.)

Novye materialy L. N. Tolstogo io Tolstom. Iz archiva N. N. Guseva.

Redaktion: A. A. Donskov.

1997, 267 S., broschiert, DM 40,-

Band 33: Martin Schneider

Postmeister und Stationsaufseher. Eine Studie zur deutschen Puškin. Rezeption.

1997, 177 S., broschiert, DM 30,-

Band 34: Leonore Scheffler

"Roman-punktir". - Indirektes Erzählen durch Leerstellen in Jurij Trifo. novs Roman "Zeit und Ort".

1998, 104 S., broschiert, DM 20,- 